\title{
Parameters influencing the impact response of fiber-reinforced polymer matrix composite materials: A critical review
}

\author{
Jefferson Andrew Ja , Sivakumar M Srinivasan ${ }^{\mathrm{a}}$, Arockiarajan $\mathrm{A}^{\mathrm{b}}$, Hom Nath Dhakal ${ }^{\mathrm{c} *}$ \\ ${ }^{a}$ Active Material Structures \& Systems Lab., Department of Applied Mechanics, Indian Institute of \\ Technology Madras, India.

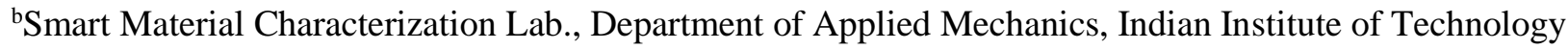 \\ Madras, India \\ *cAdvanced Materials and Manufacturing (AMM) Research Group, School of Mechanical and Design \\ Engineering, University of Portsmouth, Anglesea Road, Anglesea Building, Portsmouth, Hampshire PO1 \\ 3DJ, UK.
}

\begin{abstract}
:
The damage of fiber reinforced polymer matrix composite materials induced by impact load is one of the most critical factors that restrict extensive use of these materials. The behavior of composite structures under transient impact loading and the ways to enhance their characteristics to withstand this type of dynamic loading might be of specific significance in the aerospace sector and other applications. This paper critically reviews the important parameters from the published literature influencing the impact resistance and the damage mechanics of fiberreinforced composite materials. Firstly, the paper reviews the influence of impact velocity on various failure modes. Following this, a comprehensive review on the four key parameters specifically material, geometry, event and the environmental-related conditions that affect the structural behavior of fiber reinforced polymer matrix composites to impact loading is discussed. The review further outlines areas to improve the impact damage characteristics of composites and then conclude with a summary of the discussion on the future work relating to the most influencing parameters.
\end{abstract}

Keywords: Polymer matrix composites (PMCs), Low-velocity impact, Ballistic impact, Impact parameters, Staking sequence, Environmental conditions, Damage modes.

\footnotetext{
* Corresponding author. Tel: + 44 (0) 239284 2582; fax: + 44 (0) 2392842351.

E-mail: $\underline{\text { hom.dhakal@port.ac.uk }}$
} 


\section{Introduction}

Presently, light-weight fiber-reinforced polymer matrix composite materials are extensively employed in high-performance aerospace applications owing to their high specific strength and stiffness, corrosion resistance, reparability and fatigue resistance [1-2]. On the other hand, composites are vulnerable to impact damage [3]. The hazard of damage owing to impact is presently well established in spacecraft and aircraft design [4-5]. From the damage report of 71 Boeing 747 aircraft having an average life of 29,500 flying hours, it has been noticed that 90 out of 688 repairs (nearly 13\%) have been produced owing to foreign object impacts [4]. Radome, radar antenna, windshield, nacelle, canopy, propeller blades, wing or tail, fuel tanks are ultimate targets of impact during flight, takeoff and landing. There are numerous conditions for this impact: hailstones and bird strikes being the most significant ones, owing to their high chance of occurrence [6-7]. On the other hand, a tyre piece can strike the wing structures and the ice coming from the propeller blade edge could also impact the nacelle of the aircraft engine [8]. For instance, the Concorde aircraft accident in 2000 was in fact induced by a tyre piece striking fuel tank on the main wing of the aircraft. Damage on composite structures owing to impact can also take place if the turbine blade fails owing to fatigue and strikes the containment cell, oil tanks and airframes [9]. Other types of projectiles that might strike aircraft composites are bullets or fragments owing to explosions. Moreover, impact engineering is vital in the area of spacecraft. Space is occupied with numerous debris, where the space shuttles, satellites and international space stations orbit the Earth [10-11]. These are very tiny and ought to be independently tracked; there are several satellites in the orbit, so the chance of critical impact is non-ignorable. Furthermore, airspace composite structures could collide not only on orbit but also during re-entry stage. For instance, in the Columbia space shuttle, the impact of frozen foam on the wing induced catastrophic failure [12].

Investigating the mechanism of damage generation during an impact is the initial step to understand the main factors which decide the structural performance of the composite structure under impact loading. Damage and failure of composite materials caused by impact have been documented and investigated over the years. Owing to the anisotropic nature of composite materials and uneven distribution of stresses under the transient loading, the damage processes of composites are very complicated [13]. In conventional metals, the impact-induced damage is normally not an important safety concern owing to the intrinsic energy absorbing mechanism and material ductility. On the contrary, composite materials are naturally brittle and can absorb energy in the elastic state rendering them susceptible to impact damage [14].

Under impact loading, the consequential failure mechanism can be grouped into five key phases that happen in the subsequent order [15-16]: (1) matrix cracking and fiber/matrix interface debonding damage mode owing to high transverse shear stresses in the top layers; (2) transverse bending crack owing to high flexural stresses in the bottom layers; (3) interlaminar delamination owing to cracks restricted and diverted through the interlaminar area; (4) fiber failure damage mode under tension and fiber micro-buckling under compression loading and (5) penetration. The 
comprehensive possibilities of impact-induced damages are illustrated in Figure 1. Intraply damage such as resin cracking and fiber/matrix interfacial damage and interply damage such as interlaminar delamination among two layers are the two distinct dominant damage modes under a low-energy impact event [17]. Fiber breakage is the dominant failure mode allied particularly with high energy impact events [18-20].

The main feature that affects the impact in composite materials is the fracture toughness of the resin system. Brittle resin systems have low resistance to fracture onset and propagation. The resistance to fracture propagation increases due to improvement in the fracture toughness of the matrix, hence, raising the resistance of the composite to interlaminar delamination onset generated by resin cracking. Intraply failure modes may set off interlaminar delamination mainly owing to a mismatch in characteristics among layers of different fiber type or orientation. When a crack grows up to the interface between two nearby layers, the value of shear stress rises considerably owing to the abrupt variation in material characteristics, the crack is diverted and grows along the interface as interlaminar delamination [21]. The Mode-I and -II interlaminar fracture toughness or $\mathrm{G}_{\mathrm{I}}$ and $\mathrm{G}_{\mathrm{II}}$ are the key properties that govern the impact response of composite laminates [22]. The reason for this behavior is that delamination initiates through crack opening (Mode-I) mechanism, whilst propagation occurs because of shearing (Mode-II) due to bending [23]. Under impact loading, composite materials are able to absorb and dissipate a large quantity of impact energy in a broad range of damage modes [24]. Until up to the stage of initial damage, most of the applied impact energy of the impactor is absorbed by the elastic behavior of the structure. This capability to elastically absorb impact energy is reliant upon numerous factors including fiber toughening, matrix toughening, interface toughening, through-the-thickness reinforcements, selective interlayers and hybrids [25-26]. The broad study performed so far produced an understanding of the factors that influence the onset and propagation of impact damage [4-5, 13]. The mechanical and chemical characteristics of the fibers, matrices and interface influence the way in which the composite deforms and fractures [5]. The impact response of the composite materials is also affected by parameters such as component geometries, properties of the impactor and environmental conditions $[4-5,13]$.

It is vital to spot the various damage modes and their progression towards impact. The main aim of this review paper is to bring together the relevant findings of numerous articles published in the area of impact mechanics of polymer matrix composites with an aim to present an overall view of the state-of-the-art. Initially, the influences of impact velocity and the techniques most commonly applied for studying the impact behavior of composite materials are discussed. Following this, a comprehensive review on the four key parameters specifically material, geometry, event and environmental-related conditions that affect the structural behavior of fiber reinforced polymer matrix composites to impact loads are discussed. Impact behavior of composite materials is reviewed with the aid of previous relevant literature in theoretical, numerical and analytical investigations done by several researchers. Finally, the key issues that require to be 
solved are also addressed. The important factors influencing the impact response and damage of composite materials are depicted in Figure 2.

\section{Impact velocity}

The knowledge of dynamic behavior of composite materials and their damage resistance is required to optimize the structure. Impact load generates elastic waves from the site of impact. Energy dissipation and vibration of target allied to wave propagation may lead to a degradation behavior. Thus, the time period of impact plays a major role in controlling the types of impact responses [27]. If the contact time is in the order of the transition time for elastic waves, the behavior will be controlled by transverse waves, as depicted in Figure 3(a). For a longer time period, the behavior would be controlled by flexure and shear waves, as depicted in Figure 3(b). If the impact duration is greater than the time for the elastic waves to arrive at target edges, the consequential behavior will be quasi-static. This event takes place owing to the deflection and load might have an identical association as in static loading, as depicted in Figure 3(c). The total component is deformed under the impact with the contact force and deformation in-phase for a boundary-controlled impact, as depicted in Figure 4(a). On the other hand, the deformation is localized to the area nearby the impact site with the contact force and deformation out-of-phase for a wave-controlled impact, as depicted in Figure 4(b).

The impact event can take numerous ranges, varying from a dropped object moving at possibly 1 to $4 \mathrm{~m} / \mathrm{s}$ to space debris moving at several hundreds of $\mathrm{m} / \mathrm{s}$. Generally, there are four types of impact with respect to velocity: low-, high-, ballistic- and hyper-velocity [28]. Table 1 summarizes the different types of impacts with respect to impact velocity. A low-velocity impact event $(<11 \mathrm{~m} / \mathrm{s})$ takes place by damage from dropped tools during maintenance. A high-velocity impact event $(>11 \mathrm{~m} / \mathrm{s}$ ) occurs by damage from: debris from the runway impacting the aircraft on take-off or landing, hail and bird strikes. Damage induced by ballistic impact $(>500 \mathrm{~m} / \mathrm{s})$ is common for military applications. Hypervelocity impact events $(>2000 \mathrm{~m} / \mathrm{s})$ include space debris impact on a spacecraft. Overall, the impact events may be simplified by grouping it into two distinct cases: low-velocity impact by a large mass (e.g. dropped object) and high-velocity impact by a small mass (e.g. runway debris). In the case of low-velocity impact loading, where the contact duration among the impactor and target is comparatively large, the entire target responds allowing kinetic energy to be absorbed in sites well away from the site of impact. A low-velocity impact occurs when the contact duration of the striker is higher than the duration for the lowest vibration mode. Under low-velocity impact, the geometry of the target is a vital factor as it controls the energy-absorbing capability. The support conditions are vital as the stress waves produced outer from the impact site have time to arrive at the ends of the target, inducing its full-vibration behavior. Characteristically, the behavior in Figure 3(a) is allied with a ballistic impact. The behavior in Figure 3(b) and Figure 3(c) are normally allied to the impact of runway debris and the impact from drop-weights, respectively. In many conditions, the behavior in Figure 3(a) induces simply observable impact damage. The behavior in Figure 3(b) and Figure 3(c) may induce BVID 
(Barely Visible Impact Damage). Moreover, the behavior in Figure 3(b) and Figure 3(c) is specified as the wave- and boundary-controlled impacts, respectively [29].

On the other hand, in high-velocity impact, the component response is influenced by stress wave propagation and does not have adequate time to generate quasi-static failure mechanisms [30]. High-velocity impact loading leads to cause a more localized type of target response, leading to the energy dissipation in a relatively small area. At high impact velocities, the perforation may take place on the target and the course of the impactor would usually lead to petalling, cracking and spalling. The behavior of the target is decided by the local response of the material in the vicinity of the impact site, the impact behavior of the target being normally independent of its support conditions [31]. Obviously, these two types of impact loading might generate varying nature of damage with varying effects on the post-impact load-carrying capabilities of the composites [32].

In order to evaluate the dynamic behavior of composite materials, wide ranges of testing procedures are available. Currently, two types of tests are often employed by numerous researchers [33]. For instance, debris from the runway may induce damage on aircraft during takeoff and landing; this condition, with low mass high-velocity impact, is best replicated employing a gas gun [34]. Another is the impact of composites by a larger projectile at a low velocity which occurs when objects are unintentionally dropped on a composite. This condition is best replicated employing a drop weight tester [35]. The Charpy impact test is also employed to generate lowvelocity impacts. The prediction and characterization of the residual strength of an impacted composite is very difficult in comparison to conventional metals, as the damage mechanisms in these materials are intricate in nature. The problem is further complicated by the lack of existing standards or established testing procedures for the impact of composite materials. Many works published in the literature have been performed on purpose-built machines employing convenient specimen geometries. Hence, direct comparisons among various materials, geometries, event- and environmental-related parameters are often very complex and direct conclusions are very hard to draw. Pendulum methods such as the Izod and Charpy tests mostly necessitate specimen geometries that are not representative of component dimensions; thus, they are basically appropriate only for ranking the impact behavior of composites. Drop weight impact test and gas guns test set-ups provide more representative approaches for evaluating the impact behavior of these materials. Higher application of instrumented impactor results in a deeper understanding of the processes of energy absorption and dissipation in the composite materials [36-40].

\section{Parameters influencing impact damage}

Having heterogeneous structure with various material characteristics, nature of stress and strain, interlaminar delamination failure and crack propagation, a comprehensive understanding of various parameters influencing the impact response of composite materials is required to develop a most-optimized configuration. The parameters that influence the dynamic impact behavior of composite materials subjected to impact loads can be grouped into four key types as summarized 
in Figure 2. Material-based parameters include the type of fiber, materials and interface systems. Geometry-based parameters include thickness, scaling and curvature. Impactor-based parameters include impactor shape, size, mass, velocity and angle of obliquity. Environmental-based parameters include moisture, hydrothermal and temperature conditions.

\subsection{Influence of Constituents on the Impact Response of Composite Materials}

The path of investigating the influence of constituents on the impact response of composite structures have come a long way to reach at its most optimal stage of understanding the comprehensive mechanics of these materials and their damage response [41-42]. A composite material includes three key systems: reinforcement, matrix and interface area. Fiber/matrix interface is the region of bond among reinforcements and resin. The mechanical and chemical characteristics of the fibers, matrices and interface influence the way in which the composite deforms and fractures. The characteristics of these systems influence the mechanical stresses necessary to onset the various damage modes under impact load. Damage modes that comprise cracking of the matrix or fiber/matrix interface area lead to low fracture energies while damages comprising fiber failure lead to considerably higher energy dissipation. The fundamental characteristics of the constituents and the loading conditions influence the comparative energy absorbing capability of these damage modes.

\subsubsection{Fiber system}

The influence of various types of fiber systems on the impact response of composite materials is huge. Fiber reinforcements are the key load-bearing elements, offering the structure with the greater part of its strength and stiffness [43]. Presently, numerous varieties of fiber reinforcements are available. Aramid, carbon, and glass are the most common reinforcements employed to fabricate composites [44]. Within each of these groups, reinforcements presenting a broad range of characteristics are available. Carbon reinforcements are commonly employed in aerospace sector as it has the highest specific mechanical properties; on the other hand, it is the high brittle fiber. Glass reinforcements have high strain to failure and low strength and stiffness. Moreover, they are cheaper than carbon reinforcements. The mechanical characteristics of aramid lie between those of glass and carbon reinforcements. Comparatively, little attention has been given in the literature to the natural fiber based composites. Flexure and interlaminar shear deformations are dominant mechanisms in composites that controls the processes of energy absorption and dissipation in composite materials. The area under the material's linear stress/strain diagram represents a useful approach for predicting the impact resistance of a composite. Basically, composites with large areas under the stress/strain curve are more effective energy absorbers. Previous investigation [45], in which the comparative impact resistance of several fiber reinforced composite structures was investigated, recommended that areas under the stress/strain curve of aramid and glass FRPs (Fiber Reinforced Plastics) were considerably higher than that of a carbon FRP. It appears, as a result, that this method forms a practical guide for evaluating the impact resistance of composite materials. On the other hand, for a comprehensive analysis of the 
impact resistance of composite materials, the energy dissipation in damage modes such as matrix cracking, fiber/matrix debonding and fiber failure must be considered. Beaumont et al. [46] reported that the carbon FRP is very brittle, failing calamitously at highest load. The aramid and E-glass composites failed in a gradual way implying the energy dissipation by interlaminar delamination and other damage modes.

The capability of the reinforcements to store impact energy elastically is a basic factor in measuring the impact resistance of a fiber system. Many developments have been done by enhancing the failure strain of the fibers [47]. There is much information available in the literature regarding the impact response of different fiber materials [4-5, 13].

\subsubsection{Fiber Architecture:}

It is intricate to compare relevant published results about the influence of various fiber architectures due to different test and geometric parameters, but it is tried to take out some clear facts from the literature. Figure 5 illustrates the schematics of different fiber architectures employed in composite laminates. Conventionally, unidirectional prepreg and 2D plain-woven fabric are fiber architectures mostly employed in composite laminates. Usual 2D composite materials, whether unidirectional or woven, don't have transverse fibers. Therefore, transverse characteristics are largely managed by the matrix system. This is specifically critical under transverse impact load as interply de-cohesion can generate even in the absence of obvious failure in the top and bottom layers [48]. One promising way to enhance the transverse properties of the $2 \mathrm{D}$ composites has been the reinforcement of 3D fabrics in the composites by weaving (Figure 5). In comparison with the 2D fabric composites, there are two major benefits of 3D ones: (1) superior resistance to repeated-impacts (low damage occurrence); (2) simple and economic attainment of intricate shape structures [48-49].

To present, experimental, analytical and numerical investigations are still at a modest level and normally limited to $1 \mathrm{D}$ and 2D woven fabrics. Analytical formulations were introduced from the simplest condition (rapid impact response of a single yarn devoid of boundary conditions to the intricate one (a multilayer 2D plain-woven fabric)). The analytical formulation in the condition of ballistic impact response of a single yarn of Smith et al. [50] was derived from experimental information formerly published in 1956 [51]. In this model, constant impact velocity and experimental strain-stress curve were employed as input parameters. Single yarns have been assumed infinite (no reflection) and the interaction among projectile and yarn has been considered sharp. On the other hand, the reality is more intricate with conditions that yarns are fixed at two ends.

Developing from the formulation of Smith et al. [50], several researchers [52-53] have later introduced analytical models of ballistic impact response of woven fabrics but constrained at the linear and elastic response of yarns. All of these investigations have ignored frictions and undulations of yarns that were confirmed numerically vital in the case of $3 \mathrm{D}$ woven fabrics, except 
the investigation of Das et al. [54], where friction coefficient among yarns of a fabric structure under ballistic impact load has been shown as considerable on the fabric performance. Furthermore, the reflection of strain waves on yarns at interlacement sites is another intricate event that has not been considered yet. However, analytical models of Naik et al. [55] and Mamivand et al. [56] estimated stress distribution on primary yarns basing on experimental information of composite laminates. Hence, these investigations are not very reliable as the ballistic impact response of composite is different from dry woven fabrics devote of the matrix. In recent times, an analytical model was introduced that allows taking account for this. Certainly, the reflection of strain waves induces a sharp rise of yarn deformation at impact site that led to premature failure of principal yarns.

Roylance et al. [57] introduced a numerical model since 1970s that estimated woven fabric plies as a network of nodes with a particular mass linked together by $1 \mathrm{D}$ element. This method is theoretically comparable to that employed by other researchers, e.g. Shim et al. and Joo et al. [5859]. These models apply fabric material property together with a damage criterion and a constitutive equation as an input of 1D element. Nodal mass is estimated such that the surface density of numerical fabric is equal to the real one. 1D element, which does not have mass, can undergo compression or tension. The residual velocity subsequent to impact and the ballistic limit can be estimated as output and the effect of the boundaries of the fabric on these values is accounted for. Shim et al. [60] incorporated fiber visco-elasticity in the modeling of an identical model to evaluate the ballistic impact response among a small spherical projectile and a 2D plainwoven fabric fabricated using aramid fibers. As crimp is a particular nature of yarns in a plainwoven structure, they conducted a quasi-static tensile test on aramid fabric. The "de-crimping" add to $1.5 \%$ of the total deformation of the fabric devoid of increase of yarn stress. As a result, they considered this influence in estimating the real strain of yarns in their model by employing adaptive modeling. Joo et al. [58] proposed the model of Roylance et al. [57] to estimate the ballistic impact response of a rigid steel sphere onto 2D plain-woven fabric reinforced composite laminate. In this formulation, the yarns crossing points curvature is explicitly presented. Derived from this model, in another investigation, Joo et al. [59] have characterized the different impact energies corresponding to deformation of yarns and interactions along with yarns in a layer or at the interface among layers during the ballistic impact on the fabric. Specifically, this investigation also allowed estimating the energy of interactions among yarns with clamping devices.

Generally, the major complexity of the technique of Roylance et al. [57] lies in a simple mapping of 2D woven fabrics that cannot explain for the effect of its architecture. The extension to $3 \mathrm{D}$ woven fabric is even more intricate [61-62]. Furthermore, this mapping results in an overall deformation of the fabric having a rectangular form with edges parallel to those of the clamping cadre, which is dissimilar from the actuality. In relation to the investigation of Ivanov et al. [63], Vinson and Zukas [64] proposed a macroscopic formulation where the fabric is explained schematically by a homogeneous plate. This "continuous" modeling of fabrics allows the use of "loose" mesh and hence low computation time. In the formulation of Vinson and Zukas [64] and 
Taylor and Vinson [65], the material is isotropic and results in a similar ballistic response of fabric in all the plane directions. Such an effect is far from the experimental results of Ivanov et al. [63]. In another investigation, the macroscopic formulation of Lim et al. [66] included the viscoelastic response of fibers. On the other hand, numerical results have shown a deformation of the plateshaped cone, while the experimental tests have depicted a "pyramid" deformation.

Ivanov et al. [63] incorporated crimp and sliding of yarns in the macroscopic formulation of the fabric. The ballistic impact response of the fabric is nearer to actuality with a global dynamic deformation. Unit-cell based concepts have been employed broadly to derive the equivalent continuum level material models of woven fabric reinforced composites from the data of the mesoscale yarn properties, fabric architecture, and inter-yarn and inter-ply frictional characteristics. Several explanations and extensions of this concept were presented in recent literature [66-67]. Gu [68], Duan et al. [69] and Rao et al. [70] introduced mesoscopic models in which yarns are formulated geometrically and meshed with 3D solid elements. This concept has allowed explaining intricate events such as slipping, crimp, and fracture of yarns, delamination of the layers, etc. Ballistic impact behavior of the fabric is more sophisticatedly estimated. Barauskas et al. [71] employed shell elements to formulate their mesoscopic model, hence considerably decreasing the computation time. However, Duan et al. [69] investigated the influence of yarn/yarn and yarn/projectile frictions where the friction coefficient is represented as a function of the relative velocity of the contacting surfaces and the exponential decay coefficient expressing the shift from static friction to the stable dynamic one. This equation of the friction coefficient is presently extensively employed by numerous researchers. Barauskas et al. [71] have altered their model evaluating ranges of values of static and dynamic friction coefficients such that the number of failed yarns estimated is equal to the experimental one in the case of an impact on the 2D-plainwoven fabric fabricated using aramid fibers. Rao et al. [70] have performed an experimental investigation on a quasi-static coefficient of friction for the condition of aramid fabric. These researchers have depicted the vital role of friction coefficient, Young's modulus and strength of yarns on the ballistic impact response of fabrics. Generally, it can be observed that the prediction of full mesoscopic models is more realistic than macroscopic ones for the impact behavior of the fabric but with a very high cost [70]. The scheme is that the macroscopic model is employed to the area far from impact site and the mesoscopic one is employed for contact site with the projectile. The multiscale model depicts an interesting concept to solve impact issues with a gain of computing time.

On the experimental part, several investigations have been conducted to investigate lowvelocity and ballistic impact response of yarns, 1D, 2D and 3D fabrics [48, 72-73]. Figure 6 depicts different damage modes for various fiber architecture of composites. Results depicted that mechanical characteristics of yarns rely considerably on strain rate. On the other hand, tests on single fibers showed that this reliance is insignificant. The variation between these two types of experimental tests is still an open problem. Carr et al. [51] introduced an experimental apparatus that allows showing up two major damage modes of aramid yarns under a transversal ballistic 
impact: shearing and tension. Certainly, the damage mode relies on impact energy. A transition among two these modes is defined by critical impact energy. Applying pull-out tests, Zhou et al. [72] investigated the effect of yarn frictions on ballistic impact response of woven fabric from ultra-high molecular weight polyethylene fiber. 3D woven fabrics have depicted to offer the most favorable performance under low-velocity impact. For example, Seltzer et al. [74] showed that the specific energy absorbed by 3D fabrics was double times larger than that of 2D fabric counterparts for both glass and carbon fiber reinforced composite laminates. These variations were ascribed to the abrupt variation in the damage micro-mechanisms owing to the existence of the transverse binders. 3D woven fabrics showed three common phases under low-velocity impact prior to perforation took place: deep indentation, generation of a plug beneath the impactor, and, finally, larger localized fiber failure in tension. However, failure under low-velocity impact in 2D fabric composites initiated by interply delamination. Delamination cracks develop abruptly and ultimately deflected into the upper or lower layers by matrix shear cracking owing to the high shear stresses from the contact site. This results in the onset of a conical failure zone in which energy was dissipated by transverse resin fracture and interlaminar delamination. Ultimate fracture beneath the impact site was induced by tensile fiber fracture. Rather than 3D composites, transverse shear was not vital in 2D woven composites under to low-velocity impact, resulting in lesser energy dissipation as compared with 3D woven fabric composites. The data available regarding the mechanical behavior and the damage profile of $3 \mathrm{D}$ woven fabric composites under high-velocity impact is highly limited and obvious conclusions are not available.

3D woven preforms are made of multiple layers of orthogonal weft and warp yarns with binder yarns woven through the thickness. These binder yarns connect some or all the layers together depending on fabric architecture. Due to the load carrying capacity of the throughthickness direction fibers, 3D woven composites exhibit enhanced inter-laminar fracture toughness and better impact energy absorption performance when compared to 2D composites. On the other hand, these improved impact responses come at the cost of poor in-plane properties. During the weaving procedure, transverse yarns are physically interlocked to the parent fabric. A procedure that comprises employing flexural and tension to the yarns has been depicted to induce fiber breakage. The investigation has depicted that fiber breakage has a critical influence on woven composite strength. Another main cause of in-plane properties decrement in 3D woven fabric composite materials is the crimp and waviness related to the existence of binder yarns. As a result, it is important to study yarn flaws happening on weaving and fabrication of $3 \mathrm{D}$ woven fabric components to precisely calculate the mechanical performance of a particular element. This information may be employed to assess various fabric architectures, structural geometries, fabricating technique and finally be employed to design new 3D woven fabric architectures. Generally, these results are not adequate to exemplify impact response of 3D woven fabrics, as comprehensive damage mechanisms during impact are not investigated.

Once the materials are assorted, it is vital to know how single-layer fabric architectures influence the impact behavior of composites. Usual 2D composite materials, whether 
unidirectional or woven, not have transverse fibers and hence, the transverse characteristics are largely managed by the matrix system. This is specifically critical under transverse impact load as interply de-cohesion can generate even in the absence of obvious failure in the top and bottom layers [48]. In 3D fabric composites, the transverse fibers hold the warp and fill yarns that collectively play an important function in the impact behavior of the composites. The transverse yarn enhances the areal density, hence enabling to high fracture toughness in the transverse direction.

\subsubsection{Stitching:}

In stitching process, a fiber thread (normally glass, carbon, aramid or polyethylene fibers) is sewed through a stack of dry fabric plies or of prepreg tapes prior to applying the resin into the dry fabric perform or curing the prepreg [75-84]. Figure 7 depicts the schematics of typical stitching process in composite laminates. A considerable amount of literature has been devoted to the experimental characterization of the dynamic behavior of stitched composites to low-velocity impact. Most of the investigations depict that the application of stitches decreases the delamination area generated by impact load owing to the enhanced interlaminar fracture characteristics of the composite. Decrements by up to $50 \%$ in the damaged area were for instance observed by Wu and Wang [79] in glass/epoxy composites stitched by aramid fibers. The experimental investigations depicted that both the linear density of the thread and areal density of stitching influenced the performance of stitches in governing the delamination resistance of the composites. Also, significant decrements in the delaminated area were noted in quasi-isotropic carbon/epoxy composites stitched with carbon threads and subjected to low-velocity impacts up to impact energy of $4 \mathrm{~J}$ [80], and in aramid stitched weave fabric laminates impacted with energies ranging between 5 and $50 \mathrm{~J}$ [81]. Higher enhancements in delamination resistance were noticed with raising impact energies in both investigations.

The influence of the thread thickness and of the areal density of stitching on the low-velocity impact behavior of CFRP (carbon fiber reinforced plastic) composites stitched with Vectran threads has been comprehensively studied by Tan and co-workers [82-85]. The results of their investigations show that for low impact energies stitches act as crack initiators and are not capable to avert the interlaminar delamination onset. For larger impact energies, however, stitches show progressively more effectiveness in restraining the development of delamination, with larger stitching densities allied with higher developments in the delamination resistance. Figures 8 and 9 shows the impact damage of various specimens (thread thickness 200 and 400 denier; stitch space $3 \times 3$ and $6 \times 6$ ) subjected to impact energy of $6.7 \mathrm{~J}$ and their corresponding energy absorption curves, respectively. Identical results were obtained in [86-87] for the impact behavior of crossply composites fabricated using pre-preg carbon/epoxy plies and stitched using aramid or polyethylene fibers. In specific, it was observed that stitching does not prevent the onset of delaminations, but produces an obvious decrement of the damage area for delaminations adequately long to set off the bridging action. As a result, the competence of the toughening action generated by stitching highly relies on the extent and nature of the impact failure happening in the base composite. For instance [86], stitching was observed to enhance the impact failure resistance 
of $\left[0_{3} / 90_{3}\right]_{\mathrm{s}}$ composites, for which the main delamination was adequately large to permit the full growth of the stitch bridging area; on the contrary, no raise in delamination resistance was noticed in $[0 / 90]_{3 s}$ composites, which show a failure pattern comprising of small overlapping delaminations not capable to set off the toughening mechanism produced by stitching. As compared to the number of experimental studies, the published literature on the analytical and numerical estimation of the influence of stitching on the failure behavior of composites under lowvelocity impact is limited.

Analytical formulations to estimate the role of stitching in enhancing the resistance to delamination propagation in composite beams under mode I or mode II loading have been initially introduced by Mai and co-workers [88-90]. The damage mechanisms characteristic of continuous stitching was found as elastic stretching of the thread, debonding of the thread/resin interface, and thread failure; the main contribution to the rise in delamination toughness was ascribed to the elastic stretching of threads, which offer the crack closure forces at the interface. To determine the load carried by stitches under mode I loading, the bond among thread and resin was supposed to be entirely frictional, considering a fixed value for the friction shear stress. For ENF (End Notched Flexural) specimens, both the frictional shear stress at the interface and the bending of threads owing to relative sliding of the delaminated sections were ignored and the load withstand by threads was just estimated from the elastic deformation of the thread. To simplify the assessment, the load withstand by threads was lastly substituted by an equivalent distributed load in the governing differential equation for beam deflection. Sankar and Zhu [91] proposed an analytical formulation to estimate the influence of stitching on the delamination resistance of impacted beams. The model considers that the delamination grows under dominant mode II conditions and that the crack bridging forces are primarily owing to the resistance generated by the resin as the stitches be susceptible to plough in the course of the matrix. The bridging forces are applied in the equation of motion of the impacted composite beam as a fixed distributed shear traction acting at the delaminated interface. At one with most of the experimental information from the previous literature, the outcomes of the model show that the impact energy necessary for delamination onset is not influenced by the presence of stitches.

The application of Finite Element (FE) analyses is, on the other hand, is necessary to model the behavior of stitched composites for intricate configurations, and in the existence of different interacting failure modes such as resin cracks, delaminations or fiber failure. Spar elements were employed in [92] to study the potential of stitching for mitigating the interlaminar stresses producing at the end of a notch in composites under tensile load [93-95]. Spar elements were applied in [96] to simulate the toughening mechanism of stitches on composites in Double cantilever beam (DCB) and Compression after Impact (CAI) testing arrangements. A nonlinear response, which accounts for various phases of the damage process, was considered for the stitch elements for simulation of DCB tests, while a simple linear behavior was employed for modelling the behavior of the composites under CAI tests [96]. Two-node beam elements connecting nearby plies were employed in [80] to simulate the influence of stitched threads on the failure behavior of quasi-isotropic composites to low-velocity impact; likewise, stitching threads were modelled as 
3D linear elastic beam elements incorporated in the core and the face-sheets for studying the blast resistance of stitched sandwich composites [97]. Solid elements with isotropic characteristics were employed in [98] for modelling the stitches in composites subjected to flexural after impact. Perfect bonding was considered among the stitch and the surrounding composite. Taking into consideration the rather inadequate quantity of research into the simulation of the influence of stitching on the impact damage resistance of composites, there is, as a result, a strong case for the development and confirmation of modelling tools competent of providing correct and reliable predictions of the failure generated by impact on stitched composites.

Stitching has been established to be one of the most promising procedures to improve the interlaminar properties of composites. Stitching was observed to raise the interlaminar delamination resistance of composites under impact loads [77] and to enhance the tolerance to failure and the post-impact strength of impacted composites subjected to static loads [78]. The enhancements in damage resistance are normally ascribed to the bridging event of throughthickness threads, which employ closure tractions at the interface among delaminated plies, hence decreasing the driving force available for growth of the interfacial crack [75]. On the contrary, the stitching results in a distortion of the internal arrangement of the composite, producing localized stress concentration sites, such as layer waviness, resin-rich areas and fiber failure [76], that can function as initiating site for further failure modes in the composite.

\subsubsection{Hybridization}

Hybridization process mixes the superior mechanical characteristic of high stiffness reinforcements with the superior impact resistance of ductile fibers [99]. Two interesting events are characteristically noticed. One is that the initial damage happens in the low elongation ingredient at a certain strain, which leads to knee points in the stress-strain curve. The other event is known as the "synergistic strengthening", but the crucial examination is that the failure strain, and thus the strength, of the low elongation ingredient, founds to be higher in the hybrid than in homogenous-low elongation fiber composites. Figure 10 shows the schematic stress-strain curves of hybrid composites with synergistic strengthening. Hybridization can be broadly grouped into three main types based on the distribution of the reinforcements, as shown in Figure 11: (a) Interply hybridization, where the modification is performed at laminate level by stacking layers of various constituents, (b) Intraply hybridization, where various bundles are combined within the plies in parallel, and (c) Super hybridization, which consist metal/composite layers and matrix composite layers stacked in a particular stacking sequence [100-101].

Numerous literature on inter-ply hybrid composite materials refers to carbon/polyethylene fibers, carbon/glass, and carbon/aramid largely aimed at enhancing the impact behavior of carbonbased composites [105-123]. Table 2 summarizes impact studies on composites with various stacking sequences. During the last decade, attention has risen in a comparatively new group of

hybrid materials based on synthetic (largely glass reinforcements) and natural reinforcements, with the objective of fabricating high impact resistant environmental friendly composite materials. 
Natural fibers may be an appropriate alternative to synthetic fibers, such as carbon and glass, in numerous ecological features but not regarding impact strength. Improvements in the impact strength of the composites may be attained while hybridization of natural fibers using different synthetic fibers. In consequence of ever stricter environmental necessities, also reinforcements of mineral origins, such as basalt, are largely studied. Basalt fibers have similar stiffness and strength but much superior thermal characteristics than glass ones though the quality of the reinforcements is highly responsive to the processing aspects. On the other hand, little has been explained in the impact behavior of Intra-ply hybrid composites [102]. Pegoretti et al. [103] investigated lowvelocity impact response of E-glass-poly vinyl alcohol/polyester laminates in inter-ply and intraply hybrid composites. It was noticed that, compared to inter-ply composites, the intra-ply hybrid laminates had superior impact performance. Wang [104] investigated low-velocity impact response of inter-ply and intra-ply hybrid basalt-aramid/epoxy composites. They depicted that the inter-ply composite had larger ductile indices, least peak contact force, and greater specific energy absorption than the intra-ply composites.

Fiber metal laminates (FMLs) mix the higher ductile property allied with metals with the attractive fatigue and fracture properties of composite materials [124]. Fiber metal laminates have been employed to numerous aircraft; for example, aluminum/aramid composite is employed to the cargo door of military aircraft, and aluminum/glass on the upper fuselage of the Airbus A380 [125]. Recently, Ti/CFRP composites are employed in supersonic aircraft that necessitate operating temperatures as high as $177^{\circ} \mathrm{C}$. Impact tests on fiber metal composites signify that metal layers can restrict delamination growth and impactor penetration. Abdullah and Cantwell [126] investigated the impact response of a glass/polypropylene FML and noticed that the FML exhibited an impressive resistance to low and high-velocity impact loads. Yu at al. [127] reported that CARALL (Carbon fiber aluminum laminates) shows superior impact resistance than GLARE (Glass reinforced aluminum) owing to high strength and stiffness of carbon fiber. Vlot and Fredell [128] performed low-velocity impact tests on FMLs (glass-aluminum based) and depicted that they provide a better impact response than both a plain carbon fiber reinforced composite and an aluminum alloy. Bienias' et al. [129] revealed that fiber metal laminates with carbon reinforcements absorb impact energy largely by penetration and perforation of the composite, while composites with glass reinforcements absorb energy by plastic deformations and delamination onset and growth under low-velocity conditions [130]. Investigations into shock loading induced perforation behavior are also performed on composites with the application of various metal layers [131-132].

Shape memory alloy (SMA) wires reinforced inside the fiber-reinforced composite materials owing to their super-elastic response enabling significantly large strain-to-failure and elastic strain. With an elastic strain of about $15 \%$, this high strain property of SMAs is mainly owing to a stress-induced martensitic phase shift generating a plateau area in the stress-strain curve. This character allows them to absorb a considerably high amount of strain energy than other fibers prior to their failure. Tsoi et al. [133] studied the influences of the pre-strains, location, and 
volume proportion of SMAs on the low-velocity impact damage response of SMA hybrid composites. They revealed that the interlaminar delamination area decreases as the pre-strain of SMA wires enhanced. Lau et al. [134] investigated the option to stitch SMAs into the composites to decrease the danger of delamination of the composites under impact load. The impact resistance characteristics of SMA stitched GFRP (glass fiber reinforced plastic) laminated subsequently to low-velocity impact were investigated. They depicted that the laminate strength increases and the number of trans-laminar cracks reduces by stitching the laminates by SMA wires. Paine and Rogers [135] studied the application of SMA's reinforced into composites to enhance the lowvelocity impact damage of composites. A graphite/bismaleimide composites embedded with NiTi wires was investigated under high energy impact loads, depicting that the wires in the hybrid composite avoided entire perforation under the impact. Moreover, it was noticed that all graphite composite had higher visible delamination than the hybrid ones and the peak contact forces of the hybrid composites were very larger than the graphite composites.

It is extensively recognized that an enhancement in the impact resistance of composite materials with high stiffness fibers (e.g. carbon or glass) can be attained by combining them with high strain to failure properties (e.g. aramid, polyester or polyamide polymers), owing to the reason that this process (hybridization) mixes the superior mechanical characteristic of high stiffness reinforcements with the superior impact resistance of ductile fibers [99]. The mechanical properties and failure profile of these composites as a function of the ratio between various reinforcements and dispersion nature were studied and discussed by numerous researchers.

\subsubsection{Fiber stacking sequence}

Being a directional reliant behavior, the impact response of composite material having various fiber orientations was investigated over several years. To obtain superior impact properties, composite materials requires the correct placement of suitable reinforcements (material, orientation, and architecture) within the material, which provides a better chance to modify the material properties; on the other hand, it enhances the difficulty of the design issue [136-138]. Dorey [139] depicted that composites comprising $+/-45^{\circ}$ surface layers provided higher impact resistance and superior post impact residual strength with respect to those having $0^{\circ}$ surface plies. This was ascribed to the higher flexibility of the composite raising its capability to absorb energy elastically. Hong and Liu [140] and Liu [141] investigated the low-velocity impact response of a glass/epoxy composites having the stacking sequence $\left[0_{5} / \theta_{5} / 0_{5}\right]$, where $0=0,15,30$, 45, 60 and $90^{\circ}$. They noticed a significant rise in the delamination area as $\theta$ increased, with the energy necessary for delamination onset reducing as $\theta$ increased. The energy necessary for delamination onset was also affected by the several dissimilar interfaces, increasing as the number of interfaces raised. Clark [142] employed an analytical method to estimate the location and size of delaminations along the laminate thickness under low-velocity impact loading. Higher delaminations were estimated and noticed to happen as the angle between nearby layers increased,

which supports the results of Hong and Liu [140-141]. Strait et al. [143] studied the influence of stacking sequence on the energy absorption during low-velocity impact tests of a carbon/epoxy 
laminates comprising three major stacking sequences, quasi-isotropic, cross-ply and [0/ \pm 45$]$, with moderate changes in ply order in each fundamental lay-up geometry. The results depicted no clearcut influences of stacking sequence in terms of the energy absorption in delamination onset for the three main composite variants although the absorbed energy was affected by the minor modifications in lay-up for each basic geometry. Other investigations [144], on the other hand, concluded that the stacking sequence had insignificant or no influence on the energy absorption or the damage extent, mainly when the changes in stacking sequence were comparatively minor. The influence of stacking sequence on the impact response of laminates is, hence, not yet completely understood.

Many investigators reported that the fiber architecture of the layers in composites significantly influences the impact response of a composite. A. Aktaset al. [145] investigated the influence of stacking sequence on the low-velocity impact response of sequentially stacked woven/knit fabric glass/epoxy laminates. They reported that specimens fabricated with an outer layer of woven fabric showed the most favorable impact response than that of the specimens with knitted fabric in the outer surface. Moreover, numerous authors have investigated the influence of stacking sequence in interply and intraply based hybrid composites. Prevorsek et al. [146] performed a high-velocity impact test on composites comprising hybrid configurations fabricated using glass and more ductile polyethylene fibers. They reported that specimens with glass side impact depict superior impact damage resistance. For the same arrangement, the penetration threshold of a hard side impact is double times greater than soft side impact. Tirillò et al. [147] investigated the effect of stacking sequence on the high-velocity impact response of basaltcarbon/epoxy hybrid composite laminates. Four various stacking sequences such as sandwich-like and intercalated configurations were considered in their study. They concluded that the stacking sequence significantly influences the ballistic limit with the intercalated arrangement (basalt on the outer layers) showed the maximum ballistic limit among all the hybrids. Figures 12 and 13 shows the schematics of different hybrid configurations and damage profiles of various specimens, respectively. A similar result was reported by Sarasini et al. [148] on low-velocity impact response of basalt-carbon/epoxy hybrid laminates. Fabrizio Sarasini et al [149] studied the effect of stacking sequence on hybrid composites fabricated employing carbon (C) and flax (F) fiber epoxy prepregs with two different configurations based on the reinforcement of flax as outer layers and carbon as inner layers (FCF) or vice versa (CFC) under low-velocity impact load. They reported that FCF configuration shows better impact damage tolerance than CFC owing to the reason that the outer flax fibers hinder the crack growth in the composite. Park and Jang [150] studied the influence of stacking sequence on the low-velocity impact response of aramid-glass hybrid laminates. They reported that placement of aramid plies at the outer surface increase the impact resistance owing to the reason that the high strain to failure fibers at the outer side can undergo higher deformation. Similar results were observed by [151]. Kim et al. [152] performed a similar investigation on hybrid composites with plies of brittle CFRP bonded with ductile aramid or glass or UHMPE fibers. The conclusion was that composites on hard side impact provide superior impact resistance 
than soft side impact. The explanation is that the hard side absorbs most of the impact energy in the form of fracture and interlaminar delamination and the rest of the energy is dissipated in the form of plastic work done by the soft ductile layer. Sayer et al. [153] studied the low-velocity impact response and failure profile of Glass-Carbon/epoxy hybrid laminates with various impact face i.e. Glass-Carbon (GC) and Carbon-Glass (CG). Vital conclusions acquired from their experimental investigation are; CG sample has least energy absorption potential than GC samples, penetration threshold of CG sample is one-third time higher than GC, raising the carbon plies in CG samples depicted insignificant influence in penetration threshold value. On visually studying the impacted samples, there were numerous small matrix cracks and some interlaminar delamination in the glass plies. While the carbon plies depicted indentation and resin cracks with some fiber failure. Hosur et al. [154] performed an experimental investigation (low-velocity impact test) to evaluate the behavior of four various hybrid configurations fabricated using twill weave carbon fabric and plain weave S2 glass fabric. They reported that material on the rear side plays a significant role in the impact behavior mainly bending stiffness influence. Stacking sequence changes within the laminate lead to advanced tailoring that may result in the alternation of load paths within the material and lead to more favorable stress distribution and better structural performance. Hence, composites that are to be employed in impact-prone applications should have a stacking sequence that is optimized to both withstand the mechanical loads and enhance the damage resistance. To enhance the damage resistance of a composite material, designers should be capable to estimate the influences of varying the stacking sequence. This is a difficult task, due to the intricate mechanisms by which failure can grow along the composite.

It was concluded by many researchers that altering the ply stacking sequence influence the peak contact force, delamination area, residual impact strength, and damage width. Designing a composite includes employing the optimum configuration of the ingredient materials within the composite. Presently, impact response of composite materials with various design variables, such as geometries, material properties, fabrication and test conditions, etc. has been extensively studied by several researchers [136-137]. Attractively, one investigation factor concerning the stacking sequence, as one of the dominating aspect influencing the impact responses, has created large interest from several researchers [138]. Hence in the past, a significant number of allied investigations have been performed to explore the influence of stacking sequence on the impact response.

\subsubsection{Matrix and Interface system}

Similar to the fiber system, the impact behavior of composite materials is highly influenced by the matrix and interface systems. The matrix system in a composite material assists to defend, align and stabilize the reinforcements as well as aid load transfer from one fiber to another [155]. The application of thermoplastics dominates in short fiber-reinforced and unreinforced materials. Under impact loading, thermoplastic matrix systems such as polyetheretherketone (PEEK) and

polyphenylene sulphide (PPS) provide a promising substitute to thermosetting resins. In the early 90s, the impact behavior and damage tolerance of thermoplastic composites had been investigated 
to identify why such composites were mostly high damage tolerant than thermosetting composites [156]. A few researchers have studied the effect of matrix type on the capability of thermoplastic composite materials to resist penetration [157], absorb energy, and withstand damage at various temperatures. Carbon fiber-reinforced PEEK (APC2) composites provide the most favorite dynamic toughness. These materials absorb a significant quantity of impact energy while encountering just little extent of damage [158-159]. Another benefit of carbon fiber-reinforced PEEK (APC2) composites is that its thermoplastic resin enables quick repair employing fusion methods such as the hot press method. Here, the damage can be repaired by just heating the structure at a temperature higher than the melting point of the resin, reforming and then cooling. Carbon/PEEK composites have acquired only very little interest under high-velocity impact load. Carbon/PEEK composites have comparatively poor high-velocity impact behavior. Certainly, semi-crystalline thermoplastic matrices provide numerous benefits over traditional thermosetting matrix such as epoxies: superior chemical resistance, better impact, and excellent resistances, and they can be employed over a broad temperature range.

On the other hand, the thermosetting resin system still dominates continuous fiberreinforced composite materials, as they are mainly suitable for impregnation into the reinforcement. Thermoset resin-based composites are progressively employed as weight-critical components in the aerospace sector, largely as they offer higher strength and stiffness characteristics than conventional metals. Hence, thermosetting matrix composites have been widely employed over the past 40 years in the aeronautical sector. Although thermosetting matrix system depicts superior mechanical characteristics, they also show undeniable limitations, such as the requirement for storage at low-temperature, a hard-to-manage cure procedure, a long curing duration, and handmade draping, which induces numerous irreversible flaws of the fabricating procedure. Composites fabricated using thermosetting matrix systems experience higher interlaminar delamination than thermoplastic composites [160]. Therefore, the development and tailoring of thermoset based material characteristics for impact resistance have turned out to be a vital theme of many investigations [161].

Most of the aerospace composites were based on thermosetting matrix system, which has superior temperature performance and higher stiffness and strength compared to other matrix systems. The weaknesses of these types of matrix systems, such as brittleness, comparatively long processing cycle necessitated to make certain complete curing and provide better bonding across the interface sites, created the interest to the other type of processing conditions or matrix system. Thermoplastic matrix systems provide enhanced toughness owing to somewhat higher energy at first failure and ultimate energy than that of thermoset systems. Their production can be fast and may be economic. There is not any comprehensive research to compare the low-or high-velocity impact response of both matrix types: thermoset and thermoplastic. The recommendation for altering the conventional thermoset matrix with thermoplastic one could not be justified with the presently available data and hence, thermoplastic matrix based composites must be limited to some specific impact applications. 
The impact performance of fiber reinforced polymer matrix composites relies on the bond strength between the matrix and fiber system. The predominant damage under low-velocity impact is interlaminar delamination [162]. This damage mode is normally generated by the propagation and the bridging of the cracks owing to opening forces. Interlaminar delamination is often propagated by interlaminar shear stresses (mode II) generated by the bending of the composite under the impact load [163]. Improvements in the interlaminar characteristics of fiber reinforced polymer matrix composites were attained through various methods such as stitching [164], reinforcement surface treatment [165] and interleaving technique [166].

Commonly, the grafting-onto micro-fillers or dispersion of the carbon nanotube in the matrix were two common methods mentioned in previous literature. Figure 14 depicts the schematics of deposition or dispersion of nano- or micro-fillers on fiber or matrix system. Among these techniques, dispersing carbon nanotubes with the resin is presently the most facile and inexpensively well-matched route (Figure 14(b)). Carbon nanotubes with outstanding mechanical characteristics and high surface to volume ratio have depicted considerable improvements in the impact behavior of composites [167]. Yokozeki et al. [168] modified carbon fiber composites with various concentrations of carbon nanotubes. By incorporating 5\% (by weight) of the nanotubes, the interlaminar fracture toughness increased by $97 \%$ in mode I and by $30 \%$ in mode II. M. Siegfried et al. [169] investigated the influence of carbon nanotubes on the low-velocity impact response of carbon/epoxy composites. Three nano-composites that vary in the carbon nanotube dispersion and functionalization are employed as a matrix system. They reported that the nanotubes have a dual influence on composite characteristics: (1) they enhance the interlaminar fracture toughness (mode II), but (2) they also induce them more vulnerable to the resin cracks resulting in a higher delamination area. Of the two groups of carbon nanotubes, single-walled and multi-walled tubes, the latter has been more widely employed for the preparation of enhanced hierarchical composites [170], owing to their easy availability, low cost in large amounts and ease of uniform dispersion. Hence, the possibilities of single-walled carbon nanotubes for application in hierarchical composites are largely unknown. Some investigations, on the other hand, have depicted that single-walled tubes provide better performance owing to their smaller diameter, higher aspect ratios, more uniform load transfer and superior mechanical properties [171]. However, they are recognized to pose challenges in terms of dispersion, necessitating the introduction of appropriate functionalization methods which address these problems while not damaging the single-walled molecular structure. Asharfi et al. [172] dispersed single-walled carbon nanotubes in the epoxy matrix system of carbon fiber composites. The incorporation of the single-walled tubes led to a reduction of the resin fracture toughness by $12 \%$. On the other hand, the interlaminar fracture toughness enhanced by $13 \%$ in mode I and $28 \%$ in mode II. Wichman et al. [173] showed that the incorporation of multiwalled carbon nanotubes in $0.3 \mathrm{wt} \% \%$ in glass/epoxy laminates through resin transfer molding enhanced the shear properties although no definite improvement was recorded for mode I and mode II fracture tests. Complete utilization of carbon nanotube has not been fully effective in nano-composites owing to the restrictions associated with the uniform dispersion of aggregated nano-tubes [174, 175]. The dispersion 
efficiency of carbon nanotubes in a resin relies on the proportion of fillers, dispersion morphology, bonding nature with the polymer, aspect ratio and waviness of nano-tubes [176]. A suitable level of carbon nanotube reinforcement is mostly attained by high ultrasonication or shear mixing in three rolls process. Else, aggregation of carbon nanotubes generates flaws which aggravate the mechanical properties of nano-composite [177, 178].

Grafting of nano-particles onto the filler was developed as an alternative method to generate a multiscale reinforcement (Figure 14(a)). This method enhances stress transfer among filler and matrix system and decreases dispersing challenge. Growing carbon nanotubes on the reinforcements has established a high possibility to generate a modified interface. Mechanical attachment of carbon nanotubes forest introduced on the reinforcements to the matrix and their molecular interaction are the parameters which enhance the adhesion [179]. Rahmanian et al. [180] demonstrated a considerable rise in impact strength of carbon nanotube grown short fiberpolypropylene composite under low-velocity impact. Dichiara et al. [181] prepared hybrid filler by growing carbon nanotubes on the graphene nano-platelets. They obtained the most favorable dispersion of the hybrid fillers and enhanced the interfacial adhesion. On the other hand, the application of both carbon nanotube and micro-fillers was not often paid interest. Separate addition of nano-fillers or micro-fillers into a matrix system has established enhancement in some mechanical characteristics whereas impaired other. The literature that describes the resin modification of thermosetting composites using thermoplastics are summarized in Tables 3 and 4.

In addition, employing nano-scale fibers in composites $[182,183]$ provides the chance to develop the fiber-matrix interface strength and improve the matrix-reliant characteristics with least weight penalty (Figure 14(c)). These fillers can be applied to improve the fracture characteristics of matrices and composites owing to their capability to act as a reinforcing phase at the nano-level. Kostopoulos et al. [184] reported a rise of $100 \%$ in fracture energy subsequent to the application of $1 \%$ carbon nanofiber in the resin. The study on the fracture surfaces depicted wide fiber bridging owing to the existence of carbon nanofibers, which resulted in the improved fracture characteristics. Arai et al. [185] reported that application of carbon nanofiber interlayer in carbon fiber reinforced composites considerably enhanced the fracture toughness under mode I and mode II loading. Walker et al. [186], under low-velocity impact, employed various types of short fibers (PA web/Kevlar/nylon/PEEA) both arbitrarily and uniformly in the interlaminar site attaining thus a decrement in delamination area. Sohn and $\mathrm{Hu}$ [187] employed aramid chopped fibers as the transverse reinforcements in carbon fiber composites. The existence of the chopped fibers enhanced the interlaminar delamination toughness by around 100\%. Furthermore, Sohn and $\mathrm{Hu}$ [188] have depicted that dispersing moderate quantity of chopped fibers between two adjacent plies can enhance the mode II delamination toughness. On the other hand, these developments are attained by sacrificing in-plane mechanical properties.

Shear thickening fluid is commonly employed to impregnate with aramid reinforcements to improve the interfacial strength (Figure 14(d)). Shear thickening fluid includes oxide particles (polyethylene glycol and colloidal silica) in a liquid polymer. When shear stress is employed, the 
viscosity of the shear thickening fluid enhances as it acts as a non-Newtonian fluid. At the instant of impact loading, shear thickening fluid assumes a solid-like response. After impact loading, they go again to their fluid condition [202-203]. Colloidal silica components generate a sealing coat that improves the ballistic impact resistance of the woven reinforcements. As the colloidal silica in the shear thickening fluid generates hydro clusters, impregnation of the fibers with shear thickening fluid leads to a microstructural modification which improve the hydrodynamic stress in the suspension and enhance the ability to withstand ballistic impact [204-205]. Studies have reported that the ballistic impact resistance of aramid reinforcements is enhanced by incorporation with silica particles. Moreover, compared with aramid reinforcements with no shear thickening fluid impregnation, it was recognized that this incorporation improved the flexibility and decreased the necessary thickness for sufficient protection [206]. Majumdar et al. [204] reported that the shear thickening fluid concentration increases the energy absorption capacity and reduces the number of fiber layers necessary for the desired shielding under low-velocity impact. Shear thickening fluid enhances the friction among the fiber filaments on impacts and decreases the number of layers employed in laminates by between 40 and 80\% [207-208]. Compared to composites fabricated with aramid reinforcement that is not treated with shear thickening fluid, around a 50\% increase in energy absorption was obtained when aramid was impregnated by shear thickening fluid [209].

There are many reasons why thermoplastic composite materials are superior as aerostructures: higher toughness compared with thermosetting matrices, natural flame retardancy and they are allied with low-cost fabricating methods such as thermo-folding, stamping, welding and co-consolidation [159]. On the other hand, the thermosetting resin system still dominates continuous fiber-reinforced composite materials, as they are mainly suitable for impregnation into the reinforcement and offer higher specific strength and stiffness characteristics. Hence, thermosetting matrix composites have been widely employed in lightweight high-performance applications. On the other hand, composites fabricated using thermosetting matrix systems experience higher interlaminar delamination than thermoplastic composites [160]. Therefore, the development and tailoring of thermoset based material characteristics for impact resistance (through grafting-onto micro or nano-fillers and shear thickening fluid) have turned out to be a vital theme of many investigations [161].

\subsection{Geometrical factors}

The previous sections discussed the role of various constituent materials on the impact mechanism of the composite. In order to have a wider viewpoint on geometrical factors, this section emphasizes three key factors: thickness, scaling, and curvature.

\subsubsection{Thickness:}

A practical factor allied to the application of composites is the composite thickness, as thick composites interact on various ways with the externally applied loading than thin composites 
[227]. Thickness is the vital parameter as it alters energy absorption mode and area of failure of the composites [228]. The predominant failure mode occurred during the impact event is mainly decided by the composite laminate thickness. It is considered that the deformation response along the thickness direction of thin composite structures is the same along the whole thickness. However, if the thickness of the composite structure is raised the deformation and the induced stress response of the laminate might be different at the various position along the thickness direction.

Quaresimin et al. [229] studied the influence of laminate thickness on the energy absorption of woven carbon-epoxy composite laminates under low-velocity impact. They reported that the delamination threshold-load and -energy for the damage initiation and the peak contact force were closely reliant on the thickness. The failure threshold shifts to larger impact energies as the laminate thickness increases. It was reported that the threshold load for the main failure is independent of the incipient impact energy, but it is largely reliant on the laminate thickness. G. Caprino and V. Lopresto [230] reported that the penetration energy for composites under lowvelocity impacts increases as the panel thickness increases. Thick composites are less vulnerable to impact damages than thin composites. Wang et al. [231] investigated the low-velocity impact response of flax reinforced composites. They reported that contact force and Hertzian force increased and ductility index reduced as the thickness increased. De Morais et al. [232] investigated the effect of laminate thickness on repeated low energy impact behavior of glass, carbon and aramid fabrics reinforced composites. They reported that that below a particular energy level the laminate thickness is the most pertinent factor that decides the impact resistance. The glass fiber reinforced laminates depicted the steepest rise on the impact resistance with raising laminate thickness. This response was characterized mainly to the larger areal coverage of the glass fiber employed. Moreover, the isotropic response of glass fibers with respect to the anisotropic nature of aramid and carbon fibers was also of relevance. R. Park and J. Jang [233] studied the influence of laminate thickness on low-velocity impact response of aramid/vinyl-ester composites. The laminate thickness altered the impact absorption mode from plate bending stress to local stress. Stavropoulos C. and Papanicolaou G [234] reported that an increase in the individual lamina thickness produced superior ballistic impact behavior compared to increasing the number of plies employed in the composite. The damage modes generated under impact load in fiber-reinforced composites are quite intricate. Generally, there are three key damage modes: resin cracking, fiber failure, and interlaminar delamination. Dhakal et al. [235] reported that the thickness has a significant role in the low-velocity impact damage behavior of jute MSO biocomposites. However, the correlation among impact response and damage profile and its extent has not been well understood against laminate thickness. From the previous literature, it is observed that the influence of thickness on the dynamic response of composite structures at high velocities is not reported in detail.

The span-to-thickness ratio of the sample highly influences the failure of the fibers in the outer layers owing to the bending moment under impact loading [236]. The maximum axial fiber 
stress is positioned immediately underneath the impactor. A larger span-to-thickness ratio requires a larger strain to fail the samples. The rise in span-to-thickness ratio also negate the effects of the damage on the impact behavior as the bending tend to be more global with material effects averaged over a higher area. The general rule is that raising the span-to-thickness ratio of the sample decreases the shear mode of deformation under impact loading.

Cho [237] compared the impact response and damage pattern of composite samples with various span-to-thickness ratios under low-velocity impact using 2D and 3D FEM approach. This comparison allowed to claim that a span-to-thickness ratio higher than 30 is a fair condition for the application of the 2D FEM technique. The investigations made by [238] enabled the authors to claim that that perforation energy of composite laminates is influenced by the span-to-thickness ratio under low-velocity impact. Even with a minor change in span-to-thickness ratio significantly varies the stiffness, peak load, and contact duration. At a smaller ratio, higher stiffness, larger peak load, and short duration were observed. Moreover, a lower amount of interlaminar delamination was noticed for a smaller span-to-thickness ratio. At high-velocity impact, the perforation energy does not reliant considerably on the sample span-to-thickness ratio owing to the short contact duration of the event.

\subsubsection{Scaling effects}

There has been rising attention in understanding the effect of scaling in the dynamic impact behavior of composites as they are largely exposed to impact loads [239]. There are several factors that influence the behavior and failure onset of an impact problem. So as to understand the influence of each factor, defining some non-dimensional variable and analyze its change will be the appropriate technique. Scaling a behavior to the prototype sample is an additional benefit of non-dimensionalization. Sankar [240] developed a technique for non-dimensionalizing the impact equations in association with five-dimensional factors. Moreover, semi-empirical equations were provided for peak contact force and contact duration for both small and large mass impact tests. Damodar et al [241] discussed the preliminary analytical and experimental results to validate the accurateness of scaling laws for a thin composite laminate under low-velocity impact load. The scaled configuration seems to encounter critical failure than the reference one.

Morton [242] experimentally studied the size effects in the impact behavior of some CFRP composite laminates with various stacking sequences employing the Buckingham- $\pi$ theorem. It was reported that the contact force must scale as the scaling factor squared, whereas the contact time must scale linearly with the scaling factor. It was noticed that the impact strength enhanced considerably with reducing sample size. Swanson [243] performed low-velocity drop-weight and high-velocity air gun impact tests on CFRP laminated plates and cylinders. It was reported that the severity of interlaminar delamination reliant on specimen size, while the strength and strain to failure of the samples did not change significantly with size. Comprehensive investigations have also been done to study scaling effects in both the quasi-static and low-velocity impact behavior of FML (fiber metal laminate) composites and sandwich composites with rigid-foam core and 
CFRP skin structures. It was reported that for both types of composites, there was no considerable effect of scaling in the mechanical behavior under quasi-static conditions. Also, under impact load, the contact force, displacement, and failure threshold energy were noticed to be independent of size.

Mckown, Cantwell, and Jones [244] analyzed the scaling effect in FML based on a factor (ratio of the characteristic length in a small-scaled sample to the corresponding value in the fullscale component) with four values, namely $1.0 .75,0.5$ and 0.25 . They reported that the normalized load-deflection traces, failure threshold energy and perforation energy, resembles the better correlation of the scaling law. On the other hand, the transient behavior of the material property encourages variations in scaling laws for transient impact like strain-rate performance. The stacking sequence was scaled using two approaches viz., ply-level scaling (changing thickness of each layer) and sub-laminate level scaling (duplication of simple structure). The results of lowvelocity impact tests gave an indication of good arrangement with simple scaling laws. Zhou and G.A.O. Davies [245] reported that impact testing of full-scale components under different conditions is very costly, and is rarely performed. Instead, the prototype (small coupon) tests are carried out, and their data are employed for the valuation of scaled design in combination with the consideration of physical similarity. Scaling approaches should allow to make certain that the performance of a sample is representative of the full-scaled component and to enable the extrapolation of outcomes for variations in scale. They also found that the development of such an approach turns out to be 'almost impossible' when failure happens.

An examination of the previous published literature on scaling effects shows that some of the previous investigations have focused on studying the behavior of the composites based on unidirectional fabrics, whereas little interest has been provided to woven and textile composites, regardless of the fact that these fabrics provide several benefits, such as a higher notched sensitivity, a better impact resistance, and lower manufacturing costs, compared to their unidirectional counterparts. Also, it is obvious that very fewer investigations have been done at impact energies higher than that necessary for the impactor to perforate the composite. This perforation threshold is obviously of importance when configuring components that are necessary to defend personnel during impact loads such as blast and explosions.

\subsubsection{Curvature:}

Curvature has a considerable influence on the response of composites under impact loads. Apart from the few experimental studies allied with investigating the influence of curvature on impact response, most of the publications utilize the numerical modeling or commercial FEM software. Moreover, numerous practical composite structures comprise curved geometries, but only a few researchers have studied the influence of impact load on such components [246]. Gong et al. [247] analyzed the low-velocity impact response of orthotropic cylindrical composite shells.

They introduced an analytical force function derived from material properties, the mass of the shell/striker and the impact velocity to estimate the impact force behavior. This force function was 
employed to illustrate contact-force histories for various conditions of impactor masses and velocity. Khalili et al. [248] investigated the dynamic behavior of a thin smart (embedded with shape memory wires) curved composite materials subjected to a low-velocity impact. Their investigation was derived from the linear Hertzian contact model which is linearized for the impact study of the curved composite structures. The governing equations of the curved composites are given by the first-order shear deformation theory and solved by Fourier series. Kistler and Waas [249] investigated the effect of in-plane and transverse boundary conditions, the influence of curvature and the validity of linear and non-linear plate theory on the transverse low-velocity impact of curved composite structures. They reported that as the thickness reduces, deformations raise and the influences of curvature turn out to be progressively more important. The investigation established the significance of considering bending and membrane influences for studying the impact on curved composites and reported that these influences were more vital than inertia effects for the range of velocities and impact energies investigated. Saghafi et al. [250] studied the influence of preloading on the impact behavior of curved composite panels. The top and bottom sides of the specimens were put under tensile and compressive stress respectively, and the laminates curvature also increased. Their results depicted that preloading the plate had an extreme influence on the impact factors such as ultimate displacement and damage area. They reported that as the preload raises, the peak load and displacement raised and decreased, respectively. This was mainly owing to the rise in stiffness of the panel. Choi [251] numerically investigated the transient low-velocity impact behavior of composite plate and cylindrical shells subjected to low-velocity impact. They reported that plates/shells with higher curvatures constantly showed lower deflections and higher forces than the flat plate. Leylek et al. [252] performed a finite element analysis on the low-velocity impact of curved composite structures. It was depicted that as the radius of curvature of the structures rises, the peak contact force reduced. The mesh element ratio of striker and composite structure played a vital function and they demonstrated that the FE analyses might be employed effectively in the impact behavior of curved composite panels. Goo and Kim [253] proposed a 3D FE analyses to predict the low-velocity impact response of curved composite laminates. They mentioned drawbacks of the modified Hertz contact law such as its failure to include thickness and stacking sequence. They studied the impact force-time response of curved composite laminates with different curvatures and stacking sequences and explained the influences of curvature on the impact response of composite panels.

Shivakumar et al. [254] employed spring-mass and energy balance models to study the low-velocity impact response on curved composites laminates. In their formulation, a two-degree of freedom model is carried out comprising of four springs for bending, shear, membrane and contact deformation features. On the other hand, the impact force was measured devote of considering the failure effects of the plate. Investigations performed by Singh and Mahajan [255] showed that the force and deflection behavior of the composites is highly reliant on the extent of failure in composite laminates under low-velocity impact. Their model was capable to estimate the inter-laminar and intra-laminar failure influences on the stiffness of the curved composite panel. The failure induced a reduction of stiffness at the impact site and hence lower contact force. The 
FE simulations proved that failure alters the nature of the impact force time history. Interlaminar delamination and resin cracking induce considerable variation in the characteristics of the composite which are reliant on the extent of failure. Olsson [256-258] addressed these issues and he introduced an analytical model to study the small mass impact on composites with delamination growth and damage. Shahid et al. [259] reported the impact force behavior as a major factor characterizing impact resistance of curved composites under low-velocity impact. They introduced an analytical formulation to predict the impact resistance of curved composites beyond the initial failure state through altering the spring constant in Hertzian contact law which is a function of the failure extent in composites. Arachchige and Ghasemnejad [260] introduced a theoretical formulation to estimate the transverse impact of curved variable stiffness composite plates under low-velocity impact. They reported that varying the thickness of composites changes the impulse response of composite structures. The model was derived from the first order shear deformation theory and behavior of variable stiffness composites are estimated with a range of geometries and layups under low-velocity impact loads.

Over the past two decades, numerous researchers have studied the influence of curvature on the impact behavior of composites, with the attention, however, is largely kept on low-velocity impact tests. Composites laminates with higher curvatures constantly showed lower deflection and higher contact force than the flat plates. The majority of investigation on high-velocity impact has been performed on plane targets. Several researchers have employed various mathematical models to analyze the impact damage response of different curved composite materials and structures. From the knowledge of the authors, there is still a need to study the impact behavior of curved composite plates experimentally. Invoking such kind of experimental studies may reveal sufficient realistic and accurate information on complicated damage mechanism of curved composites.

\subsection{Impactor characteristics:}

The constituent and geometrical parameters are broadly investigated parameters in the study of impact mechanics of composites. Relatively little interest has been given in the literature to the impactor shape, size, velocity, mass, and angle.

\subsubsection{Impactor shape and size}

In past research, the most frequent impactor shape employed has been hemispherical, usually $12.7 \mathrm{~mm}$ ( $0.5 \mathrm{in}$.) diameter. On the other hand, a dropped tool on a composite structure during maintenance may not always impact the structure with a comparatively blunt shape such as a hemisphere [261]. Figures 15 and 16 depicts the photographic images of various shapes of impactor and perforation patterns in the target plate impacted by different nose projectiles, respectively. In Mitrevski et al. [262], the influence of impactor shape was studied employing hemispherical, conical and ogival impactors using a drop weight test set up on thin quasi-isotropic CFRP composite laminates. They reported that the laminates impacted by the conical impactor absorbed the most energy and generated the highest penetration depth. The blunter hemispherical 
impactor generated the highest peak contact force and shortest contact duration. The failure threshold limit was largest for the hemispherical impactor subsequently the ogival and conical impactors, respectively. Lee et al. [263] performed low-velocity impact tests on simply supported sheet molding compound laminates employing flat, conical, hemispherical, and semi-cylindrical impactors. They noticed that flat and hemispherical impactors generated identical damage mechanisms and energy dissipation levels. The semi-cylindrical impactor generated a vertically propagating crack. The local indentation generated by the flat and hemispherical impactors led to a rise in energy dissipation compared to the semi-cylindrical impactor. Local penetration was noticed from the conical impactor which led to the lowest dissipated impact energy. Zhou et al. [264] observed that altering the impactor shape changed the failure mechanism of composite laminates under low-velocity impact. Moreover, they reported that the type of damage mechanism generated by the impact influenced the energy dissipation capacity of the specimen. Mines et al. [265], under high-velocity impact, noticed that flat and hemispherical impactors generated higher delamination areas compared to a conical impactor in both z-stitched and woven composite laminates of varying thickness. Using finite element analysis, Kim and Goo [266] modeled the influence of changing the ratio among impactor nose lengths to impactor radius, where a ratio of one depicts a hemispherical impactor, on the low-velocity impact behavior of GFRP composites. The ratios tested were $0.1,1$ and 10 . It was noticed that as the ratio reduced, the peak force raised and the contact duration shortened. The post-impact residual compressive and tensile properties of composite structures are affected by the damage area and mechanisms produced by the impact [267-271]. Dhakal et al. [272] studied the effects of impact tup geometries on the damage resistance of non-woven hemp fiber reinforced unsaturated polyester composites under lowvelocity impact. They reported that there was a significant influence of impact tup geometry on the impact damage modes. Different impactor shapes will generate various failure mechanisms and damage areas in composite structures; thus the residual characteristics of the material will vary as per the impactor shape. It is thus vital to investigate the influence of various impactor shapes on the damage resistance and tolerance of composite structures.

Bulent Murat Icten et al. [273] studied the effect of impactor diameter on low-velocity impact response of woven GFRP composites. Laminas were impacted by applying an impactor of mass $5 \mathrm{~kg}$ at various energy levels ranging from $5 \mathrm{~J}$ to perforation thresholds of the material at ambient condition. They concluded that the impactor diameter considerably affects the impact and post impact compression response of composite laminates. For the same impact energies, the stiffness and peak contact force is higher for the larger diameter of the impactor. Furthermore, penetration and perforation thresholds increase with raising impactor diameter. At low impact energies (below penetration threshold), the absorbed energy decreases with raising impactor diameter. For all impactor diameters, residual compression strength after impact decreases with raising impact energy. At specific impact energy, residual strength increases with raising impactor diameter. Research which considered the influence of impactor shape and size has largely been in the high-velocity impact field where, for example, the impact resistance of armor has resulted in research into the ballistic limit of projectile shapes [274]. On the other hand, it is known that 
specimens respond in a different way to high-velocity impacts where there is a localized behavior compared to low-velocity impacts where a global response may dominate. Further investigation is necessary to study the influence of impactor size and shape on damage mechanisms and impact properties of composite materials under low-velocity impact loading conditions.

\subsubsection{Impactor mass and velocity:}

A few pieces of research have dealt with investigating the role of impactor mass and velocity on impact response of composite materials. Numerous previous investigations on this area are based on constant mass testing approaches devote of considering how this impact energy is obtained (velocity and mass combination). Various impact velocities result in various strain rates, and some researchers have reported that strain rate effects may play a role in the response of composites subjected to impact loads [275]. Woven and tape laminates have dissimilar strain rate sensitivity [276], and thus it is vital to differentiate them. Numerous researchers have studied the influence of impactor mass under the low-velocity impact of tape composite laminates, obtaining identical conclusions. Ambur et al. [277] performed impact test on 48 plies composite laminates at four different masses (ranging from 1.1 to $9 \mathrm{~kg}$ ); in the range investigated (from 10 to $33 \mathrm{~J}$ ) no obvious effect was noticed allied to the impactor mass. Feraboli et al. [278] investigated various factors in low-velocity impact comprising the impactor mass; one of the most important conclusions was that equi-energetic impacts doubling the impactor mass do not generate any influence on damage and stiffness. Bucinell et al. [279] increased the mass ratio among the heaviest and the lightest up to 5, and even with this large difference of impactor mass, the peak contact force was noticed to be only a function of the impact energy. With those results, it could be concluded that tape composite laminates do not depict impactor mass effect for the same impact energy. The strain rate influence was noticed to be not ignorable for woven composite laminates [280-281]. It is likely to find some investigations [281-284] in which the strain rate sensitivity has been investigated, achieving sensible changes in the strength properties. Concerning the response of this architecture under low-velocity impacts, various authors have arrived various conclusions regarding the effect of impactor mass. Robinson and Davies [285] investigated the effect of impactor mass in carbon/epoxy woven composite laminates; in this case three various masses $(1.15,1.59$ and $2.04 \mathrm{~kg})$ have been employed for the investigation, concluding that, in the range of energies investigated (up to $12 \mathrm{~J}$ ) impact failure was function of only on impact energy. In recent times, Zabala et al. [285], investigated the failure produced by equi-energetic impacts employing five various masses (from 2 to $9 \mathrm{~kg}$ ) in $2.3 \mathrm{~mm}$ thickness CFRP woven composite laminates. In this condition, they have concentrated in the energy range in which just interlaminar delamination is produced (from 1.5 to $9 \mathrm{~J}$ ) arguing that only resin dominant failures are rate sensitive. They have noticed that lighter impacts produce larger delaminated area, owing to the reduction of interlaminar fracture toughness as the impact velocity (and hence strain rate) raises. Afterward, the same authors

have noticed similar conclusions in the double cantilever beam test carried out at various rates [286]. It is likely to state that in the condition of woven composite laminates, there is no obvious consensus regarding the effect of the impactor mass. 


\subsubsection{Angle of obliquity}

The investigations on the impact that explains the influence of impact angles on composite structures are still in their infancy. Published literature on oblique impact behavior is very less [287]. Most of research and publications [288] concerning the analysis of impacts on composite materials deal with the normal impact. However, normal impacts not often take place in the practical case; composite structures are mostly impacted at some oblique angle. Also, depending on the impact angle with respect to the target, rebounding or ricocheting can take place. Figures 17 and 18 shows an aerofoil section subjected to impact under normal and oblique angle conditions, and variation of the energy transfer and ballistic limit with the impact angle, respectively. The influence of obliquity on energy dissipation and the damage have not been broadly investigated, mainly lacking researches concerning the discussion of different kinds of failure modes. Therefore it is vital to investigate the influence of oblique impacts on composite structures to enhance their impact performance.

One of the initial efforts to investigate oblique ballistic impact was performed by Zener and Peterson [289]. They reported that compared to normal impact, the oblique impact had larger ballistic limit velocity mainly owing to the rise in distance traveled by the impactor. Kumar and Bhat [290] investigated the influence of impact angle on the energy dissipation and the damage area of GFRP composites under high-velocity impact. They made a correlation between the energy dissipation and the damage area. Interestingly, they also noticed that the energy dissipated by the target reduced and then rose with the angle of impact. In 2006 Yang, I. Y et al. [291] studied the influence of oblique impact on the penetration characteristics of composite laminates, reporting that the penetration energy raised as the angle of slope on the target increased. W. Xie et al. [292] studied the ballistic impact response of CFRP composites at impact angles of $0^{\circ}, 30^{\circ}$ and $45^{\circ}$ with the velocity ranging from 70 to $280 \mathrm{~m} / \mathrm{s}$. They concluded that, for a particular impact velocity, the energy absorption increases with an increase in impact angle. Figure 19 shows the $\mathrm{C}$-scan images for different oblique angles and impact energies. The failure profile on the front side was different among normal and oblique impact [296]. Under normal impact, fiber failure induced by shearing was noticed on the front side. Under oblique impact, a visible crater associated with fiber failure and numerous splits at both crater ends were produced owing to a higher contact area. Chu C. K. et al. [293] performed oblique ballistic impact test with basket fabric AFRP composites, they depicted that the degree of ricochet of AFRP laminates is higher than conventional metal. In recent times, Pernas-Sanchez, J. et al. [294] have investigated the influence of high-velocity impacts on CFRP tape quasi-isotropic laminates. They depicted that the damage generated by the oblique impact is lower than the normal impact at velocities below the ballistic limit. The response is the contrary at velocities higher than the ballistic limit.

Zhou et al. [295] investigated the influence of the angle of obliquity on the penetration resistance of three various sandwich composites derived from two cross-linked PVC (Polyvinyl chloride) cores and PET (polyethylene terephthalate) foam under low-velocity impact. Similar values of peak force were noticed for the three angles investigated when the impact energy was 
raised. The damaged area was identical for low-impact energies (up to $10 \mathrm{~J}$ ); on the other hand from $10 \mathrm{~J}$, the damaged area was higher at lower impact angles. In addition, they employed an analytical model to predict the peak contact force at differing angles. For an impact angle of $0^{\circ}$, the model depicted better correlation among predicted and experimental peak contact force up to $10 \mathrm{~J}$, while higher than this energy, the model over-predicted the peak contact force. Moreover, the model over-predicted the peak contact force for an angle of $20^{\circ}$ and under-predicted the result for an angle of $10^{\circ}$. Experimental data on oblique impact response of composite structures are limited [297]. Goldsmith [297] gave a complete review of the non-ideal projectile impact (ballistic) on composites, considering the oblique impact in particular.

\subsection{Environmental service conditions}

The effect of environmental service conditions on impact was investigated by many researchers because the real impact may strike a composite structure exposed to various environments [298-321]. As most composites are employed out-of-doors, it is expected that the composites are subjected to critical environmental conditions. Exposure to different environmental conditions can result in both irreversible or permanent and reversible damages (e.g. softening of the matrix, degradation) [298]. It is well-known fact that the strain to ultimate failure, the fracture toughness of adhesives, and resistance to plastic deformation are mechanical properties strongly reliant on exposure condition.

\subsubsection{Moisture and hygro-thermal aging}

The necessity for the application of composites in a marine environment is rising significantly. Composites boats are about 35\% and 10\% lighter than steel and aluminum boats, respectively [299]. It is vital for the investigators to establish a relationship among various conditions and their influences on the composites, mainly dynamic loading conditions like impact loads. Imielin'ska and Guillaumat [300] investigated the influence of water immersion aging on low-velocity impact response of woven aramid-glass/epoxy laminates. They concluded that water immersion aging influenced micro-structural integrity inducing internal flaws and the impact failure area was moderately less extensive in wet specimens, which is suggested to be the result of the development of interfacial failure present in the wet specimens before impact, which absorbed impact energy and inhibited delamination generation. Pang et al. [301], under low-velocity impact, reported that the presence of moisture increased the failure effect of UV (ultraviolet) radiation. Alkaline environment degrades glass reinforcements, mainly owing to the existence of silica in the reinforcements. Glass reinforcements are also vulnerable to chemical corrosion when subjected to acidic environments $(\mathrm{pH}<7)$. Consequently, glass fiber reinforced composites have a larger possibility to debond at the fiber/matrix interface area. Carbon reinforcements do not absorb liquids and are thus resistant to all types of solvent or alkali ingress. Therefore, the carbon fiber reinforced composites is a possible candidate for application in marine composites owing to its superior moist-environment-resistance and high impact properties. 
Alkaline moisture of seawater could be absorbed by the epoxy resin and/or diffused along the fiber/matrix interface into the composite by immediate surface absorption followed by diffusion along the resin in a humid environment during service life [302]. The quantity of moisture absorbed by the epoxy matrix is significantly larger than fiber reinforcements owing to larger moisture diffusivity of epoxy compared to that of the fiber. This variation in the absorption by both the resin and reinforcements leads to a considerable mismatch in the volumetric expansion that can induce a localized stress and strain field in the material. These events result in premature damage of the composites during impact loading. Therefore, the moisture barrier characteristics of this resin should be enhanced for it to be employed successfully in marine components. Under this rationale, nano-particle filled composite materials are attractive as, at lower volume fractions, they may improve moisture resistance over conventional composites. For instance, nano-clay has outstanding barrier characteristics that may be employed to decrease the permeability of moisture. The intercalated and/or exfoliated surface of the silicate layer and anisotropic shape of nano-clay function as barriers to moving moisture in composites. A rise in the path length of the moisture by infusion of silicate layer along the composites leads to the decrement of moisture absorption. Silicate layers of montmorillonite have established decreased moisture ingress, higher resistance to solvent and superior impact properties. Ray [303] reported that the moisture absorption rate and degree of degradation enhanced at a larger conditioning temperature. He depicted that degradation takes place owing to the thermal stress at an elevated temperature, which can enhance crack initiation and growth through a high cross-linked fiber/matrix interface. K. Berketis et al [304] studied the low-velocity impact response of glass/isophthalic polyester composites subjected to a hydrothermal environment $\left(65^{\circ} \mathrm{C}\right)$ for very long duration (30 months). Figures 20 and 21 shows the close up photos of $5 \mathrm{~J}$ impact damage and absorbed energy for various immersion time intervals, respectively. Impacting subsequent to aging for different time durations did not increase significantly the damage area but generated a higher amount of through-thickness damage, which led to lower post impact strength [305].

\subsubsection{Temperature}

The impact response of fiber reinforced polymer matrix composites exposed to various elevated temperatures has been investigated and reported in many pieces of literature. Composite materials may be employed in aircraft or space structures, where they are exposed to temperatures in the range 73 to $80^{\circ} \mathrm{C}$ or 140 to $120^{\circ} \mathrm{C}$, respectively [306]. Akay et al. [307], under low-velocity impact, reported that the damage modes altered with exposure duration from a brittle transverse tensile damage to damage where the reinforcements fracture by buckling, subsequent to delamination and extreme deflection. Most of the investigations available in the published literature are allied with glass fibers [308] or carbon fibers [309], and more recently the influence of reinforcement hybridization on the impact behavior has been studied in hemp-basalt [310] or aramid/glass composite materials [311]. In terms of low temperatures, the low-velocity impact results acquired by Río et al. [312] depict that a reduction of the temperature has an influence on failure similar to that noticed with the raising of impact energy: higher resin cracking and 
interlaminar delamination growth, higher penetration on the impacted side, and more critical debonding and fiber failure on the rear side. The embrittlement of the resin system, along with the interlaminar thermal stresses produced in the composite at low temperature, enables to allow the onset and growth of failure when subject to impact loads. Actually, low temperatures generate interlaminar residual thermal stresses, high sufficient to induce resin cracking on low-velocity impact, with resulting delamination of the composites. Icten et al. [313] investigated the lowvelocity impact response of GFRP composites, with a stacking sequence of [0/90/45/-45]s, at low temperatures. This investigation was carried out for temperatures of $-20,20$ and $60^{\circ} \mathrm{C}$, and impact energies that ranged from 5 to $70 \mathrm{~J}$. The impact behavior and the damage tolerance of the material was noticed to be almost the same for all temperatures up to the $E_{i}=20 \mathrm{~J}$. The main failure mechanism up to this energy was resin cracking, interlaminar delaminations, and rear side delaminations. Beyond that impact energy level, temperature influences considerably the impact response, where the fiber breakages and back surface delaminations turn out to be dominant failure modes. Lastly, they noticed that the perforation threshold rises with reduction of test temperature [313]. Ibekwe et al. [314] studied unidirectional and cross-ply GFRP composites under lowvelocity impact load, where the temperatures ranged from -20 to $20^{\circ} \mathrm{C}$, and they reported that higher damages were produced with reducing the temperature. However, as a result of the viscoelastic nature, the resistance to plastic deformation, strain to failure and fracture toughness of the resin system is highly influenced by elevated temperatures [315]. Hence, the damage tolerance of composites can be compared with ductility and fracture toughness of the resin system. For instance, mode I interlaminar fracture toughness raises with the rising temperature over broad temperature ranges from $60^{\circ} \mathrm{C}$ to $120^{\circ} \mathrm{C}$ [315]. Mode II interlaminar fracture toughness raises with temperature mainly marked near the glass-transition temperature of the resin system [315]. Hence, a reduction in interlaminar delamination area happens with the raising in temperature for composites under impact loads.

Numerous references deal with epoxy-based composite materials [316], but very few with thermoplastic-based composites [317]. Karaseket al. [318] carried out low-velocity impact tests on CFRP composites comprising unmodified and rubber-modified epoxies at various temperatures. The energy necessary for failure onset was observed to reduce with temperature for all types of resin investigated, and this is reliable with a decrement in matrix properties at higher temperatures [318]. Identical investigations carried out by Hiraiet al. [315], to study the influence of temperature on the low-velocity impact behavior of glass/vinyl ester-matrix composites, depicted that, at higher temperatures, the overall impact behavior is dominated by the decreased matrix stiffness and strength. The poor mechanical characteristics decrease the impact-damage resistance and damage tolerance of the composite. Through the comparison of carbon/epoxy and carbon/PEEK composites, Im et al. [317] have investigated the influence of temperature variations on ballistic impact damage of orthotropic composites. They reported that the delamination areas reduce as the temperature rises. In PEEK-based composites, the frequency of transverse cracks is decreased. Moreover, Bibo et al. [319] have studied the effect of matrix type and morphology on the capability of the composite material to endure penetration, absorb energy and uphold damage 
at various temperature levels $\left(\mathrm{RT}, 80^{\circ} \mathrm{C}\right.$ and $150^{\circ} \mathrm{C}$ ). At high impact energy, complete penetration of the composite occurs by the striker. At low impact energy, impact damage is produced but the plate is not fractured. They reported that test temperature has a moderate effect on throughpenetration impact results, although high-temperature testing does raise the delamination in epoxybased composites under low-energy impacts [315]. Moreover, the influence of impact-induced damage on high-temperature post impact compressive properties has been studied. A rise in the testing temperature has a considerable influence on the residual strength, while the impact temperature has a minor effect. There is proof that the development of impact generated delamination is constrained at the high temperatures during compression compared to propagation at ambient temperature in the condition of the thermosetting toughened epoxy, but this is not the condition for the PolyAryl Sulfone thermoplastic. In contrast, at low temperatures (e.g. $25^{\circ} \mathrm{C}$ and $50^{\circ} \mathrm{C}$ ), Russo et al. [320] have investigated the low-velocity impact response of thermoplastic composite laminates derived from thermoplastic polyurethane reinforced with woven glass fibers. To confirm the possible applications of these materials, they reported that low-temperature impacts led to a raised stiffness of tested composites and a higher propensity to fail. Moreover, they noticed no impact-induced delamination at low temperatures.

The decrease in temperature and increase of composite thickness resulted in improved friction event at the material-dart contact. Finally, thermoplastic can be considered to reinstate conventional brittle thermosetting matrix system for applications under severe environmental conditions. In recent times, Sorrentino et al. [321] have investigated the influence of temperature on low-velocity impact properties of polyethylene-naphthalate thermoplastic composite materials. Through low-velocity impact tests, they investigated the structural behavior of carbon fibers plain weave fabrics reinforced polyethylene-naphthalate composites at various temperatures $\left(20^{\circ}, 60^{\circ}\right.$ and $100^{\circ} \mathrm{C}$ ). Considering that the glass transition temperature of the composite is around $120^{\circ} \mathrm{C}$, they noticed a decreased effect of temperature (even at $100^{\circ} \mathrm{C}$ ) on the flexural stiffness, but a low impact resistance. On the other hand, it appears that carbon/ polyethylene-naphthalate composites are characterized by a rise in their impact performance as temperature rises. They considered that temperature contributes to the improvement of the thermoplastic matrix toughness and a larger strength of the fiber/matrix interface, finally explaining this phenomenon [321].

When exposed to an elevated temperature; composite materials encounter a residual stress system over the through-thickness owing to unequal thermal contraction. Carrying residual stresses results in low energy absorption and decrement of the first failure energy (perforation). As matrix toughness and ductility are increased at elevated temperature, several researchers have studied the effect of temperature on the impact response and damage tolerance of fiber-fiber reinforced PMCs.

\section{Conclusions:}

This paper has attempted a comprehensive review of four key groups of parameters, specifically, material, geometry, event and environmental-related aspects that affect the structural 
behavior of polymer matrix composites under impact loading. The critical review performed has identified, discussed and presented an in-depth understanding of the factors that influence the onset and propagation of impact damage on composite materials. The mechanical and chemical characteristics of the material system influence the way in which the composite deforms and fractures. By cautiously choosing the fiber orientation or fiber architecture and material behavior of each layer, a designer can configure a composite that may proficiently uphold all load necessities while reducing the number of layers. The matrix system in a composite material assists to defend, align and stabilize the reinforcements as well as assure stress transfer from one fiber to another. The mechanical performance of fiber reinforced polymer matrix composites relies on the bond strength between the matrix and fiber. The bond strength may be manipulated to enhance the toughness by absorbing energy in interface debonding. Only a few investigations into the simulation of the influence of material parameters on the impact resistance of composite structures are available; there is thus, a strong case for the development and confirmation of modeling tools capable of giving correct and consistent predictions of the damage generated by impact on composites.

Geometrical parameters such as thickness and curvature are vital aspects that affect the impact behavior of a composite structure as it alters energy absorption mode and damage area of the composites. The composite toughness is considerably influenced by thickness as the damage threshold and restriction of damage area rises with an increase in thickness. Over the past two decades, a majority of investigation on high-velocity impact has been performed on plane targets. On the other hand, a direct investigation comparing the high-velocity impact response of a curved composite structure altering with its radii of curvature has not yet been carried out. The influence of the impactor shape, mass, angle, and size on impact resistance or energy absorption has been studied by numerous researchers but this effect is still not entirely formulated. In specific, the combined effects of impactor nose shape, the angle of obliquity, mass, size and boundary condition on the impact resistance of composite materials are not clearly addressed. There is a lack of investigation on the oblique impact response of composites.

Exposure to different environmental conditions can result in both irreversible (permanent) and reversible damages in composites. Variation in the moisture diffusivity of different constituents leads to a considerable mismatch in the volumetric expansion that can induce a localized stress and strain field in these materials. These events result in premature damage of the composites during impact loading. Moreover, the moisture absorption rate and degree of degradation enhance at a larger conditioning temperature. Owing to the viscoelastic behavior of polymer matrix in composites, the failure strain, resistance to plastic deformation and fracture toughness of matrices is highly influenced by elevated temperatures. There are numerous literature available that deals with impact response of composites; yet, very few have reported their behavior to impact loading when they are subjected to different temperature and/or humid conditions over an extended period of time. 


\section{References}

1. Andrew, J. Jefferson, Sivakumar M. Srinivasan, and A. Arockiarajan. "The role of adhesively bonded super hybrid external patches on the impact and post-impact response of repaired glass/epoxy composite laminates." Composite Structures 184 (2018): 848-859.

2. K.B. Katnam, L.F.M. Da Silva, T.M. Young, Bonded repair of composite aircraft structures: A review of scientific challenges and opportunities, Progress in Aerospace Sciences, Volume 61, 2013, Pages 26-42, ISSN 0376-0421, http://dx.doi.org/10.1016/j.paerosci.2013.03.003.

3. J. Jefferson Andrew, V. Arumugam, K. Saravanakumar, H.N. Dhakal, C. Santulli, Compression after impact strength of repaired GFRP composite laminates under repeated impact loading, Composite Structures, Volume 133, 1 December 2015, Pages 911-920, ISSN 0263-8223, https://doi.org/10.1016/j.compstruct.2015.08.022.

4. Vogelesang LB, Vlot A. Development of fiber metal laminates for advanced aerospace structures. J Mater Process Technol 2000; 103: 1-5.

5. Agrawal, Sandeep, Kalyan Kumar Singh, and P. K. Sarkar. "Impact damage on fibrereinforced polymer matrix composite-a review." Journal of Composite Materials 48, no. 3 (2014): 317-332.

6. Airoldi A, Cacchione B. Modelling of impact forces and pressures in Lagrangian bird strike analyses. Int J Impact Eng 2006; 32: 1651-77.

7. Anghileri M, Castelleti LML, Invernizzi F, Mascheroni M. A survey of numerical models for hail impact analysis using explicit finite element codes. Int J Impact Eng 2005; 31: 929_ 44.

8. Mines RAW, McKown S, Birch RS. Impact of aircraft rubber tyre fragments on aluminium alloy plates: I-experimental. Int J Impact Eng 2007;34:627-46

9. Varas D, López-Puente J, Zaera R. Experimental analysis of fluid-filled aluminium tubes subjected to high-velocity impact. Int J Impact Eng 2009; 36: 81-91.

10. Farenthold EP, Hernandez RJ. Simulation of orbital debris impact on the space shuttle wing leading edge. Int J Impact Eng 2006; 33: 231-43.

11. Schonberg WP. Hole size and crack length models for spacecrafts walls under oblique hypervelocity projectile impact. Aerospace Sci Technol 1999; 3: 461-71.

12. J. López-Puente, D. Varas, J.A. Loya, R. Zaera, Analytical modeling of high velocity impacts of cylindrical projectiles on carbon/epoxy laminates, Composites Part A: Applied Science and Manufacturing, Volume 40, Issue 8, August 2009, Pages 1223-1230, ISSN 1359-835X, https://doi.org/10.1016/j.compositesa.2009.05.008.

13. Jefferson, Andrew J., Vellayaraj Arumugam, and Hom Dhakal. Repair of Polymer Composites: Methodology, Techniques, and Challenges. Woodhead Publishing, 2018.

14. J. Jefferson Andrew, Srinivasan, S. M. and Arockiarajan, A. (2018), Effect of multiphase fiber system and stacking sequence on low-velocity impact and residual tensile behavior of glass/epoxy composite laminates. Polym. Compos.. . doi:10.1002/pc.24884. 
15. Greenhalgh E, Hiley M. The assessment of novel materials and processes for the impact tolerant design of stiffened composite aerospace structures. Compos Part A - Appl S. 2003; 34(2):151-61.

16. Andrew, J. Jefferson, Sivakumar M. Srinivasan, and A. Arockiarajan. "Influence of patch lay-up configuration and hybridization on low velocity impact and post-impact tensile response of repaired glass fiber reinforced plastic composites." Journal of Composite Materials (2018): 0021998318779430.

17. Jefferson, A. J., V. Arumugam, C. Santulli, A. Jennifers, and M. Poorani. "Failure modes of GFRP after multiple impacts determined by acoustic emission and digital image correlation." Journal of Engineering and Technology (JET) 6, no. 2 (2015): 29-51.

18. Tiberkak R, Bachene M, Rechak S, Necib B. Damage prediction in composite plates subjected to low velocity impact. Compos Struct. 2008; 83(1):73-82.

19. Bull DJ, Scott AE, Spearing SM, Sinclair I. The influence of toughening-particles in CFRPs on low velocity impact damage resistance performance. Compos Part A - Appl S. 2014; 58(0):47-55.

20. Hongkarnjanakul N, Rivallant S, Bouvet C, Miranda A. Permanent indentation characterization for low-velocity impact modeling using three-point bend test. Journal of Composite Materials. 2013; 0(0):1-14.

21. Tita V, de Carvalho J, Vandepitte D. Failure analysis of low velocity impact on thin composite laminates: Experimental and numerical approaches. Compos Struct. 2008; 83(4):413-28.

22. Vieille B, Casado VM, Bouvet C. Influence of matrix toughness and ductility on the compression-after-impact behavior of woven-ply thermoplastic- and thermosettingcomposites: A comparative study. Compos Struct. 2014; 110 (0): 207-18.

23. Davies GAO, Zhang $X$. Impact damage prediction in carbon composite structures. Int $J$ Impact Eng. 1995; 16(1):149-70.

24. Alcock B, Cabrera NO, Barkoula NM, Wang Z, Peijs T. The effect of temperature and strain rate on the impact performance of recyclable all-polypropylene composites. Composites 2008; 39: 537-47.

25. N.K. Naik, P. Shrirao, and B.C.K. Reddy. "Ballistic impact behavior of woven fabric composites: formulation". Int J Impact Eng 2006, Vol. 32, Issue 9, Pages 1521-1552.

26. J. Jefferson Andrew, V. Arumugam, C. Santulli, Effect of post-cure temperature and different reinforcements in adhesive bonded repair for damaged glass/ epoxy composites under multiple quasi-static indentation loading, Compos.Struct. 143 (20) (May 2016) 63e74. ISSN 0263e8223, http://doi.org/10.1016/j. compstruct.2015.10.037.

27. T. Børvik, "An introduction to impact and penetration dynamics", Department of Structural Engineering, Norwegian University of Science and Technology (2003).

28. Daihua Zheng." Low Velocity Impact Analysis of Composite Laminated Plates". Ph.D. Thesis. The Graduate Faculty of the University of Akron, (2007). 
29. W. J. Cantwell and J. Morton. "Impact Perforation of Carbon Fibre Reinforced Plastic." Department of Aeronautics, Imperial College, Exhibition Road, London SW7, UK, (1990) Vol. 38, Issue 2, Pages 119-141.

30. F. Grytten, "Low-Velocity Penetration of Aluminium Plates" Norwegian University of Science and Technology (2008) NTNU, ISSN 1503-8181; 2008:46.

31. JA. Zukas, et al. "Impact dynamics" John Wiley \& Sons, New York; (1990).

32. Yang FJ and Cantwell WJ. Impact damage initiation in composite materials. Compos Sci Technol 2010; 70: 336-342.

33. J.G. Avery, "Design Manual for Impact Damage Tolerant Aircraft Structures", AGARDograph No 238 NATO, (1981), ISBN92-835-1403-3.

34. M.T.H. Sultan, S. Basri, A.S.M. Rafie, F. Mustapha, D.L. Majid, and M.R. Ajir, "High Velocity Impact Damage Analysis for Glass Epoxy - Laminated Plates", Advanced Materials Research (2012) Vols. 399-401 pp 2318-2328.

35. E.M. Soliman, M.P. Sheyka, M.R. Taha, Low-velocity impact of thin woven carbon fabric composites incorporating multi-walled carbon nanotubes, Int. J. Impact Eng. 47 (2012) 3947.

36. NassierA. Nassir, Z.W. Guan, R.S. Birch, W.J. Cantwell. Damage initiation in composite materials under off-centre impact loading. Polymer Testing, Volume 69, 2018, Pages 456461.

37. Özen, M. Influence of Stacking Sequence on the Impact and Postimpact Bending Behavior of Hybrid Sandwich Composites. Mechanics of Composite Materials. January 2017, Volume 52, Issue 6, pp 759-766

38. C. Atas, O. Sayman, An overall view on impact response of woven fabric composite plates, Compos. Struct. 82 (3) (2008) 336-345.

39. Shivdayal Patel, C. Guedes Soares. Reliability assessment of glass epoxy composite plates due to low velocity impact. Composite Structures, Volume 200, 2018,Pages 659-668.

40. L.S. Sutherland. A review of impact testing on marine composite materials: Part III Damage tolerance and durability. Composite Structures, Volume 188, 2018, Pages 512518.

41. Gin Boay Chai, Periyasamy Manikandan, Low velocity impact response of fibre-metal laminates - A review, Composite Structures, Volume 107, January 2014, Pages 363-381, ISSN 0263-8223, https://doi.org/10.1016/j.compstruct.2013.08.003.

42. M.O.W. Richardson, M.J. Wisheart, Review of low-velocity impact properties of composite materials, Composites Part A: Applied Science and Manufacturing, Volume 27, Issue 12, 1996, Pages 1123-1131, ISSN 1359-835X, http://dx.doi.org/10.1016/1359835X(96)00074-7.

43. Custódio, J., and S. Cabral-Fonseca. Advanced fibre-reinforced polymer (FRP) composites for structural applications: 22. Advanced fibre-reinforced polymer (FRP) composites for the rehabilitation of timber and concrete structures: assessing strength and durability. Elsevier Inc. Chapters, 2013. 
44. Soutis C. Carbon fibre reinforced plastic in aircraft construction. Mater Sci Eng A 2005; 412(1-2): 171-176.

45. Adams, D.F. and Miller, A.K. 'An analysis of the impact behavior of hybrid composite materials' Mater Sci and Engng 19 (1975) pp 245-260

46. Beaumont, P.W.R., Riewald, P.G. and Zweben, C. 'Methods for improving the impact resistance of composite materials' ibid. pp 134-158

47. Moon, F.C. Wave propagation and impact in composite materials. In 'Composite Materials Vol. 7: Structural Design and Analysis-Part 1' (Eds L.J. Broutman and R.J. Krock), Academic Press, London, 1975, pp. 259-332.

48. Smith JC, McCrackin FL, Scniefer HF. Stress-strain relationships in yarns subjected to rapid impact loading. part $\mathrm{V}$. wave propagation in long textile yarns impacted transversely. Text Res J 1958; 28(4):288-302.

49. L. Ye, Y.-W. Mai, Z. Su, Composite Technologies for 2020,Woodhead Publishing,2004, Page iii,ISBN 9781855738317,https://doi.org/10.1533/9781845690625.

50. Smith JC, McCrackin FL, Schiefer HF, Stone WK, Towne KM. Stress-strain relationships in yarns subjected to rapid impact loading: 4 transverse impact tests. J Res Natl Bur Stand 1956; 57(2):83-9.

51. Carr DJ. Failure mechanisms of yarns subjected to ballistic impact. J Mater Sci Lett 1999;18:585-8.

52. Billon HH, Robinson DJ. Models for the ballistic impact of fabric armour. Int J Impact Eng 2001;25:411-22.

53. Chocron S, Figueroa E, King N, Kirchdoerfer T, Nicholls AE, Sagebiel E, et al. Modeling and validation of full fabric targets under ballistic impact. Compos Sci Technol 2010;70:2012-22.

54. Sanhita Das, S. Jagan, Amit Shaw, Anjali Pal. Determination of inter-yarn friction and its effect on ballistic response of para-aramid woven fabric under low velocity impact, Composite Structures, Volume 120, 2015, Pages 129-140, ISSN 0263-8223, https://doi.org/10.1016/j.compstruct.2014.09.063.

55. Naik NK, Shrirao P. Composite structures under ballistic impact. Compos Struct 2004;66:579-90.

56. Mamivand M, Liaghat GH. A model for ballistic impact on multi-layer fabric targets. Int J Impact Eng 2010;37(7):806-12.

57. Roylance DK, Wilde AF, Tocci GC. Ballistic impact of textile structures. Textile Res J 1973;43:34-41.

58. Joo K, Kang TJ. Numerical analysis of multi-ply fabric impacts. Textile Res J 2007;77:359-68.

59. Joo K, Kang TJ. Numerical analysis of energy absorption mechanism in multi-ply fabric impacts. Text Res J 2008;78:561-76.

60. Shim VPW, Tan VBC, Tay TE. Modelling deformation and damage characteristics of woven fabric under small projectile impact. Int J Impact Engng 1995;16(4):585-605. 
61. King M, Jearanaisilawong P, Socrate S. A continuum constitutive model for the mechanical behavior of woven fabrics. Int J Solids Struct 2005; 42(13): 3867-96.

62. Shahkarami A, Vaziri R. A continuum shell finite element model for impact simulation of woven fabrics. Int J Impact Eng 2007; 34(1):104-19.

63. Ivanov I, Tabiei A. Loosely woven fabric model with viscoelastic crimped fibres for ballistic impact simulations. Int J Numer Methods Eng 2004;61: 1565-83.

64. Vinson JR, Zukas JA. On the ballistic impact of textile armor. J Appl Mech 1975;6:2638.

65. Taylor WJ Jr, Vinson JR. Modeling ballistic impact into flexible materials. AIAA Journal 1990;28:2098-103.

66. Lim CT, Shim VPW, Ng YH. Finite-element modeling of the ballistic impact of fabric armor. Int J Impact Eng 2003;28:13U31.

67. Zhu D, Mobasher B, Vaidya A, Rajan SD. Mechanical behaviors of Kevlar 49 fabric subjected to uniaxial, biaxial tension and in-plane large shear deformation. Compos Sci Technol 2013;74(1):121-30.

68. Gu B. Ballistic penetration of conically cylindrical steel projectile into plainwoven fabric target - a finite element simulation. J Compos Mater 2004;38:2049-74.

69. Duan Y, Keefe M, Wetzel ED, Bogetti TA, Powers B, Kirkwood JE, et al. Effects of friction on the ballistic performance of a high-strength fabric structure. In International Conference on Impact Loading of Lightweight Structure 2005, May 8U12, Forianopolis, Brazil; 2005.

70. Rao MP, Nilakantan G, Keefe M, Powers BM, Bogetti TA. Global/local modeling of ballistic impact onto woven fabrics. Comp Mater 2009;43:445-67.

71. Barauskas R, Abraitiene A. Computational analysis of impact of a bullet against the multilayer fabrics in ls-dyna. Int J Impact Eng 2007;34:1286-305.

72. Zhou Y, Chen X,Wells G. Influence of yarn gripping on the ballistic performance of woven fabrics from ultra-high molecular weight polyethylene fibre. Com B 2014;62:198-204.

73. Chocron S, Anderson CE Jr, Ranjan Samant K, Figueroa E, Nicholls AE, Walker JD. Measurement of strain in fabrics under ballistic impact using embedded nichrome wires, part II: results and analysis. Int J Impact Eng 2010;37:69-81.

74. R. Seltzer, C. González, R. Muñoz, J. LLorca, T. Blanco-Varela, X-ray microtomography analysis of the damage micromechanisms in 3D woven composites under low-velocity impact, Composites Part A: Applied Science and Manufacturing, Volume 45, 2013, Pages 49-60, ISSN 1359-835X, http://dx.doi.org/10.1016/j.compositesa.2012.09.017.

75. Tong L, Mouritz AP, Bannister M. 3D fibre reinforced polymer composites. Oxford: Elsevier; 2002.

76. Kim JK, Mai YW. Engineered interfaces in fibre-reinforced composites. Oxford: Elsevier; 1998.

77. Liu D. Delamination resistance in stitched and unstitched composite plates subjected to impact loading. J Reinf Plast Compos 1990;9(1):59-69. 
78. Cheng XQ, Al-Mansour A, Li Z. Residual strength of stitched laminates after low velocity impact. J Reinf Plast Compos 2009;28(14):1679-88.

79. Wu E, Wang J. Behavior of stitched laminates under in-plane tensile and transverse impact loading. J Compos Mater 1995;29(17):2254-89.

80. Yoshimura A, Nakao T, Yashiro S, Takeda N. Improvement on out-of-plane impact resistance of CFRP laminates due to through-the-thickness stitching. Compos A Appl Sci Manuf 2008;39(9):1370-9.

81. Hosur MV, Adya M, Alexander J, Jeelani S, Vaidya U, Mayer A. Studies on impact damage resistance of affordable stitched woven/epoxy composite laminates. J Reinf Plast Compos 2003;22(10):927-52.

82. Tan KT, Watanabe N, Iwahori Y, Hoshi H, Sano M. Interlaminar fracture toughness of Vectran-stitched composites - experimental and computational analysis. J Compos Mater 2010;44(26):3203-29.

83. Tan KT, Watanabe N, Iwahori Y. X-ray radiography and micro-computed tomography examination of damage characteristics in stitched composites subjected to impact loading. Compos B Eng 2011;42(4):874-84.

84. Tan KT, Watanabe N, Iwahori Y. Impact damage resistance, response, and mechanisms of laminated composites reinforced by through-thickness stitching. Int J Damage Mech 2012;21:51-80.

85. Tan, N. Watanabe, Y. Iwahori. Effect of stitch density and stitch thread thickness on lowvelocity impact damage of stitched composites. Composites Part A: Applied Science and Manufacturing, Volume 41, Issue 12, 2010, Pages 1857-1868.

86. Aymerich F, Pani C, Priolo P. Damage response of stitched cross-ply laminates under impact loadings. Eng Fract Mech 2007;74(4):500-14.

87. Francesconi L, Aymerich F. Impact damage resistance of thin stitched carbon/epoxy laminates. J Phys: Conf Ser 2015;628(1):012099.

88. Shu D, Mai YW. Delamination buckling with bridging. Compos Sci Technol 1993;47(1):25-33.

89. Jain LK, Mai YW. On the effect of stitching on mode I delamination toughness of laminated composites. Compos Sci Technol 1994;51(3):331-45.

90. Jain LK, Mai YW. Analysis of stitched laminated ENF specimens for interlaminar mode II fracture toughness. Int J Fract 1994;68(3):219-44.

91. Sankar BV, Zhu H. The effect of stitching on the low-velocity impact response of delaminated composite beams. Compos Sci Technol 2000;60(14):2681-91.

92. Guo Z, Han X, Zhu X. Finite element analysis of interlaminar stresses for composite aminates stitched around a circular hole. Appl Compos Mater 2012;19(3):561-71.

93. Stickler PB, Ramulu M. Parametric analyses of stitched composite T-joints by the finite element method. Mater Des 2002;23(8):751-8.

94. Sun X, Wood MD, Tong L. A parametric study on the design of stitched laminated DCB specimens. Compos Struct 2006;75(1):72-8. 
95. Aymerich F, Onnis R, Priolo P. Analysis of the fracture behaviour of a stitched single-lap joint. Compos A Appl Sci Manuf 2005;36(5):603-14.

96. Tan KT, Watanabe N, Iwahori Y. Finite element model for compression after impact behaviour of stitched composites. Compos B Eng 2015;79:53-60.

97. Guan ZW, Aktas A, Potluri P, Cantwell WJ, Langdon G, Nurick GN. The blas resistance of stitched sandwich panels. Int J Impact Eng 2014;65:137-45.

98. Vachon PL, Brailovski V, Terriault P. Impact-induced damage and damage propagation under flexural load in TiNi and Kevlar-stitched carbon/epoxy laminates. Compos Struct 2013;100:424-35.

99. J. Jefferson Andrew, V. Arumugam, C. Ramesh, S. Poorani, C. Santulli, Quasi- static indentation properties of damaged glass/epoxy composite laminates repaired by the application of intra-ply hybrid patches, Polymer Testing, Volume 61, 2017, Pages 132145, ISSN 0142-9418, http://dx.doi.org/10.1016/j.polymertesting.2017.05.014.

100. J. Jefferson Andrew, V Arumugam, and C Ramesh. Acoustic emission characterization of local bending behavior for adhesively bonded hybrid external patch repaired glass/epoxy composite laminates. Structural Health Monitoring. https://doi.org/10.1177/1475921718770596.

101. J. Jefferson Andrew, V. Arumugam. Effect of patch hybridization on the tensile behavior of patch repaired glass/epoxy composite laminates using acoustic emission monitoring. International Journal of Adhesion \& Adhesives 74 (2017) 155-166.

102. Chamis CC, Lark RF, Sinclair JH. Mechanical property characterization of intraply hybrid composites. Pentagon reports; 2003 (report number A665103).

103. Pegoretti A, Fabbri E, Migliaresi C, Pilati F. Intraply and interply hybrid composites based on E-glass and poly (vinyl alcohol) woven fabrics: tensile and impact properties. Polym Int 2004;53:1290-7.

104. Wang X. Low velocity impact properties of 3D woven basalt/aramid hybrid composites. Compos Sci Technol 2008;68:444-50.

105. Sarasini F, Tirillò J, Valente M, Ferrante L, Cioffi S, Iannace S, et al. Hybrid composites based on aramid and basalt woven fabrics: impact damage modes and residual flexural properties. Mater Des 2013;49:290-302.

106. Dehkordi MT, Nosraty H, Shokrieh MM, Minak G, Ghelli D. Low velocity impact properties of intra-ply hybrid composites based on basalt and nylon woven fabrics. Mater Des 2010;31(8):3835-44.

107. Dehkordi MT, Nosraty H, Shokrieh MM, Minak G, Ghelli D. The influence of hybridization on impact damage behavior and residual compression strength of intraply basalt/nylon hybrid composites. Mater Des 2013;43:283-90.

108. Wang X, Hu B, Feng Y, Liang F, Mo J, Xiong J, et al. Low velocity impact properties of 3D woven basalt/aramid hybrid composites. Compos Sci Technol 2008;68(2):444-50.

109. Park R, Jang J. Impact behavior of aramid fiber/glass fiber hybrid composite: Evaluation of impact behavior using delamination area. J Compos Mater 2000;34(13):1117-35. 
110. Park R, Jang J. Impact behavior of aramid fiber/glass fiber hybrid composite: evaluation of four-layer hybrid composites. J Mater Sci 2001;36(9):2359-67.

111. Park R, Jang J. Impact behavior of aramid fiber/glass fiber hybrid composites: the effect of stacking sequence. Polym Compos 2001;22(1):80-9.

112. Sayer M, Bektas NB, Çallioglu H. Impact behavior of hybrid composite plates. J Appl Polym Sci 2010;118(1):580-7.

113. Imielinska K, Castaings M, Wojtyra R, Haras J, Clezio EL, Hosten B. Air-coupled ultrasonic c-scan technique in impact response testing of carbon fibre and hybrid: glass, carbon and Kevlar/epoxy composites. J Mater Process Technol 2004;157-158(Spec. Iss.):513-22.

114. Naik NK, Ramasimha R, Arya H, Prabhu SV, ShamaRao N. Impact response and damage tolerance characteristics of glass-carbon/epoxy hybrid composite plates. Compos Part B: Eng 2001;32(7):565-74.

115. Hosur MV, Adbullah M, Jeelani S. Studies on the low-velocity impact response of woven hybrid composites. Compos Struct 2005;67(3 Spec. Iss.):253-62.

116. Sevkat E, Liaw B, Delale F, Raju BB. Drop-weight impact of plain-woven hybrid glassgraphite/toughened epoxy composites. Compos Part A: Appl Sci Manufact 2009;40(8):1090-110.

117. Enfedaque A, Molina-Aldareguia JM, Galvez F, Gonzalez C, Llorca J. Effect of glass fiber hybridization on the behavior under impact of woven carbon fiber/epoxy laminates. $\mathrm{J}$ Compos Mater 2010;44(25):3051-68.

118. Sevkat E, Liaw B, Delale F, Raju BB. Effect of repeated impacts on the response of plainwoven hybrid composites. Compos Part B: Eng 2010;41(5):403-13.

119. Sayer M, Bektas NB, Sayman O. An experimental investigation on the impact behavior of hybrid composite plates. Compos Struct 2010;92(5):1256-62.

120. Sayer M, Bektas NB, Demir E, Çallioglu H. The effect of temperatures on hybrid composite laminates under impact loading. Compos Part B: Eng 2012;43(5): 2152-60.

121. Peijs AAJM, Venderbosch RW, Lemstra PJ. Hybrid composites based on polyethylene and carbon fibres. Part III: Impact resistant structural composites through damage management. Composites 1990;21(6):522-30.

122. Peijs AAJM, Venderbosch RW. Hybrid composites based on polyethylene and carbon fibres. Part IV: Influence of hybrid design on impact strength. J Mater Sci Lett 1991;10(19):1122-4.

123. Pegoretti A, Fabbri E, Migliaresi C, Pilati F. Intraply and interply hybrid composites based on E-glass and poly(vinyl alcohol) woven fabrics: tensile and impact properties. Polym Int 2004;53(9):1290-7.

124. Fan, J., Guan, Z. W. and Cantwell, W. J., "Numerical modelling of perforation failure in fiber metal laminates subjected to low velocity impact loading", Composite Structures, 2011, 93(9): 2430-2436.

125. Vlot A, Gunnink JW. Fibre Metal Laminates: An Introduction. Kluwer Academic; 2001. 
126. Abdullah MR, Cantwell WJ. The impact resistance of polypropylene-based fibre metal laminates. Compos Sci Technol 2006;66:1682-93.

127. Yu G, Wu L, Ma L, Xiong J. Low velocity impact of carbon fiber aluminum laminates. Compos Struct 2015;119:757-66.

128. Vlot A, Fredell RS. Impact damage resistance and damage tolerance of fibre metal laminates. In: Proceedings of the 9th international conference on composite materials Spain, vol.6; 1993. p. 51-8.

129. Bienias J, Surowska B, Jakubczak P. The comparison of low velocity impact resistance of aluminum/carbon and glass fiber metal laminates. Polym Composite 2016;4(3):1056-63.

130. Lawcock GD, Ye L, Mai YW, Sun CT. Effects of fibre/matrix adhesion on carbonfibrereinforced metal laminates-II. Impact behaviour. Compos Sci Technol 1997;57:1621-8.

131. E. Sitnikova, Z.W. Guan, G.K. Schleyer, W.J. Cantwell, Modelling of perforation failure in fibre metal laminates subjected to high impulsive blast loading, International Journal of Solids and Structures, Volume 51, Issue 18, 2014, Pages 3135-3146, ISSN 0020-7683, http://dx.doi.org/10.1016/j.ijsolstr.2014.05.010.

132. Sitnikova, E., Guan, Z.W and Cantwell, W.J. "The analysis of the ultimate blast failure modes in fibre metal laminates". Composites Science and Technology, 2016, 135: 1-12.

133. Tsoi K et al. Impact damage behaviour of shape memory alloy compositesMater Sci Eng 2003:207-15.

134. Lau Kin-Tak et al. Low velocity impact on shape memory alloy stitchedcomposite plates. Smart Mater Struct 2004;13:364-70.

135. Paine JSN, Rogers CA. J Intell Mater Syst Struct 1994;5:530.

136. Kalhor R, Akbarshahi H, Case SW. Numerical modeling of the effects of FRP thickness and stacking sequence on energy absorption of metal-FRP square tubes. Compos Struct 2016;147:231-46.

137. Ochelski S, Gotowicki P. Experimental assessment of energy absorption capability of carbon-epoxy and glass-epoxy composites. Compos Struct 2009;87(3):215-24.

138. Heidari-Rarani M, Khalkhali-Sharifi SS, Shokrieh MM. Effect of ply stacking sequence on buckling behavior of E-glass/epoxy laminated composites. Comp Mater Sci 2014;89(12):89-96.

139. Dorey, G. in 'Failure Mode of Composite Materials with Organic Matrices and Their Consequences in Design', AGARD CP 163, 1975, paper 8

140. Hong, S. and Liu, D. Exp. Mech. 1989, 115

141. Liu, D. J. Compos. Mater. 1988, 22, 674

142. Clark, G. Composites, 1989, 20, 209

143. Strait, L.H., Karasek, M.L. and Amateau, M.F.J. Compos. Mater. 1989, 26, 1

144. Morton, J. and Goodwin, E.W. Compos. Struct. 1989, 13, 1

145. Alaattin Aktaş, Mehmet Aktaş, Fatih Turan, The effect of stacking sequence on the impact and post-impact behavior of woven/knit fabric glass/epoxy hybrid composites, Composite Structures, Volume 103, September 2013, Pages 119-135, ISSN 0263-8223. 
146. Prevorsek DC, Chin HB, Bhatnagar A. Damage tolerance. Design for structural integrity and penetration. Compos Struct 1993;23:137-48.

147. J. Tirillò, L. Ferrante, F. Sarasini, L. Lampani, E. Barbero, S. Sánchez-Sáez, T. Valente, P. Gaudenzi, High velocity impact behaviour of hybrid basalt-carbon/epoxy composites, Composite Structures, Volume 168, 15 May 2017, Pages 305-312, ISSN 0263-8223.

148. F. Sarasini, J. Tirillò, L. Ferrante, M. Valente, T. Valente, L. Lampani, P. Gaudenzi, S. Cioffi, S. Iannace, L. Sorrentino, Drop-weight impact behaviour of woven hybrid basaltcarbon/epoxy composites, Composites Part B: Engineering, Volume 59, March 2014, Pages 204-220, ISSN 1359-8368.

149. Fabrizio Sarasini, Jacopo Tirillò, Simone D'Altilia, Teodoro Valente, Carlo Santulli, Fabienne Touchard, Laurence Chocinski-Arnault, David Mellier, Luca Lampani, Paolo Gaudenzi, Damage tolerance of carbon/flax hybrid composites subjected to low velocity impact, Composites Part B: Engineering, Volume 91, 15 April 2016, Pages 144-153, ISSN 1359-8368, https://doi.org/10.1016/j.compositesb.2016.01.050.

150. Park, R. and Jang, J. (2001), Impact behavior of aramid fiber/glass fiber hybrid composites: The effect of stacking sequence. Polym Compos, 22: 80-89. doi:10.1002/pc.10519

151. Cristiano Fragassa, Ana Pavlovic, Carlo Santulli, Mechanical and impact characterisation of flax and basalt fibre vinylester composites and their hybrids, Composites Part B: Engineering, Available online 6 January 2017, ISSN 1359-8368, https://doi.org/10.1016/j.compositesb.2017.01.004.

152. Kim J-K, Sham M-L, Sohn M-S, Hamada H. Effect of hybrid layers with different silane coupling agents on impact response of glass fabric reinforced vinylester matrix composites. Polymer 2001;42:7455-60.

153. Sayer M, Bektas NB, Sayman O. An experimental investigation on the impact behavior of hybrid composite plates. Compos Struct 2010;92:1256-62.

154. Hosur MV, Adbullah M, Jeelani S. Studies on the low-velocity impact response of woven hybrid composites. Compos Struct 2005;67:253-62.

155. Hancox NL. An overview of the impact behavior of fibre-reinforced composites. In: Reid SR, Zhou G, editors. Impact behavior of fiber-reinforced composite materials and structures. CRC Press, Woodhead Pub. Ltd.; 2000.

156. N.H. Nash, T.M. Young, P.T. McGrail, W.F. Stanley, Inclusion of a thermoplastic phase to improve impact and post-impact performances of carbon fibre reinforced thermosetting composites - A review, Materials \& Design, Volume 85, 2015, Pages 582-597, ISSN 0264-1275, http://dx.doi.org/10.1016/j.matdes.2015.07.001.

157. Reyes G, Sharma U. Modeling and damage repair of woven thermoplastic composites subjected to low velocity impact. Compos Struct 2010;92(2):523-31.

158. X. Xu, Z. Zhou, Y. Hei, B. Zhang, J. Bao, X. Chen, Improving CAI performance of carbonfibre composites by CNTs/thermoplastic hybrid film interlayer, Compos. Sci. Technol. 95 (2014) 75-81. 
159. Husmn, G.E., Whitney, J.M. and Halpin, J.C. 'Residual strength characterization of laminated composites subjected to impact loading' in Foreign Object Impact Damage to Composites op.cit, pp 92-113

160. Barbezat, M. 'The influence of loading rate on the behaviour of epoxy composites' $\mathrm{PhD}$ thesis (Ecole Polytechnique F d rale de Lausanne, Switzerland, 1990) (in French)

161. D.W.Y.Wong, L. Lin, P.T.McGrail, T. Peijs, P.J. Hogg, Improved fracture toughness of carbon fibre/epoxy composite laminates using dissolvable thermoplastic fibres, Compos. A: Appl. Sci. Manuf. 41 (6) (2010) 759-767.

162. Harris B and Bunsell AR. Impact properties of glass fibre/carbon fibre hybrid composites. Composites 1975; 7: 197-201.

163. Trabelsi W, Michel L, Othomene R. Effects of stitching on delamination of satinweave carbon-epoxy laminates under mode I, mode II and mixed-mode I/IIloadings. Appl Compos Mater 2010; 17(6):575-95.

164. Ronald FG. A review of recent research on mechanics of multifunctional composite materials and structures. Compos Struct 2010; 92(12):2793-810.

165. Chung DDL. Structural composite materials tailored for damping. J AlloyCompd 2003; 355(1-2):216-23.

166. Aksoy A, Carlsson LA. Interlaminar shear fracture of interleaved graphite epoxy composites. Compos Sci Technol 1992; 43(1):55-69.

167. Shazed MA, Suraya AR, Rahmanian S, Amran MS. Effect of fibre coating and geometry on the tensile properties of hybrid carbon nanotube coated carbonfibre reinforced composite. Mater Des 2014;54:660-9.

168. Yokozeki T, Iwahori Y, Ishiwata S, Enomoto K. Mechanical properties of CFRP laminates manufactured from unidirectional prepregs using CSNT-dispersed epoxy. Composites Part A 2007;38:2121-30

169. Marcel Siegfried, Carmen Tola, Michael Claes, Stepan V. Lomov, Ignaas Verpoest, Larissa Gorbatikh, Impact and residual after impact properties of carbon fiber/epoxy composites modified with carbon nanotubes, Composite Structures, Volume 111, May 2014, Pages 488-496, ISSN 0263-8223, https://doi.org/10.1016/j.compstruct.2014.01.035.

170. Qian H, Greenhalgh ES, Shaffer MSP, Bismarck A. Carbon nanotube-based hierarchical composites: a review. J Mater Chem 2010; 20:4751-62.

171. Ma P, Siddiqui NA, Marom G, Kim J. Dispersion and functionalization of carbon nanotubes for polymer-based nanocomposites: A review. Compos Part A-Appl S 2010; 41:1345-67.

172. Asharif B, Guan J, Mirjalili V, Zhang Y, Chun L, Hubert P, et al. Enhancement of mechanical performance of epoxy/carbon fiber laminate composites using single-walled carbon nanotubes. Compos Sci Technol 2011;71:1569-78.

173. Wichman MHG, Sumfleth J, Gojny FH, Quaresimin M, Fiedler B, Schulte K. Glass-fibre reinforced composites with enhanced mechanical and electricalproperties - benefits and limitations of a nanoparticle modified matrix. Eng Fract Mech 2006;73:2346-59. 
174. Gkikas G, Barkoula NM, Paipetis AS. Effect of dispersion conditions on the thermomechanical and toughness properties of multi walled carbon nanotubes-reinforced epoxy. Compos Part B: Eng 2012;43:2697-705.

175. Shirkavand Hadavand B, Mahdavi Javid K, Gharagozlou M. Mechanical properties of multi-walled carbon nanotube/epoxy polysulfide nanocomposite. Mater Des 2013;50:627.

176. An F, Lu C, Li Y, Guo J, Lu X, Lu H, et al. Preparation and characterization ofcarbon nanotube-hybridized carbon fiber to reinforce epoxy composite. MaterDes 2012;33(1):197-202.

177. Bose S, Khare RA, Moldenaers P. Assessing the strengths and weaknesses of various types of pre-treatments of carbon nanotubes on the properties of polymer/carbon nanotubes composites: a critical review. Polymer 2010; 51:975-93.

178. Cui L-J, Wang Y-B, Xiu W-J, Wang W-Y, Xu L-H, Xu X-B, et al. Effect of functionalization of multi-walled carbon nanotube on the curing behavior and mechanical property of multi-walled carbon nanotube/epoxy composites. Mater Des 2013; 49:279-84.

179. Li M, Gu Y, Liu Y, Li Y, Zhang Z. Interfacial improvement of carbon fiber/epoxy composites using a simple process for depositing commercially functionalized carbon nanotubes on the fibers. Carbon 2013; 52:109-21.

180. Rahmanian S, Thean K, Suraya A, Shazed M, Mohd Salleh M, Yusoff H. Carbon and glass hierarchical fibers: influence of carbon nanotubes on tensile, flexural and impact properties of short fiber reinforced composites. Mater Des 2013; 43:10-6.

181. Dichiara A, Yuan JK, Yao SH, Sylvestre A, Bai J. Chemical vapor deposition sythesis of carbon nanotube-graphene nanosheet hybrids and their application in polymer composites. J Nanosci Nanotechnol 2012; 12:6935-40.

182. Vlasveld DPN, Bersee HEN, Picken SJ. Nanocomposite matrix for increased fibrecomposite strength. Polymer 2005; 46(23):10269-78.

183. Hudnut SW, Chung DDL. Use of submicron diameter carbon filaments forreinforcement between continuous carbon-fiber layers in a polymer-matrixcomposite. Carbon 1995;33(11):1627-31.

184. Kostopoulos V, Tsotra P, Karapappas P, Vavouliotis A, Tsantzalis S, Tanimoto T, et al. On the improvement of toughness of CFRPs with resin doped with CNF and PZT particles. Compos Sci Technol 2007; 67:822-8.

185. Arai M, Noro Y, Sugimoto K, Endo M. Mode I and mode II interlaminar fracture toughness of CFRP laminates toughened by carbon nanofiber interlayer. Compos Sci Technol 2008; 68:516-25.

186. Walker L, Sohn MS, Hu XZ. Improving impact resistance of carbon-fibre composites through interlaminar reinforcement. Composites Part A 2002;33:893-902.

187. Sohn MS, Hu XZ. Processing of carbon-fibre/epoxy composites with costeffective interlaminar reinforcement. Compos Sci Technol 1998;58:211-20. 
188. Sohn MS, Hu XZ. Vode II delamination toughness of carbon/epoxy composites with chopped Kevlar fiber reinforcement. Compos Sci Technol 1994;52:439-48.

189. N. Chikhi, S. Fellahi, M. Bakar, Modification of epoxy resin using reactive liquid (ATBN) rubber, Eur. Polym. J. 38 (2002) 251-264.

190. J. Jang, H. Yang, Toughness improvement of carbon-fibre/polybenzoxazine composites by rubber modification, Compos. Sci. Technol. 60 (3) (2000) 457-463.

191. R. Thomas, D. Yumei, H. Yuelong, Y. Le, P. Moldenaers, Y.Weimin, et al.,Miscibility, morphology, thermal, and mechanical properties of a DGEBA based epoxy resin toughened with a liquid rubber, Polymer 49 (1) (2008) 278-294.

192. A. Ozturk, C. Kaynak, T. Tincer, Effects of liquid rubber modification on the behavior of epoxy resin, Eur. Polym. J. 37 (12) (2001) 2353-2363.

193. D.J. Bull, A.E. Scott, S.M. Spearing, I. Sinclair, The influence of toughening-particles in CFRPs on low velocity impact damage resistance performance, Compos. A: Appl. Sci. Manuf. 58 (2014) 47-55.

194. D.J. Bull, S.M. Spearing, I. Sinclair, L. Helfen, Three-dimensional assessment of low velocity impact damage in particle toughened composite laminates using microfocus $\mathrm{X}$ ray computed tomography and synchrotron radiation laminography, Compos. A: Appl. Sci. Manuf. 52 (2013) 62-69.

195. Y.-x. He, Q. Li, T. Kuila, N.H. Kim, T. Jiang, K.-t. Lau, et al., Micro-crack behavior of carbon fiber reinforced thermoplastic modified epoxy composites for cryogenic applications, Compos. Part B 44 (1) (2013) 533-539.

196. P. Akangah, S. Lingaiah, K. Shivakumar, Effect of nylon-66 nano-fiber interleaving on impact damage resistance of epoxy/carbon fiber composite laminates, Compos. Struct. 92 (6) (2010) 1432-1439.

197. K. Magniez, T. Chaffraix, B. Fox, Toughening of a carbon-fibre composite using electrospun poly(hydroxyether of bisphenol A) nanofibrous membranes through inverse phase separation and inter-domain etherification, Materials 4 (11)(2011) 1967-1984.

198. D.W.Y.Wong, L. Lin, P.T.McGrail, T. Peijs, P.J. Hogg, Improved fracture toughness of carbon fibre/epoxy composite laminates using dissolvable thermoplastic fibres, Compos. A: Appl. Sci. Manuf. 41 (6) (2010) 759-767.

199. J. Zhang, T. Yang, T. Lin, C.H. Wang, Phase morphology of nanofibre interlayers: critical factor for toughening carbon/epoxy composites, Compos. Sci. Technol. 72 (2) (2012) 256262

200. J.-S. Kim, D.H. Reneker, Mechanical properties of composites using ultrafine electrospun fibres, Polym. Compos. 20 (1) (1999) 124-131.

201. G. Li, P. Li, C. Zhang, Y. Yu, H. Liu, S. Zhang, et al., Inhomogeneous toughening of carbon fiber/epoxy composite using electrospun polysulfone nanofibrous membranes by in situ phase separation, Compos. Sci. Technol. 68 (3-4) (2008) 987-994. 
202. Srivastava A, Majumdar A, Butola BS. Improving the impact resistance of textile structures by using shear thickening fluids: a review. Crit Rev Solid State Mater Sci 2012;37(2):11529.

203. Srivastava A, Majumdar A, Butola BS. Improving the impact resistance performance of Kevlar fabrics using silica based shear thickening fluid. Mater Sci Eng A 2011;529(1):2249.

204. Majumdar A, Butola BS, Srivastava A. An analysis of deformation and energy absorption modes of shear thickening fluid treated Kevlar fabrics as soft body armour materials. Mater Des 2013;51:148-53.

205. Hassan TA, Rangari VK, Jeelani S. Synthesis, processing and characterization of shear thickening fluid (STF) impregnated fabric composites. Mater Sci Eng A 2010;527(12):2892-9.

206. Lee YS, Wetzel ED, Wagner NJ. The ballistic impact characteristics of Kevlar woven fabrics impregnated with a colloidal shear thickening fluid. J Mater Sci 2003; 38(13):282533.

207. Edison E. Haro, Akindele G. Odeshi, Jerzy A. Szpunar, The energy absorption behavior of hybrid composite laminates containing nano-fillers under ballistic impact, International Journal of Impact Engineering, Volume 96, 2016, Pages 11-22, ISSN 0734-743X, http://dx.doi.org/10.1016/j.ijimpeng.2016.05.012.

208. Abrate S. Impact engineering of composite structures, CISM Courses and Lectures, vol. 526. New York: Springer Wien; 2011.

209. Wetzel ED, Wagner PNJ, Lee YS. Protective fabrics utilizing shear thickening fluids (STFs), in 4th International Conference on Safety and Protective Fabrics Pittsburgh, PA, pp. 1-23. 2004.

210. P.J. Hogg, Toughening of thermosetting composites with thermoplastic fibres, Mater. Sci. Eng. A 412 (1-2) (2005) 97-103.

211. A.A.J.M. Peijs, R.W. Venderbosch, Hybrid composites based on polyethylene and carbon fibres. Part IV: influence of hybrid design on impact strength, J. Mater. Sci. Lett. 10 (1991) $1122-1124$.

212. W.H. Lu, F.S. Liao, A.C. Su, P.W. Kao, T.J. Hsu, Effect of interleaving on the impact response of a unidirectional carbon/epoxy composite, Composites 26 (3) (1995) 215-222.

213. M.S. Sohn, X.Z. Hu, J.K. Kim, L. Walker, Impact damage characterisation of carbon fibre/epoxy composites with multi-layer reinforcement, Compos. Part B 31 (8) (2000) 681691.

214. M. Hojo, S. Matsuda, M. Tanaka, S. Ochiai, A. Murakami, Mode I delamination fatigue properties of interlayer-toughened CF/epoxy laminates, Compos. Sci. Technol. 66 (5) (2006) 665-675.

215. W. Jiang, S.C. Tjong, P.K. Chu, R.K.Y. Li, J.K. Kim, Y.W. Mai, Interlaminar fracture properties of carbon fibre/epoxymatrix composites interleaved with polyethylene terephtalate (PET) films, Polym. Polym. Compos. 9 (2) (2001) 141-145. 
216. X. Xu, Z. Zhou, Y. Hei, B. Zhang, J. Bao, X. Chen, Improving CAI performance of carbonfibre composites by CNTs/thermoplastic hybrid film interlayer, Compos. Sci. Technol. 95 (2014) 75-81.

217. R.W. Hillermeier, J.C. Seferis, Interlayer toughening of resin transfer molding composites, Compos. A: Appl. Sci. Manuf. 32 (5) (2001) 721-729.

218. L. Zhu, Investigations on damage resistance of carbon fiber composite panels toughened using veils, Chin. J. Aeronaut. 26 (3) (2013) 807-813

219. A.A.J.M. Peijs, R.W. Venderbosch, Hybrid composites based on polyethylene and carbon fibres. Part IV: influence of hybrid design on impact strength, J. Mater. Sci. Lett. 10 (1991) $1122-1124$.

220. P.J. Hogg, Toughening of thermosetting composites with thermoplastic fibres, Mater. Sci. Eng. A 412 (1-2) (2005) 97-103.

221. M.S. Sohn, X.Z. Hu, J.K. Kim, L. Walker, Impact damage characterisation of carbon fibre/epoxy composites with multi-layer reinforcement, Compos. Part B 31 (8) (2000) 681691.

222. L. Walker, M. Sohn, X. Hu, Improving impact resistance of carbon-fibre composites through interlaminar reinforcement, Compos. A: Appl. Sci. Manuf. 33 (6) (2002) 893-902.

223. M. Kuwata, P.J. Hogg, Interlaminar toughness of interleaved CFRP using non-woven veils: part 1. Mode-I testing, Compos. A: Appl. Sci. Manuf. 42 (10) (2011) 1551-1559.

224. M. Kuwata, P.J. Hogg, Interlaminar toughness of interleaved CFRP using non-woven veils: part 2. Mode-II testing, Compos. A: Appl. Sci. Manuf. 42 (10) (2011) 1560-1570.

225. D. Tzetzis, P.J. Hogg, Bondline toughening of vacuum infused composite repairs, Compos. A: Appl. Sci. Manuf. 37 (9) (2006) 1239-1251.

226. N.H. Nash, D. Ray, T.M. Young, W.F. Stanley, Characterization of the mechanical properties and water absorption of carbon/benzoxazine composites with a thermoplastic interlayer, SETEC 14: Efficient Composite Solutions to Foster Economic Growth2014. (Tampere, Finland).

227. Abu Talib AR, Abbud LH, Ali A, Mustapha F. Ballistic impact performance of Kevlar-29 and Al2O3 powder/epoxy targets under high velocity impact. Mater Des 2012; 35:12-19.

228. Celal Evci, Thickness-dependent energy dissipation characteristics of laminated composites subjected to low velocity impact, Composite Structures, Volume 133, 1 December 2015, Pages 508-521, ISSN 0263-8223, https://doi.org/10.1016/j.compstruct.2015.07.111.

229. Quaresimin M, Ricotta M, Martello L, et al. Energy absorption in composite laminates under impact loading. Composites Part B 2013; 44: 133-140.

230. G. Caprino, V. Lopresto, A. Langella, M. Durante. Irreversibly absorbed energy and damage in GFRP laminates impacted at low velocity. Composite Structures 93 (2011) 2853-2860. 
231. Wenjie Wang, Nawawi Chouw, Krishnan Jayaraman. Effect of thickness on the impact resistance of flax fibre-reinforced polymer. Journal of Reinforced Plastics and Composites. Vol 35, Issue 17, pp. $1277-1289$.

232. De Morais WA, Monteiro SN, d'Almeida JRM. Evaluation of repeated low energy impact damage in carbon-epoxy composite materials. Compos Struct 2005; 67: 307-15.

233. Rohchoon Park, Jyongsik Jang, Effect of laminate thickness on impact behavior of aramid fiber/vinylester composites, Polymer Testing, Volume 22, Issue 8, December 2003, Pages 939-946, ISSN 0142-9418, https://doi.org/10.1016/S0142-9418(03)00044-8.

234. Stavropoulos, C. \& Papanicolaou, G. Journal of Materials Science (1997) 32: 931. doi:10.1023/A:1018553617046

235. Dhakal, H.N., Skrifvars, M., Adekunle, A., Zhang, Z.Y. (2014). Falling weight impact response of jute/methacrylated soybean oil bio-composites under low velocity impact loading. Composites Science and Technology, 92:134-141.

236. Resnyansky, A. D. The impact response of composite materials involved in helicopter vulnerability assessment: Literature Review-Part 2. No. DSTO-TR-1842. DEFENCE SCIENCE AND TECHNOLOGY ORGANISATION EDINBURGH (AUSTRALIA) WEAPONS SYSTEMS DIV, 2006.

237. Cho C. and Zhao G., Effects of Geometric and Material Factors on Mechanical Response of Laminated Composites Due to Low Velocity Impact. J. Composite Materials, v. 36, n. 12, 2002, pp. 1403-1428.

238. Cantwell W.J. and Morton J., Impact Perforation of Carbon Fibre Reinforced Plastic, Composites Science and Technology, v. 38, n. 2, 1990, pp. 119-141.

239. Z.W. Xu, Z.W. Guan, W.J. Cantwell. "An Experimental Study of Scaling Effects in the Perforation Resistance of Woven CFRP Laminates". Composite Structures. 2017, 181: 285-293.

240. B.V. Sankar. Scaling of low-velocity impact for symmetric composite laminates. J Reinf Plast Compos, 11 (1992), pp. 296-309

241. Damodar A, Prasad C, Cheryl R, Paolo F, Wade J. Scaling the non-linear impact response of flat and curved composite panels. In: 46th AIAA/ASME/ASCE/AHS/ASC structures, structural dynamics and materials conference. American Institute of Aeronautics and Astronautics; 2005.

242. J. Morton. Scaling of impact-loaded carbon-fiber composites. AIAA J, 26 (1988), pp. 989994.

243. S.R. Swanson. Scaling of impact damage in fiber composites from laboratory specimens to structures. Compos Struct, 25 (1993), pp. 249-255.

244. S. McKown, W.J. Cantwell, N. Jones. Investigation of scaling effects in fiber-metal laminates. J Compos Mater, 42 (2008), pp. 865-888.

245. G. Zhou, G.A.O. DaviesImpact response of thick glass fibre reinforced polyester laminates Int J Impact Eng, 13 (1995), pp. 357-374 
246. L. Ballère, P. Viot, J.-L. Lataillade, L. Guillaumat, S. Cloutet, Damage tolerance of impacted curved panels, International Journal of Impact Engineering, Volume 36, Issue 2, February 2009, Pages 243-253, ISSN 0734-743X, https://doi.org/10.1016/j.ijimpeng.2008.03.004. 246

247. Gong S. The elastic response of orthotropic laminates shells to low velocity impact. Compos Eng 1994;4:247-66.

248. Khalili SMR, Ardali A. Low velocity impact response of doubly curved symmetric crossply laminated panel with embedded SMA wires. Compos Struct 2013:216-26.

249. Kistler LS, Waas AM. On the response of curved laminated panels subjected to transverse impact loads. Int J Solids Struct 1999;36(9):1311-27.

250. Saghafi H, Minak G, Zucchelli A. Effect of preload on the impact response of curved composite panels. Compos B Eng 2014;60:74-81.

251. Choi IH. Geometrically nonlinear transient analysis of composite laminated plate and shells subjected to low-velocity impact, 2016. Compos Struct 2016;142:7-14.

252. Leylek Z, Scott ML, Georgiadis S, Thomson RS. Computer modelling of impact on curved fibre composite panels. Compos Struct 1999;47(1-4):789-96.

253. Goo NS, Kim SJ. Dynamic contact analysis of laminated composite plates under lowvelocity impact. AIAA J 1997;35(9):1518-21.

254. Shivakumar KN, Elber W, Illg W. Prediction of low-velocity impact damage in composite laminates. AIAA J 1984;23(5):442-9.

255. Singh H, Mahajan P. Analytical modelling of low velocity large mass impact on composite plate including damage evolution. Compos Struct 2016;149:79-92.

256. Olsson R. Analytical prediction of large mass impact damage in composite laminates. Compos Part A Appl Sci Manuf 2001;32(9):1207-15.

257. Olsson R. Analytical model for delamination growth during small mass impact on plates. Int J Solids Struct 2010;47(21):2884-92.

258. Olsson R. Analytical prediction of damage due to large mass impact on thin ply composites. Compos Part A Appl Sci Manuf 2015;72:184-91.

259. Shahid I, Chang FK, Shah BM. Impact Damage Resistance and Damage Tolerance of Composite with Progressive Damage. 37th AIAA Structures, Structural Dynamics and Materials Conference, 1996: pp. 766-775.

260. Arachchige B, Ghasemnejad H, Augousti A. Theoretical approach to predict transverse impact response of variable-stiffness curved composite plates. Composites Part B 2016;89:34-43.

261. Fan, J., Guan, Z. W. and Cantwell, W. J., "Modelling perforation in glass fiber reinforced composites subjected to low velocity impact loading", Polymer Composites, 2011, 32(9): 1380-1388.

262. Mitrevski T, Marshall IH, Thomson R, Jones R. The influence of impactor shape on the damage to the composite laminates. Compos Struct 2006; 76:116-22. 
263. Lee SM, Cheon JS, Im YT. Experimental and numerical study of the impact behavior of SMC plates. Compos Struct 1999; 47: 551-61.

264. Zhou G, Lloyd JC, McGuirk JJ. Experimental evaluation of geometric factors affecting damage mechanisms in carbon/epoxy plates. Compos Part A: Appl S 2001; 32:71-84.

265. Mines RAW, Roach AM, Jones N. High velocity perforation behaviour or polymer composite laminates. Int J Impact Eng 1999; 22:561-88.

266. Kim SJ, Goo NS. Dynamic contact responses of laminated composite plates according to the impactors shapes. Comput Struct 1997; 65(1):83-90.

267. Andrew, Jefferson, Vellayaraj Arumugam, Adhithya Plato Sidharth, and Benny Thomas. "Acoustic emission based monitoring of cut-out geometry effects in carbon/epoxy laminates under uni-axial compression." International Journal of Vehicle Structures \& Systems 6, no. 1/2 (2014): 17.

268. Andrew, J. Jefferson, V. Arumugam, D. J. Bull, and Hom Nath Dhakal. "Residual strength and damage characterization of repaired glass/epoxy composite laminates using $\mathrm{AE}$ and DIC." Composite Structures 152 (2016): 124-139.

269. Bhatia, Gursahib Singh, J. Jefferson Andrew, and A. Arockiarajan. "Experimental investigation on compressive behaviour of different patch-parent layup configurations for repaired carbon/epoxy composites." Journal of Composite Materials (2019): 0021998318822706.

270. Jefferson Andrew, J., and V. Arumugam. "Effect of patch hybridization on the compression behavior of patch repaired glass/epoxy composite laminates using acoustic emission monitoring." Polymer Composites 39, no. 6 (2018): 1922-1935.

271. Bhatia, Gursahib Singh, J. Jefferson Andrew, G. Balaganesan, and A. Arockiarajan. "The role of patch-parent configurations on the tensile response of patch repaired carbon/epoxy laminates." Polymer Testing 70 (2018): 413-425.

272. Dhakal, H. N., Zhang, Z. Y., Bennett, N., \& Reis, P. N. B. (2012). Low-velocity impact response of non-woven hemp fibre reinforced unsaturated polyester composites: Influence of impactor geometry and impact velocity. Composite Structures; 94, 2756-2763.

273. Benzeggagh ML, Benmedakhene S. Residual strength of a glass/polypropylene composite material subjected to impact. Compos Sci Technol 1995; 55: 1-11.

274. Hamed Zarei, Mojtaba Sadighi, Giangiacomo Minak, Ballistic analysis of fiber metal laminates impacted by flat and conical impactors, Composite Structures, Volume 161, 2017, Pages 65-72, ISSN 0263-8223.

275. Zabala H, Aretxabaleta L, Castillo G, Urien J, Aurrekoetxea J. Impact velocity effect on the delamination of woven carbon-epoxy plates subjected to low velocity equienergetic impact loads. Compos Sci Technol 2014; 94: 48-53.

276. López-Puente J, Li S. Analysis of strain rate sensitivity of carbon/epoxy woven composites. Int J Impact Eng 2012;48:54-64. 
277. Ambur DR, Kemmerly HL. Influence of impactor mass on the damage characteristics and failure strength of laminated composites plates, $39^{\text {th }}$ AIAA/ASME/ASCE/AHS/ASC structures. Struct Dyn Mater Conf 1998:98-1784.

278. Feraboli P, Kedward KT. A new composite structure impact performance assessment program. Compos Sci Technol 2006; 66: 1336-47.

279. Bucinell R, Nuismer RJ, Koury JL. Response of composites plates to quasi-static impact events. ASTM STP 1991; 1110: 528-49.

280. J.A. Artero-Guerrero, J. Pernas-Sánchez, J. López-Puente, D. Varas, Experimental study of the impactor mass effect on the low velocity impact of carbon/epoxy woven laminates, Composite Structures, Volume 133, 2015, Pages 774-781, ISSN 0263-8223.

281. Foroutanb R, Nemesa J, Ghiasib H, Hubertb P. Experimental investigation of high strainrate behaviour of fabric composites. Compos Struct 2013; 106: 261-71.

282. Fitoussi J, Meraghni F, Jendli Z, Hug G, Baptiste D. Experimental methodology for high strain-rates tensile behaviour analysis of polymer matrix composites. Compos Sci Technol 2005; 65: 2174-88.

283. Hosur M, Adya M, Vaidya U, Mayer A, Jeelani S. Effect of stitching and weave architecture on the high strain rate compression response of affordable woven carbon/epoxy composites. Compos Struct 2003; 59: 507-23.

284. Hosur M, Islam SW, Vaidya U, Kumar A, Dutta P, Jeelani S. Dynamic punch shear characterization of plain weave graphite/epoxy composites at room and elevated temperatures. Compos Struct 2005; 70: 295-307.

285. Robinson P, Davies G. Impactor mass and specimen geometry effects in low velocity impact of laminated composites. Int J Impact Eng 1992; 12: 189-207.

286. Zabala H, Aretxabaleta L, Castillo G, Aurrekoetxea J. Loading rate dependency on mode I interlaminar fracture toughness of unidirectional and woven carbon fibre epoxy composites. Compos Struct 2015; 121: 75-82.

287. Wenbo Xie, Wei Zhang, Naihang Kuang, Dacheng Li, Wei Huang, Yubo Gao, Nan Ye, Licheng Guo, Peng Ren, Experimental investigation of normal and oblique impacts on CFRPs by high velocity steel sphere, Composites Part B: Engineering, Volume 99, 2016, Pages 483-493, ISSN 1359-8368, http://dx.doi.org/10.1016/j.compositesb.2016.06.020.

288. P. Navarro, J. Aubry, S. Marguet, J.-F. Ferrero, S. Lemaire, P. Rauch. Experimental and numerical study of oblique impact on woven composite sandwich structure: Influence of the firing axis orientation. Composite Structures, Volume 94, Issue 6, 2012, Pages 19671972.

289. Zener C, Peterson RE. Mechanism of armor penetration. DTIC Document; 1943.

290. Siva Kumar K, Balakrishna Bhat T. Response of composite laminates on impact of high velocity projectiles. Key Eng Mater Trans Tech Publ 1997:337e48.

291. Yang IY, Cho YJ, Im KH, Cha CS, Kim YN. Penetration fracture characteristics of CFRP curved shells according to oblique impact. In: Putra IS, Suharto D, editors. Fracture and 
strength of solids Vi, pts 1 and 2. Zurich-Uetikon: Trans Tech Publications Ltd; 2006. p. 291 e6.

292. Wenbo Xie, Wei Zhang, Naihang Kuang, Dacheng Li, Wei Huang, Yubo Gao, Nan Ye, Licheng Guo, Peng Ren, Experimental investigation of normal and oblique impacts on CFRPs by high velocity steel sphere, Composites Part B: Engineering, Volume 99, 2016, Pages 483-493, ISSN 1359-8368, http://dx.doi.org/10.1016/j.compositesb.2016.06.020.

293. Chu CK, Chen YL, Hseu GC, Hwang DG. The study of obliquity on the ballistic performance of basket fabric composite materials. J Compos Mater 2007;41(13):1539e58.

294. Pernas-Sanchez J, Artero-Guerrero JA, Varas D, Lopez-Puente J. Experimental analysis of normal and oblique high velocity impacts on carbon/epoxy tape laminates. Compos Part A Appl Sci Manuf 2014;60:24e31.

295. Zhou J, Hassan MZ, Guan Z, Cantwell WJ. The low-velocity impact response of foambased sandwich panels. Compos Sci Technol 2012;72:1781-90.

296. I. Ivañez, M.M. Moure, S.K. Garcia-Castillo, S. Sanchez-Saez. The oblique impact response of composite sandwich plates. Composite Structures, Volume 133, 2015, Pages $1127-1136$.

297. Goldsmith W. Non-ideal projectile impact on targets. Int J Impact Eng 1999;22:95-395.

298. C. Ramesh, Joseph Stanley, Vellayaraj Arumugam, J. Jefferson Andrew, S. Aruna bharathi Effect of Multiple Impacts on GFRP Laminates Exposed to Hydrolytic Ageing using Acoustic Emission Monitoring International Journal of Vehicle Structures and Systems 01/2014; 6(1-2). DOI:10.4273/ijvss.6.1-2.05.

299. Heller SR. Proc Fifth Symp Struct Mech 1967:69e111.

300. Imielin'ska K, Guillaumat L. The effect of water immersion ageing on lowvelocity impact behaviour of woven aramid-glass fiber/epoxy composites. Compos Sci Technol 2004;64(13-14):2271-8.

301. Su-Seng Pang, Guoqiang Li, Jack E Helms, Samuel I Ibekwe, Influence of ultraviolet radiation on the low velocity impact response of laminated beams, Composites Part B: Engineering, Volume 32, Issue 6, September 2001, Pages 521-528, ISSN 1359-8368, https://doi.org/10.1016/S1359-8368(01)00027-0.

302. Moy P, Karasz FE. Polym Eng Sci 1980;20:315e9.

303. Ray BC. J Colloid Interface Sci 2006;298:111e7.

304. K. Berketis, D. Tzetzis, P.J. Hogg, The influence of long term water immersion ageing on impact damage behavior and residual compression strength of glass fibre reinforced polymer (GFRP), Materials \& Design, Volume 29, Issue 7, 2008, Pages 1300-1310, ISSN 0261-3069, https://doi.org/10.1016/j.matdes.2007.07.008.

305. F.B. Boukhoulda, L. Guillaumat, J.L. Lataillade, E. Adda-Bedia, A. Lousdad, Agingimpact coupling based analysis upon glass/polyester composite material in hygrothermal environment, Materials \& Design, Volume 32, Issue 7, August 2011, Pages 4080-4087, ISSN 0261-3069, https://doi.org/10.1016/j.matdes.2011.03.009. 
306. Amaro AM, Reis PNB. Environmental effects on compressive strength after impact loads in composite laminates. Adv Compos Lett 2010;19:109e12.

307. Akay M, Spratt GR, Meenan B. The effects of long-term exposure to high temperatures on the ILSS and impact performance of carbon fiber reinforced bismaleimide. Compos Sci Technol 2003;63:1053-9.

308. Aktas M, Karakuzu R, Arman Y. Compression-after impact behavior of laminated composite plates subjected to low velocity impact in high temperatures. Compos Struct 2009;89:77-82.

309. Bhoominathan R, Arumugam Vellayaraj, Ashok Thompson and Jefferson Andrew Jeyakumar. Residual strength estimation of CFRP laminates subjected to impact at different velocities and temperatures. Polymer Composites DOI: 10.1002/pc.23796.

310. C. Jefferson Andrew, Ramesh. Residual strength and damage characterization of unidirectional glassebasalt hybrid/epoxy CAI laminates, Arab. J. Sci. Eng. (2015) $2191 \mathrm{e} 4281$.

311. Salehi-Khojin A, Bashirzadeh R, Mahinfalah M, Nakhaei-Jazar R. The role of temperature on impact properties of Kevlar/fiberglass composite laminates. Compos Part B: Eng 2006;37(7-8):593-602

312. Río TG, Zaera R, Baarbero E, Navarro C. Damage in CFRPs due to low velocity impact at low temperature. Compos Part B Eng 2005;36:41e50.

313. Icten BM, Atas C, Aktas M, Karakuzu R. Low temperature effect on impact response of quasi-isotropic glass/epoxy laminated plates. Compos Struc 2009;91:318e23.

314. Ibekwe SI, Mensah PF, Li G, Pang SS, Stubblefield MA. Impact and post impact response of laminated beams at low temperatures. Compos Struct 2007;79: 12e7.

315. Hirai Y, Hamada H, Kim J-K. Impact response of woven glass-fabric composites - II. Effect of temperature. Compos Sci Technol 1998;58:119e28.

316. Badawy AAM. Impact behavior of glass fibers reinforced composite laminates at different temperatures. Ain Shams Eng J 2012;3(2):105-11.

317. Im K-H, Cha C-S, Kim S-K, Yang I-Y. Effects of temperature on impact damages in CFRP composite laminates. Compos Part B: Eng 2001;32(8):669-82.

318. Karasek ML, Strait LH, Amateau MF, Runt JP. Effect of temperature and moisture on the impact behaviour of graphite/epoxy composites: Part 1- Impact energy absorption. J Compos Technol Res 1995;17:3e10.

319. Bibo GA, Hogg PJ, Kemp M. High-temperature damage tolerance of carbon fibrereinforced plastics: Part 2 - post-impact compression characteristics. Composites 1995;26(2):91-102.

320. Russo P, Langella A, Papa I, Simeoli G, Lopresto V. Thermoplastic polyurethane/glass fabric composite laminates: low velocity impact behavior under extreme temperature conditions. Compos Struct 2017;166:146-52. 
321. Sorrentino L, de Vasconcellos DS, D'Auria M, Sarasini F, Tirillo J. Effect of temperature on static and low velocity impact properties of thermoplastic composites. Compos Part B 2017; 113:100-10.

\section{Figure Captions:}

Figure 1: Schematic showing different damage mechanisms due to impact load (a) high energy, (b) medium energy and (c) low energy.

Figure 2: Factors influencing impact response of composite materials

Figure 3: Classification of different impacts [28].

Figure 4: Different impact responses: (a) boundary-controlled (b) wave-controlled [28].

Figure 5: Schematic of (a) UD, (b) 2D and (c) 3D woven fabric [48].

Figure 6: Damage modes for various architectures of composites (a) Uni-directional (b) 2D and 3D woven fabrics [48].

Figure 7: (a) Stitching process, (b) definitions and (c) graphic of modified lock stitches [84].

Figure 8: Impact damage of various specimens (thread thickness 200 and 400 denier; stitch space $3 \times 3$ and $6 \times 6$ ) subjected to impact energy $6.7 \mathrm{~J}$ [82]

Figure 9: Energy absorption curves (thread thickness 200 and 400 denier; stitch space $3 \times 3$ and $6 \times 6)[84]$.

Figure 10: Schematic stress-strain curves of hybrid composites with synergistic strengthening [101].

Figure 11: Hybrid configurations (a) Interply-, (b) Intraply- and (c) Super-hybridization [101].

Figure 12: Damage of hybrid Basalt-B, Carbon-C, Basalt/Carbon/Basalt-Sandwich-BCBS, Carbon/Basalt/Carbon-Sandwich-CBCS, Basalt/Carbon/Basalt-intercalated-BCBI and Carbon/Basalt/Carbon-Intercalated-CBCI composite configurations beyond the ballistic limit velocity [147].

Figure 13: Ballistic limit velocity for different specimen configurations [147].

Figure 14: Schematic of the (a) CNT-depositing process on fibers [179], (b) dispersion of the carbon nano tube in matrix, (c) Nano-fiber reinforcement of the matrix [183] and (d) particles in a STF during shear thinning and shear thickening w.r.t. increasing shear rate [202]. 
Figure 15: Impactors (a) Charpy-straight line, (b) spherical (25.4 mm), (c) spherical (12.7 mm) and (d) flat-ended (10 $\mathrm{mm})$ [261].

Figure 16: Perforation pattern in target plate impacted by different nose projectile [261].

Figure 17: Aerofoil section subjected to impact under normal and oblique angle conditions [288].

Figure 18: Variation of the energy transfer and ballistic limit with the impact angle [287].

Figure 19: C-scan images for different oblique angles and impact energies [296].

Figure 20: Close up photos of $5 \mathrm{~J}$ impact damage on (a) dry specimen (front face), (b) dry specimen (back face), (c) 24 months aged (front face) and (d) 24 months aged (back face) [304].

Figure 21: Absorbed energy for various immersion time intervals [304].

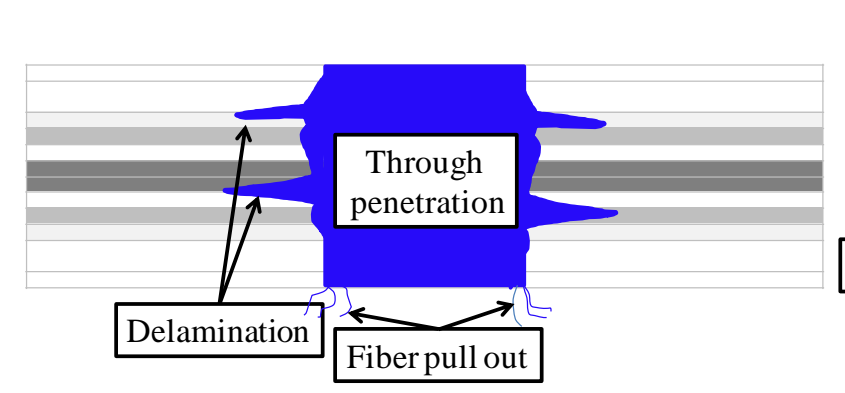

(a)

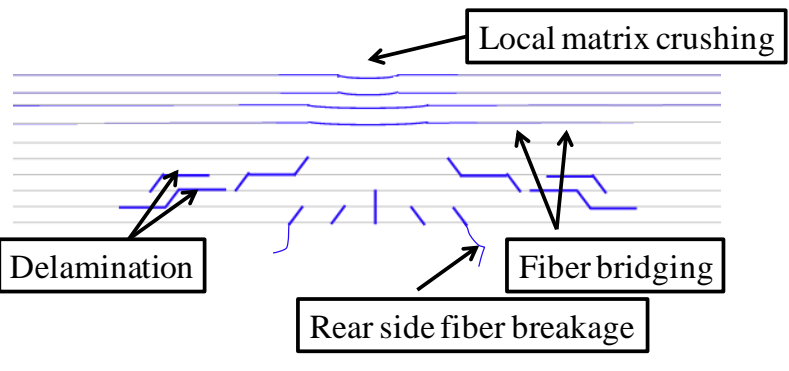

(b)

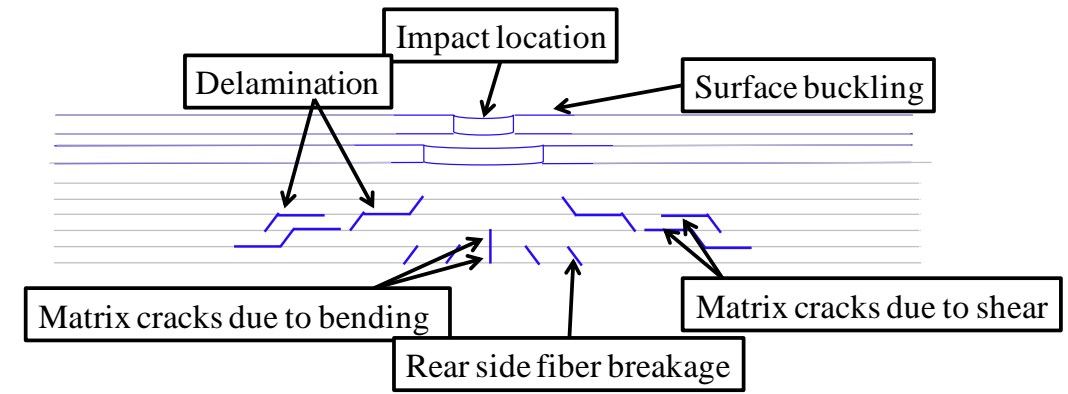

(c)

Figure 1: Schematic showing different damage mechanisms due to impact load (a) high energy, (b) medium energy and (c) low energy. 


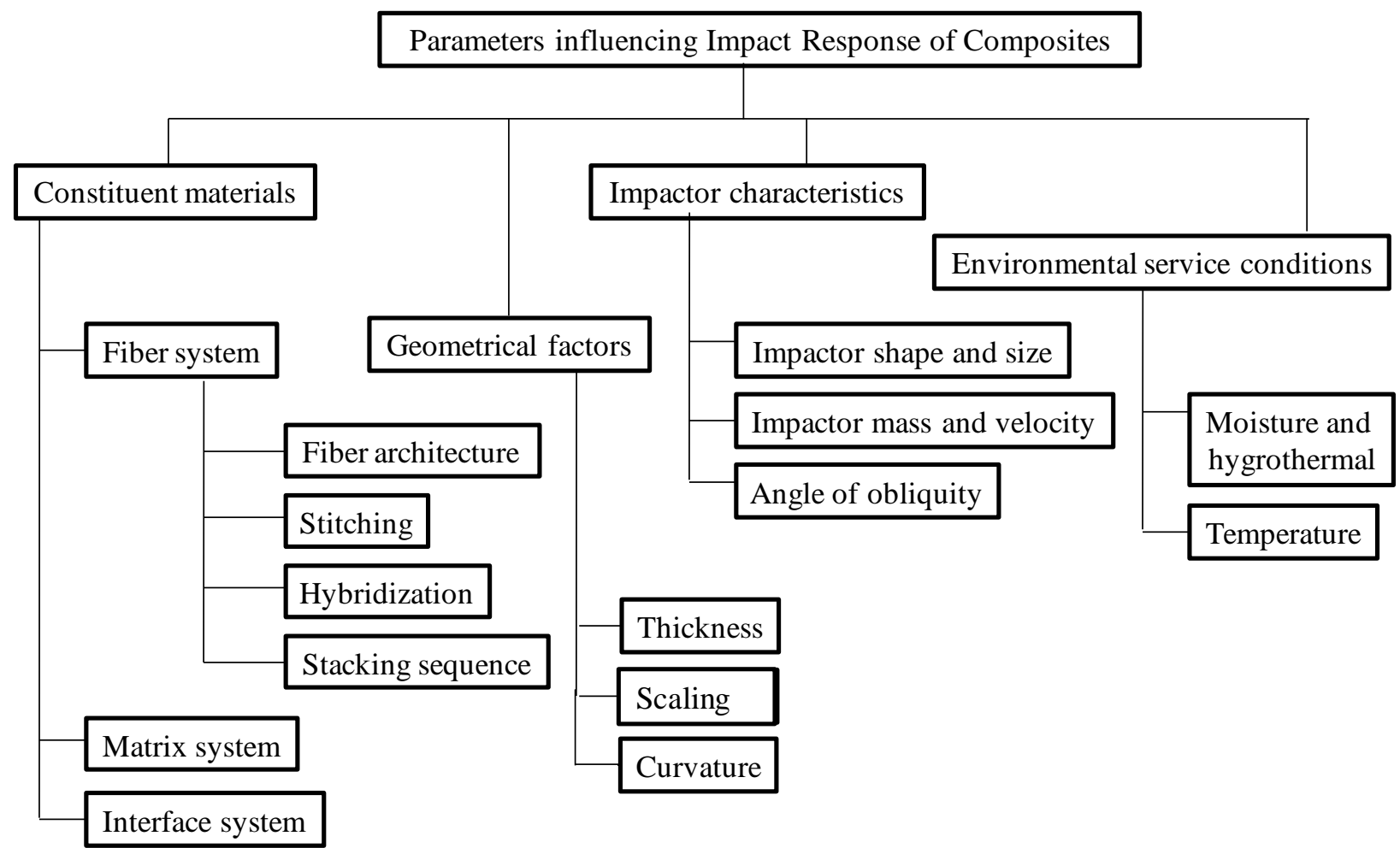

Figure 2: Factors influencing impact response of composite materials

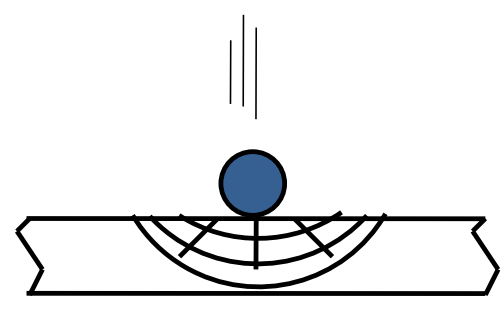

(a)

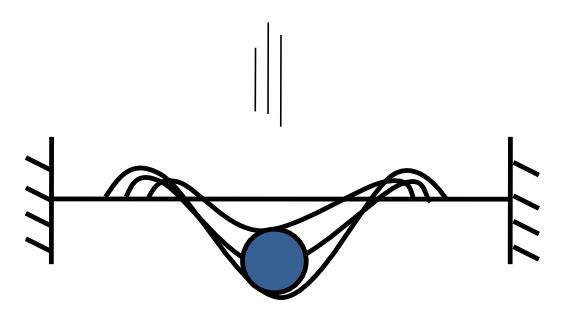

(b)

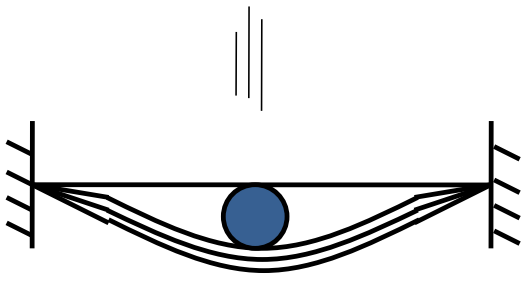

(c)

Figure 3: Classification of different impacts (a) transverse wave (b) flexural and shear waves (c) static loading [28]. 


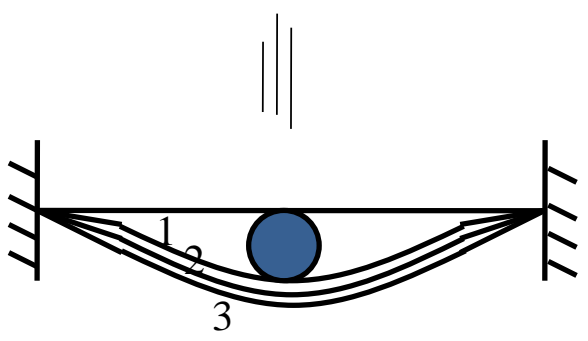

(a)

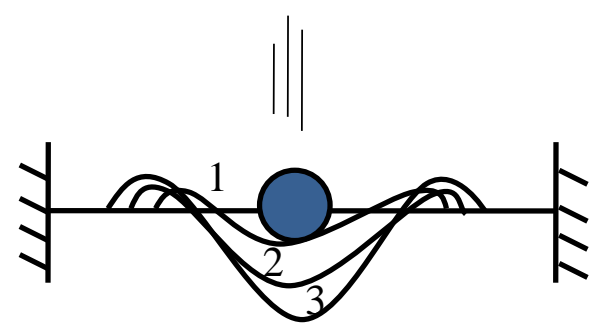

(b)

Figure 4: Different impact responses: (a) boundary-controlled (b) wave-controlled [28].

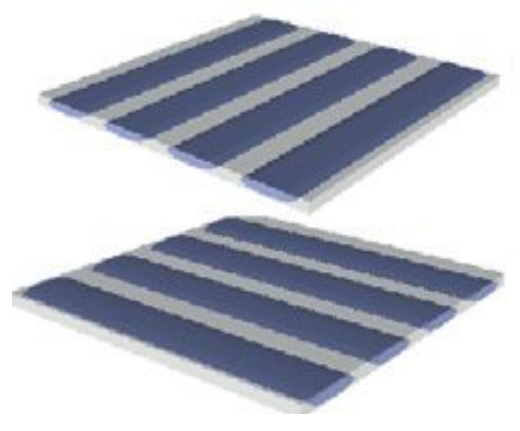

(a)

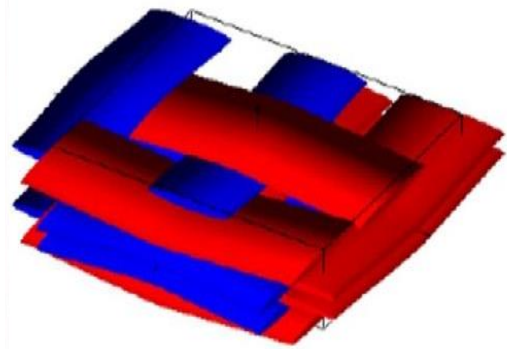

(b)

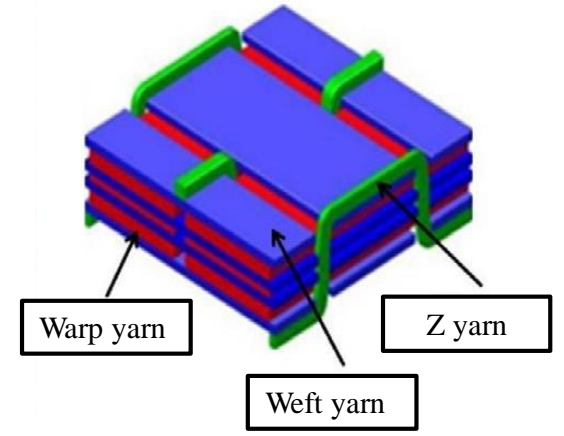

(c)

Figure 5: Schematic of (a) Uni-directional, (b) 2D and (c) 3D woven fabric [48].

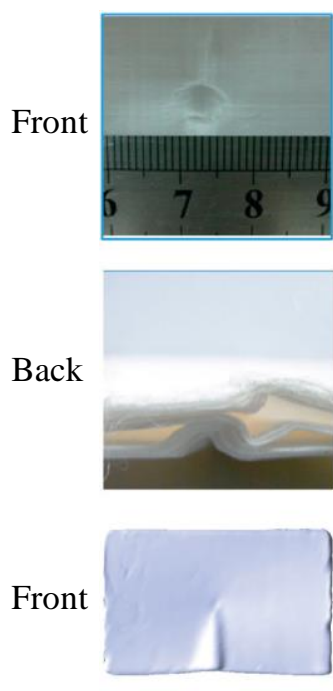

Side
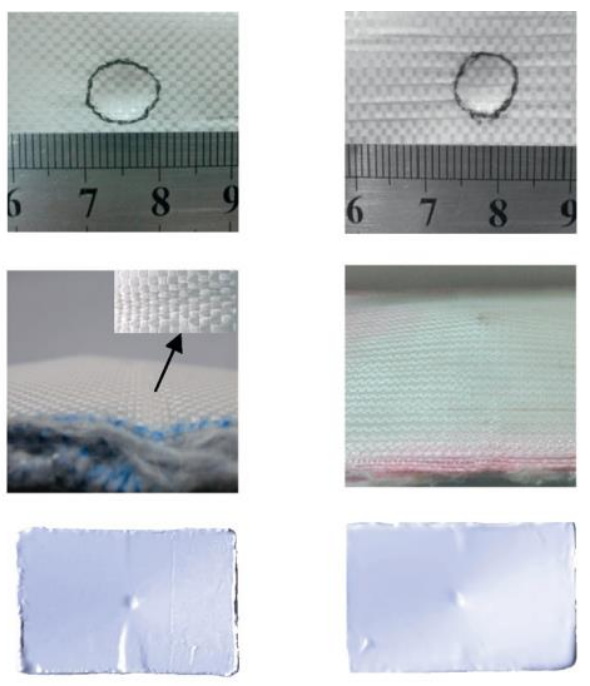

(b)

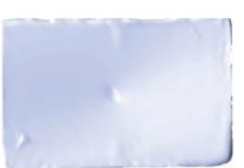

(c) 
Figure 6: Damage modes for various architectures of composites (a) Uni-directional (b) 2D and 3D woven fabrics [48].

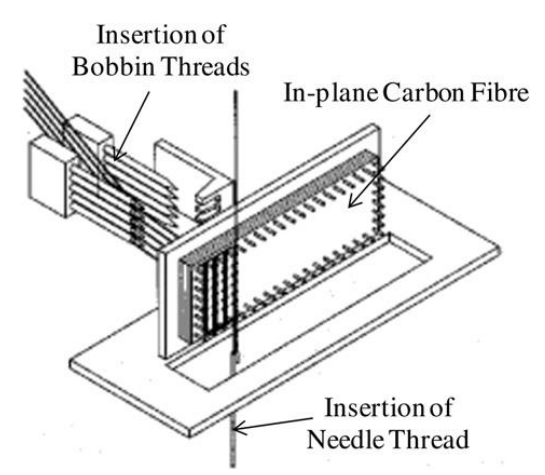

(a)

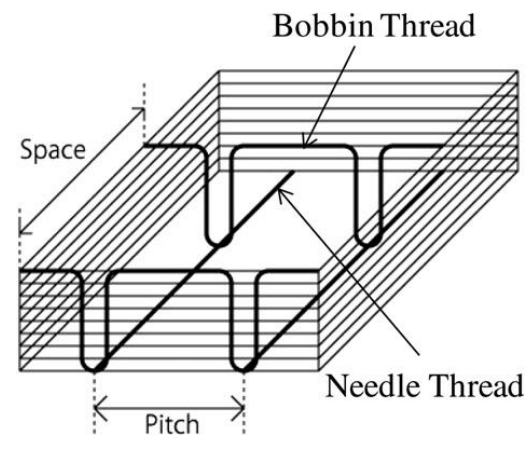

(b)

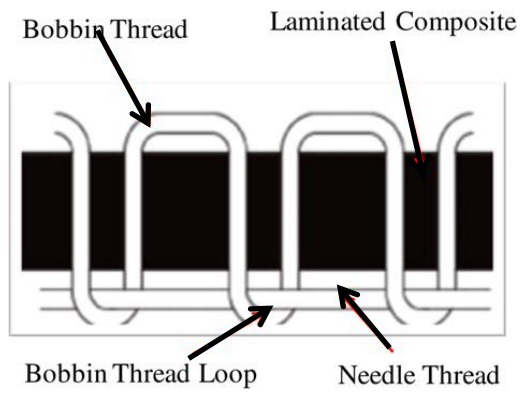

(c)

Figure 7: (a) Stitching process, (b) definitions and (c) graphic of modified lock stitches [84]. 


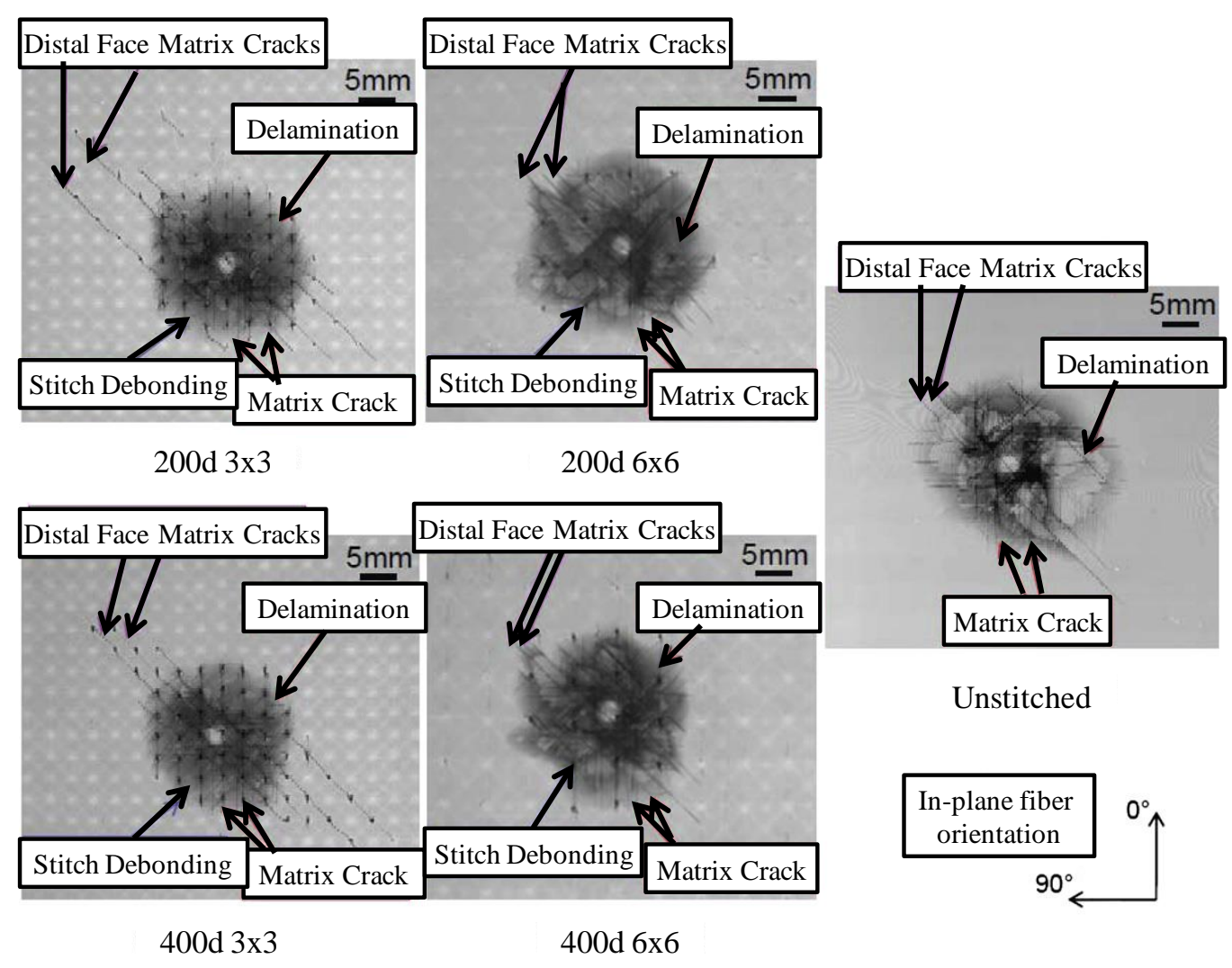

Figure 8: Impact damage of various specimens (thread thickness 200 and 400 denier; stitch space $3 \times 3$ and $6 \times 6$ ) subjected to impact energy $6.7 \mathrm{~J}$ [82]

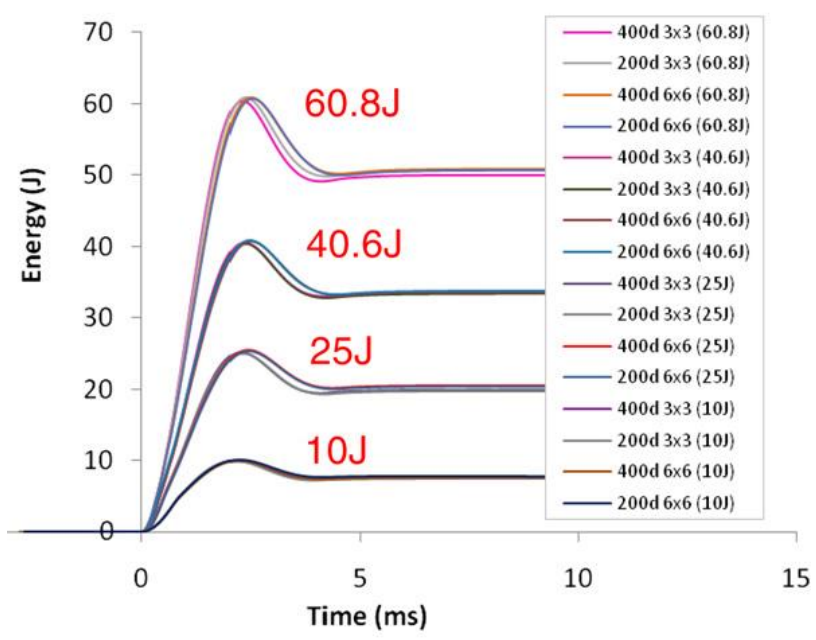

Figure 9: Energy absorption curves (thread thickness 200 and 400 denier; stitch space $3 \times 3$ and 6×6) [84]. 


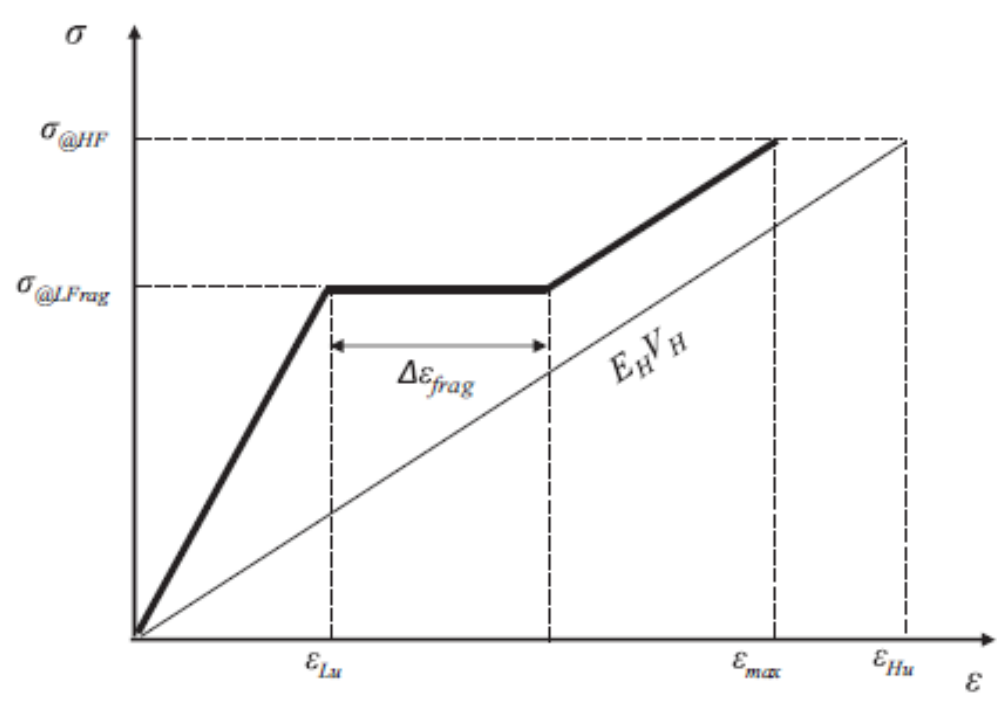

Figure 10: Schematic stress-strain curves of hybrid composites with synergistic strengthening [101].

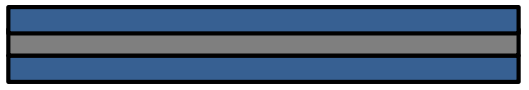

(a)

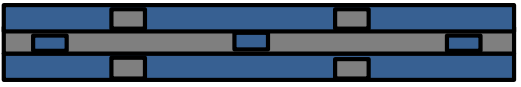

(b)

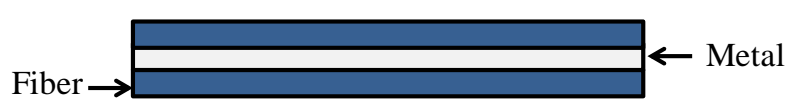

(c)

Figure 11: Hybrid configurations (a) Interply-, (b) Intraply- and (c) Super-hybridization [101]. 

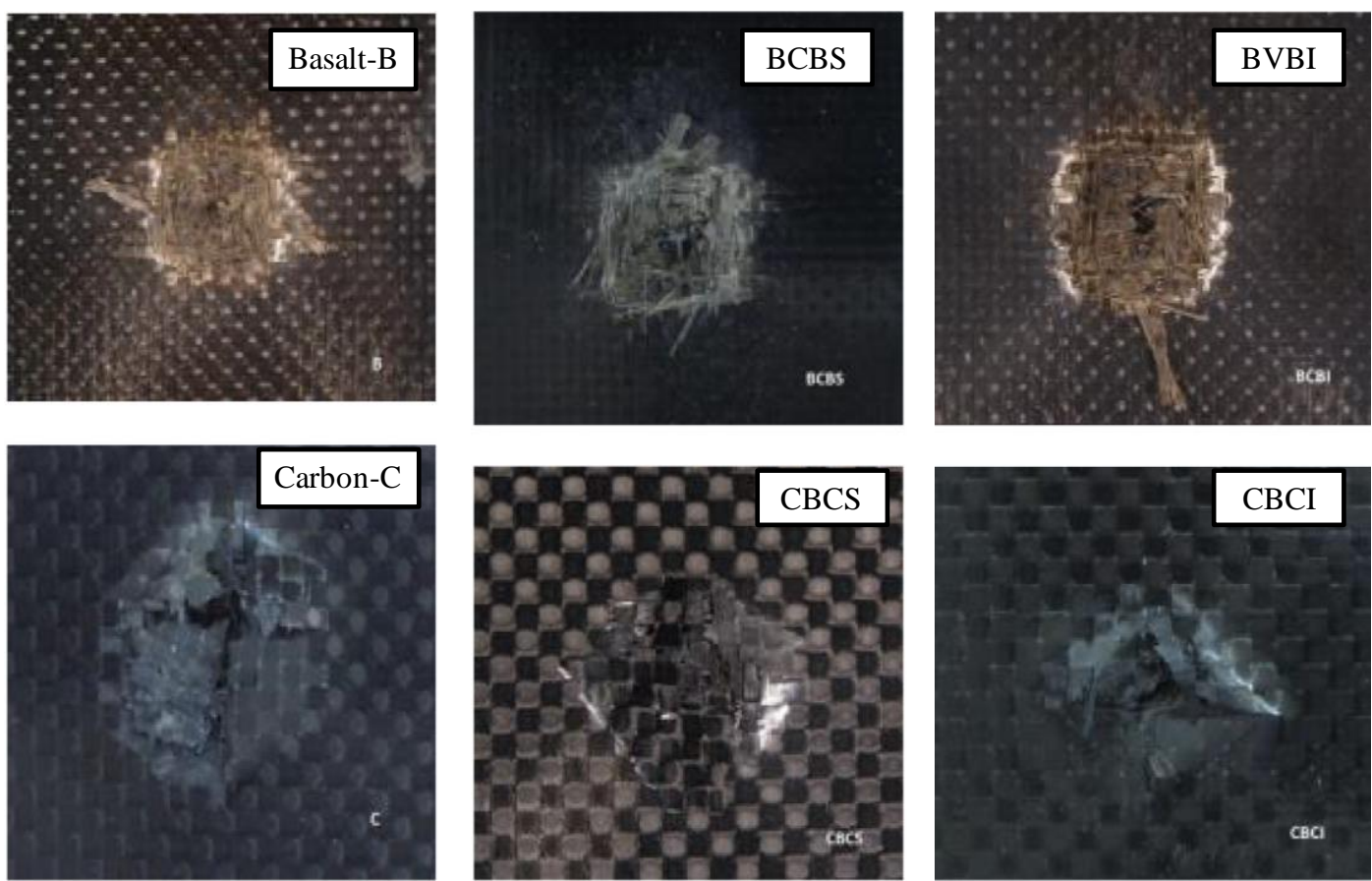

Figure 12: Damage of hybrid Basalt-B, Carbon-C, Basalt/Carbon/Basalt-Sandwich-BCBS, Carbon/Basalt/Carbon-Sandwich-CBCS, Basalt/Carbon/Basalt-intercalated-BCBI and Carbon/Basalt/Carbon-Intercalated-CBCI composite configurations beyond the ballistic limit velocity [147].

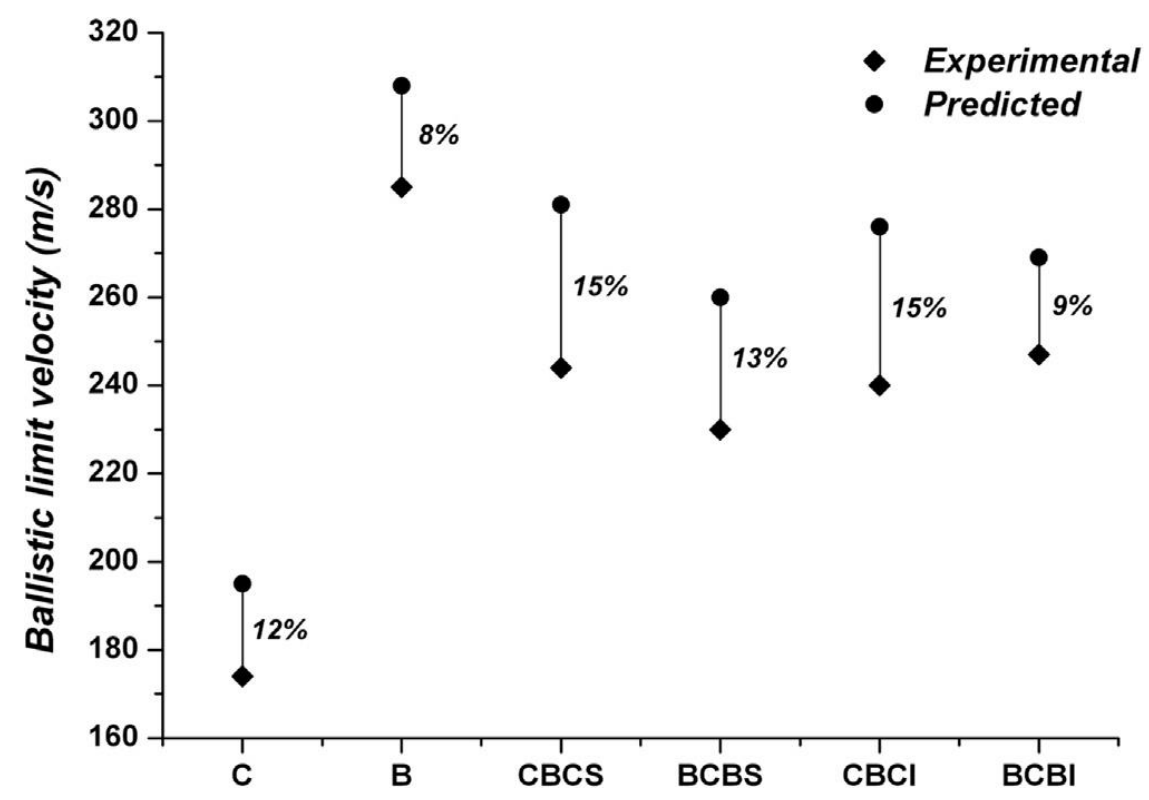

Figure 13: Ballistic limit velocity for different specimen configurations [147]. 


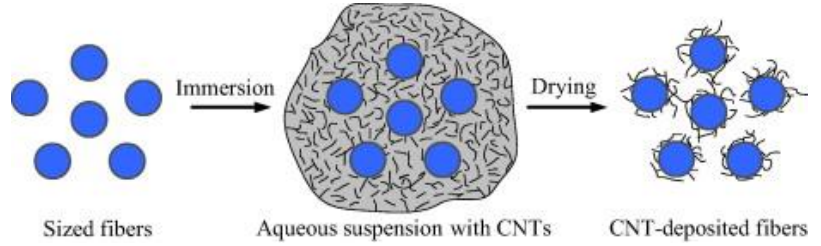

(a)

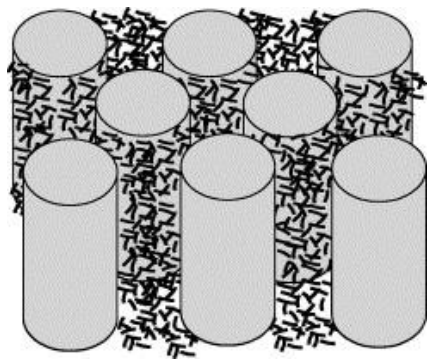

(c)

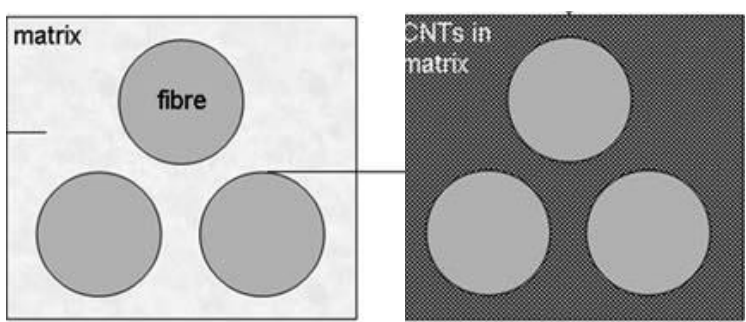

(b)

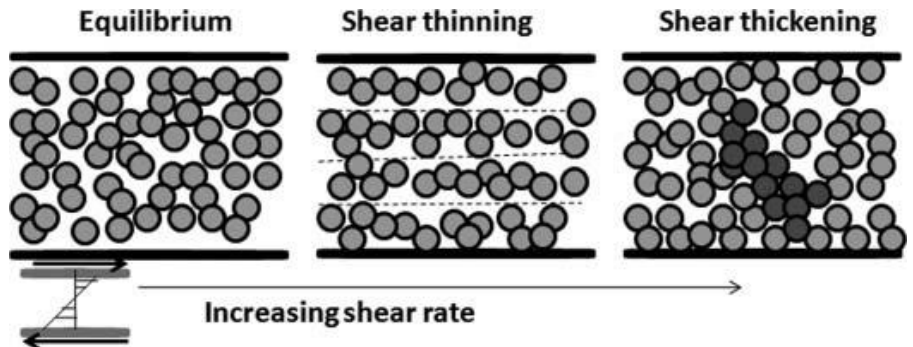

(d)

Figure 14: Schematic of the (a) CNT-depositing process on fibers [179], (b) dispersion of the carbon nano tube in matrix, (c) Nano-fiber reinforcement of the matrix [183] and (d) particles in a STF during shear thinning and shear thickening w.r.t. increasing shear rate [202].

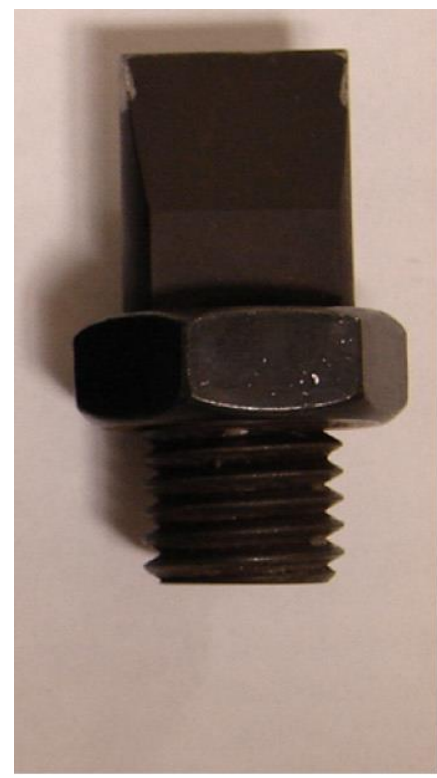

(a)

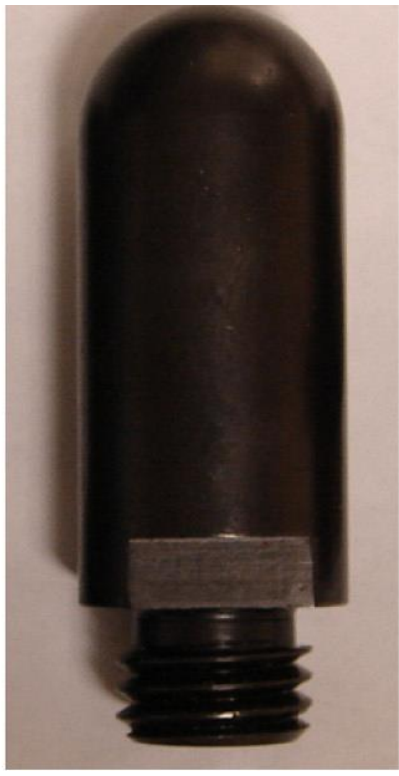

(b)

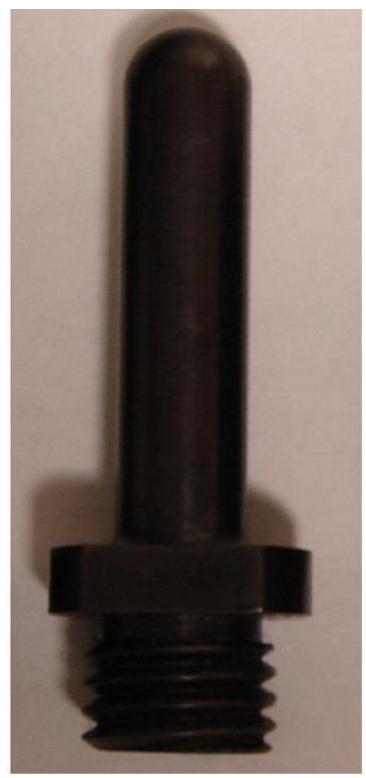

(c)

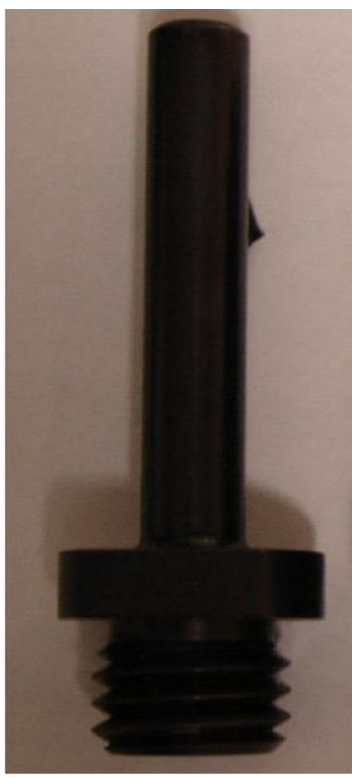

(d)

Figure 15: Impactors (a) Charpy-straight line, (b) spherical (25.4 mm), (c) spherical (12.7 mm) and (d) flat-ended (10 mm) [261] 

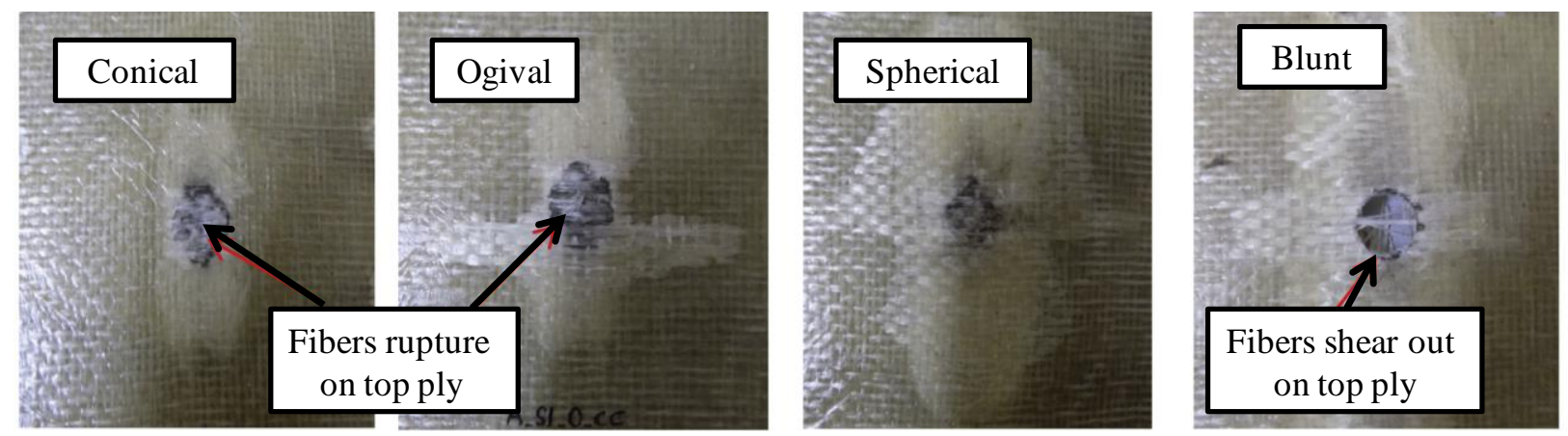

Figure 16: Perforation pattern in target plate impacted by different nose projectile [261].

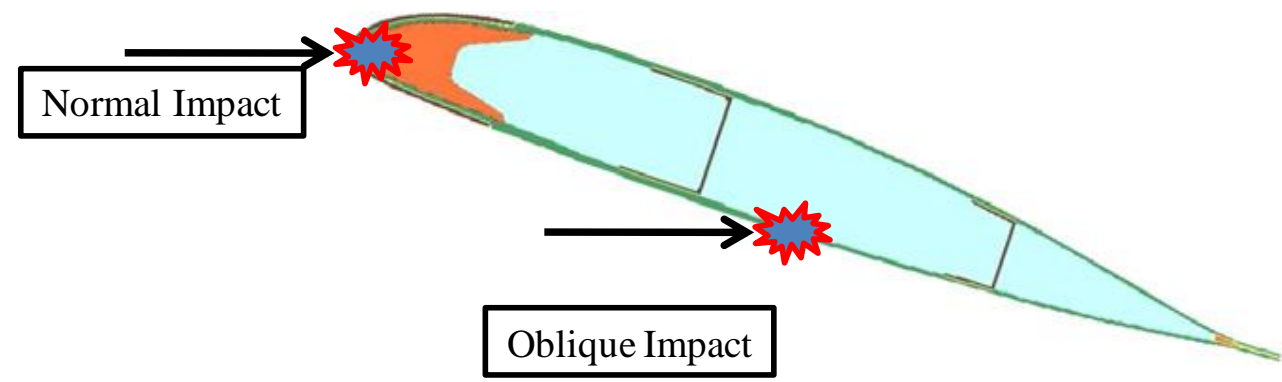

Figure 17: Aerofoil section subjected to impact under normal and oblique angle conditions [288].

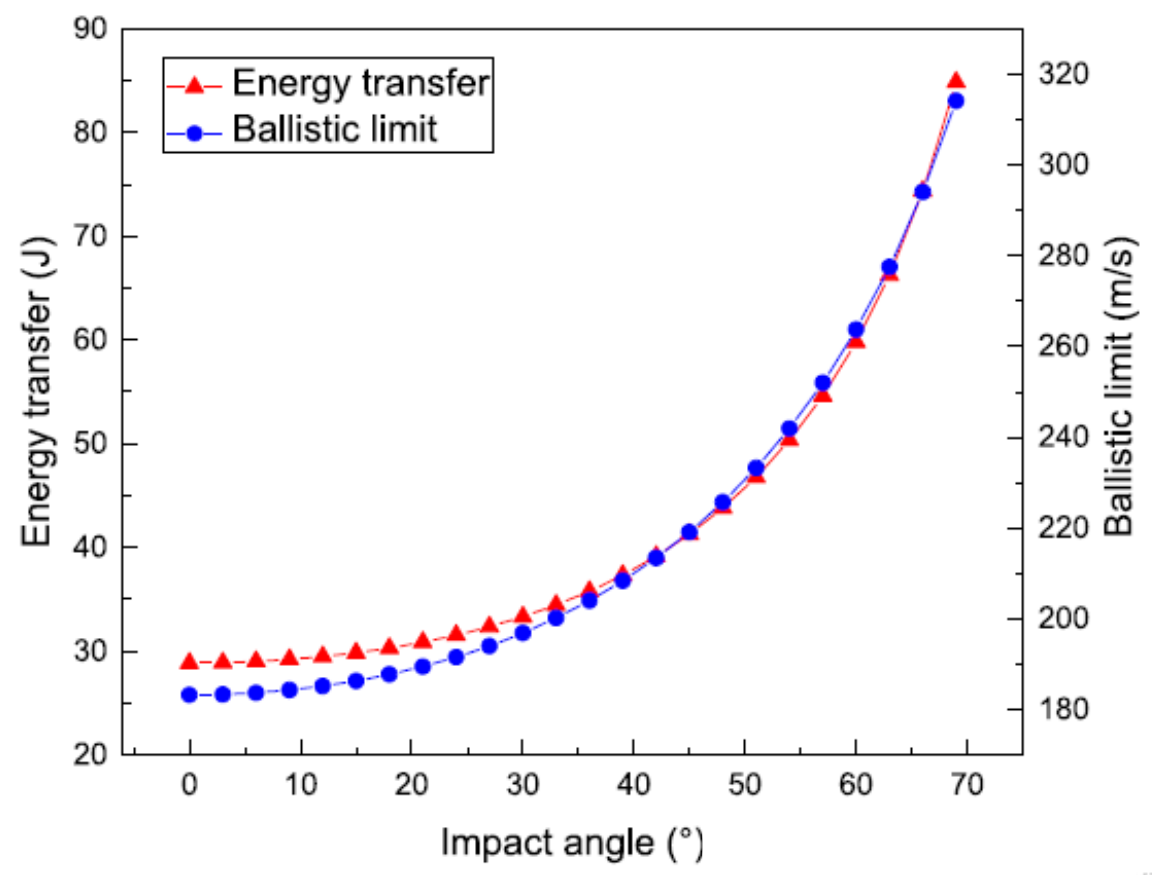

Figure 18: Variation of the energy transfer and ballistic limit with the impact angle [287]. 

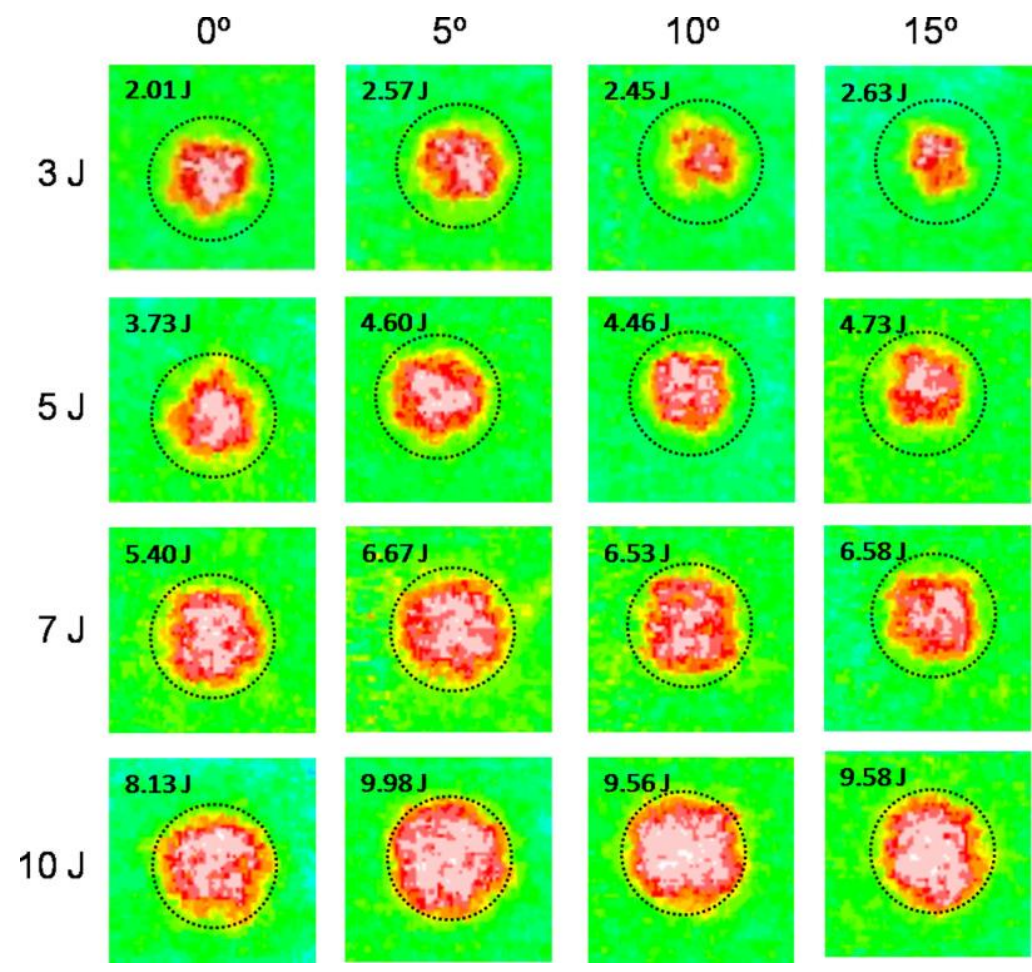

Figure 19: C-scan images for different oblique angles and impact energies [296].

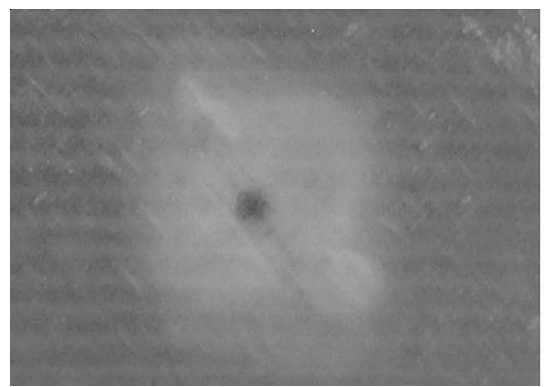

(a)

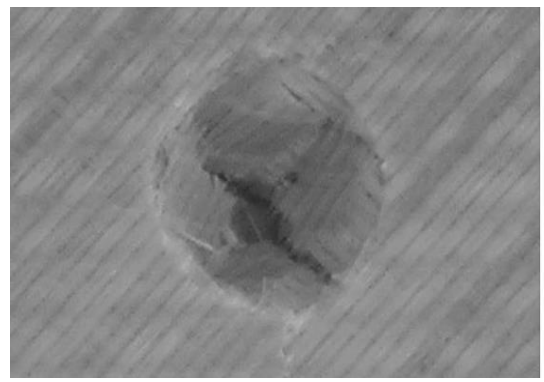

(c)

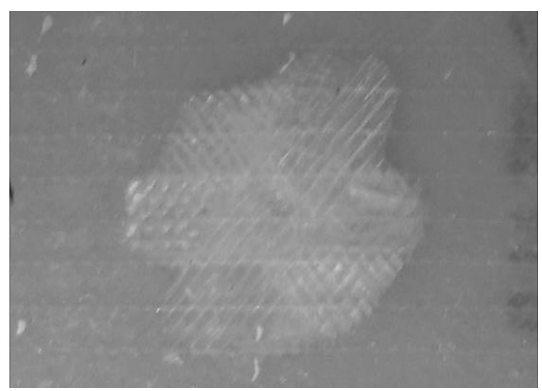

(b)

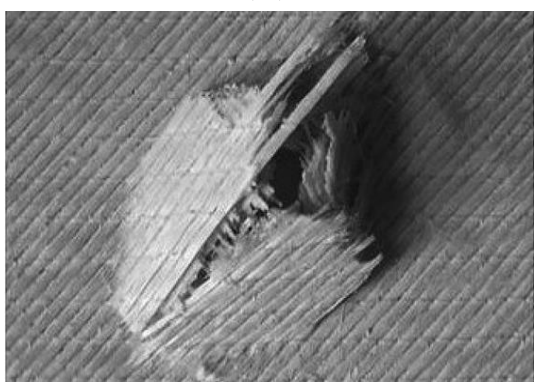

(d)

Figure 20: Close up photos of $5 \mathrm{~J}$ impact damage on (a) dry specimen (front face), (b) dry specimen (back face), (c) 24 months aged (front face) and (d) 24 months aged (back face) [304]. 


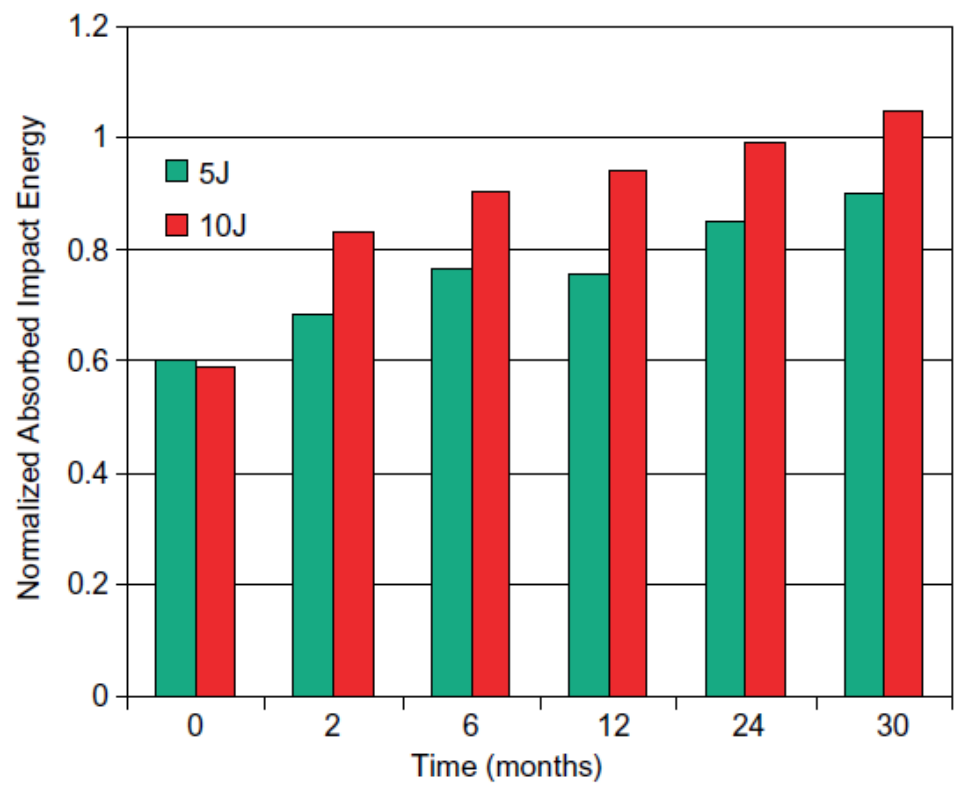

Figure 21: Absorbed energy for various immersion time intervals [304].

\section{Table Captions}

Table 1: Types of impact with respect to velocity [28]

Table 2: Impact studies of composites alternating the stacking sequence

Table 3: Summary of bulk resin modification of thermosetting composites using thermoplastics

Table 4: Summary of interlaminar modification of thermosetting composites using thermoplastics

Table 1: Types of impact with respect to velocity [28]

\begin{tabular}{|c|l|l|l|}
\hline S. No. & \multicolumn{1}{|c|}{ Velocity range } & \multicolumn{1}{c|}{ Test equipment } & \multicolumn{1}{c|}{ Applications } \\
\hline 1 & $\begin{array}{l}\text { Low velocity } \\
0-11 \mathrm{~m} / \mathrm{s}\end{array}$ & $\begin{array}{l}\text { Drop Hammer } \\
\text { Pneumatic accelerator }\end{array}$ & $\begin{array}{l}\text { Dropped items } \\
\text { Vehicle impact crash }\end{array}$ \\
\hline 2 & $\begin{array}{l}\text { High velocity } \\
>11 \mathrm{~m} / \mathrm{s}\end{array}$ & $\begin{array}{l}\text { Compressed air gun } \\
\text { Gas dun }\end{array}$ & $\begin{array}{l}\text { Free falling bombs } \\
\text { Fragments owing to explosion }\end{array}$ \\
\hline 3 & $\begin{array}{l}\text { Ballistic impact } \\
>500 \mathrm{~m} / \mathrm{s}\end{array}$ & $\begin{array}{l}\text { Compressed air gun } \\
\text { Gas dun }\end{array}$ & Military \\
\hline 4 & $\begin{array}{l}\text { Hyper velocity impact } \\
>2000 \mathrm{~m} / \mathrm{s}\end{array}$ & $\begin{array}{l}\text { Powder gun } \\
\text { Two stage light gas gun }\end{array}$ & $\begin{array}{l}\text { Military, Space vessels } \\
\text { Exposed to meteoroid impact }\end{array}$ \\
\hline
\end{tabular}


Table 2: Impact studies of composites alternating the stacking sequence

\begin{tabular}{|l|l|l|l|c|}
\hline \multicolumn{1}{|c|}{ In-plane fibers } & \multicolumn{1}{|c|}{ Hybrid type } & \multicolumn{1}{|c|}{ Fabric } & Matrix & References \\
\hline Polyamide-Basalt & Interply & Woven & Epoxy & {$[105]$} \\
\hline & Intraply & & & {$[106-107]$} \\
\hline Polyamide-Glass & Interply or Intraply & & & {$[108]$} \\
\hline & Interply & Woven & Vinylester & {$[109-111]$} \\
\hline & & Unidirectional & Epoxy & {$[112]$} \\
\hline Polyamide-Carbon & Intraply & Woven & & {$[113]$} \\
\hline & Intraply & Unidirectional & Epoxy & {$[112]$} \\
\hline Carbon-Glass & Intraply & Woven & & {$[113]$} \\
\hline & & Woven & Epoxy & {$[113-118]$} \\
\hline Carbon-Polyethylene & Intraply & Unidirectional & & {$[119-120]$} \\
\hline Glass-Polyvinyl & Interply or Intraply & Woven & Polyester & {$[123]$} \\
\hline
\end{tabular}

Table 3: Summary of bulk resin modification of thermosetting composites using thermoplastics

\begin{tabular}{|l|l|l|c|}
\hline \multicolumn{1}{|c|}{ Toughening method } & \multicolumn{1}{|c|}{ Materials } & \multicolumn{1}{|c|}{ Results } & Reference \\
\hline \multicolumn{3}{|c|}{ Rubber toughening } \\
\hline $\begin{array}{l}12.5 \mathrm{phr} \text { amine- } \\
\text { terminated butadiene } \\
\text { acrylonitrile (ATBN) }\end{array}$ & $\begin{array}{l}\text { DGEBA } \\
\text { epoxy }\end{array}$ & $\begin{array}{l}\text { Tg-11\%, KIC }+150 \%, \text { Tensile } \\
\text { modulus }-30 \%, \text { Izod impact } \\
\text { strength }+236 \%,\end{array}$ & {$[189]$} \\
\hline 10 phr ATBN & $\begin{array}{l}\text { Carbon/poly- } \\
\text { benzoxazine }\end{array}$ & $\begin{array}{l}\text { KIC, GIIC, ILSS + 100\% flexural } \\
\text { strength }+0 \%\end{array}$ & {$[190]$} \\
\hline
\end{tabular}




\begin{tabular}{|c|c|c|c|}
\hline $\begin{array}{l}10 \text { phr carboxy- } \\
\text { terminated butadiene } \\
\text { acrylonitrile (CTBN) }\end{array}$ & $\begin{array}{l}\text { Carbon/poly- } \\
\text { benzoxazine }\end{array}$ & $\begin{array}{l}\text { G IIC, ILSS } \sim+0 \%, \mathrm{~K}_{\mathrm{IC}} \sim+50 \% \\
\text { flexural strength } \sim-25 \%\end{array}$ & \\
\hline $\begin{array}{l}10 \text { phr hydroxyl } \\
\text { terminated } \\
\text { polybutadiene (HTPB) }\end{array}$ & $\begin{array}{l}\text { DGEBA } \\
\text { epoxy }\end{array}$ & $\begin{array}{l}\mathrm{Tg}+0 \%, \mathrm{G}_{\mathrm{IC}}+400 \% \\
\mathrm{~K}_{\mathrm{IC}}+400 \%, \text { Flexural } \\
\text { modulus } \sim-25 \%, \text { Flexural } \\
\text { strength } \sim-25 \%, \text { Impact } \\
\text { strength }+30 \%,\end{array}$ & {$[191]$} \\
\hline $\begin{array}{l}1 \% \mathrm{HTPB} \text { and } 2 \% \\
\text { silane }\end{array}$ & $\begin{array}{l}\text { DGEBA } \\
\text { epoxy }\end{array}$ & Impact strength $+43 \%$ & {$[192]$} \\
\hline \multicolumn{4}{|c|}{ Thermoplastic particles } \\
\hline Thermoplastic particles & Carbon/epoxy & $\begin{array}{l}\text { Decrement in damage area by a } \\
\text { factor of } 2\end{array}$ & [193] \\
\hline Thermoplastic particles & Carbon/epoxy & $\begin{array}{l}\text { Enhances in delamination } \\
\text { resistance }\end{array}$ & [194] \\
\hline $\begin{array}{l}\text { Polyetherimide particles } \\
(2 \mathrm{wt} . \%)\end{array}$ & Carbon/epoxy & $\begin{array}{l}\text { Storage modulus }+30 \% \\
\text { Impact strength (Izod) }+29 \%\end{array}$ & {$[195]$} \\
\hline $\begin{array}{l}\text { Polycarbonate particles } \\
(2 \mathrm{wt.} \%)\end{array}$ & Carbon/epoxy & \begin{tabular}{|l|} 
Storage modulus $21 \%$ \\
Impact strength (Izod) +39\%
\end{tabular} & \\
\hline PBT particles (2 wt. \%) & Carbon/epoxy & $\begin{array}{l}\text { Storage modulus }+17 \% \\
\text { Impact strength (Izod) }+59 \%\end{array}$ & \\
\hline \multicolumn{4}{|c|}{ Soluble thermoplastic fibers } \\
\hline $\begin{array}{l}\text { Nylon-6,6 electrospun } \\
\text { nano- fibers }\end{array}$ & Carbon/epoxy & $\begin{array}{l}\text { Threshold impact force }+\sim 60 \% \\
\text { Damage area }-\sim 50 \%\end{array}$ & {$[196]$} \\
\hline $\begin{array}{l}\text { Poly(hydroxyether of } \\
\text { bisphenol A) i.e. } \\
\text { phenoxy nano- fibers }\end{array}$ & Carbon/epoxy & $\begin{array}{l}2.0 \mathrm{wt} . \%-\mathrm{G}_{\mathrm{IC}}+98 \% \\
\mathrm{G}_{\mathrm{IIC}}+21 \%\end{array}$ & [197] \\
\hline
\end{tabular}




\begin{tabular}{|c|c|c|c|}
\hline Phenoxy veil (10 wt. \%) & Carbon/epoxy & $\begin{array}{l}\text { GIC } \sim 900 \%, \text { ILSS } \sim+10 \%, \\
\text { Young's modulus } \sim+10 \%, \\
\text { бUTS } \sim+20 \%\end{array}$ & {$[198]$} \\
\hline $\begin{array}{l}\text { Poly ( } \varepsilon \text {-caprolactone }) \\
\text { nano- fibers }\end{array}$ & Carbon/epoxy & $\begin{array}{l}\mathrm{G}_{\text {IC-init }}+92 \% \mathrm{G}_{\mathrm{IC}-\mathrm{prop}}+65 \% \\
\text { Flexural strength }-20 \%\end{array}$ & [199] \\
\hline $\begin{array}{l}\text { Poly-benzimidazole } \\
\text { nano- fibers }\end{array}$ & Epoxy resin & $\begin{array}{l}\text { Young's modulus }+27 \%, \\
\mathrm{~K}_{\mathrm{IC}}+76 \%, \mathrm{G}_{\mathrm{IC}}+144 \%\end{array}$ & {$[200]$} \\
\hline $\begin{array}{l}\text { Polysulfone electrospun } \\
\text { nano- fibers }\end{array}$ & Carbon/epoxy & 5 wt. $\% \mathrm{G}_{\mathrm{IC}}+281 \%$ & {$[201]$} \\
\hline
\end{tabular}


Table 4: Summary of interlaminar modification of thermosetting composites using thermoplastics

\begin{tabular}{|c|c|c|c|}
\hline $\begin{array}{l}\text { Toughening } \\
\text { method }\end{array}$ & Materials & Results & Reference \\
\hline \multicolumn{4}{|c|}{ Co-mingled fibers } \\
\hline Nylon fibers & Carbon/epoxy & $\begin{array}{l}\text { Impact threshold } \sim+30 \% \\
\text { CAI strength } \sim+50 \% \\
\text { GIC } \sim+250 \%, \text { GIIC }_{\text {II }}+300 \%\end{array}$ & [210] \\
\hline Polyethylene fibers & Carbon/epoxy & $\begin{array}{l}\text { Ductility index }(\mathrm{DI}) \\
\text { Baseline }-\mathrm{DI}=0.2 \\
\text { Co-mingled }-\mathrm{DI}=7.4\end{array}$ & \\
\hline $\begin{array}{l}\text { Polyetherketone- } \\
\text { cardo (PEK-C) }\end{array}$ & Carbon/BMI & $\begin{array}{l}\text { Damage area }-5.4 \% \\
\text { CAI strength }+14 \%\end{array}$ & {$[211]$} \\
\hline \multicolumn{4}{|c|}{ Thermoplastic films } \\
\hline $\begin{array}{l}\text { Polyethylene-co- } \\
\text { acrylic acid film }\end{array}$ & Carbon/epoxy & $\begin{array}{l}\text { Impact damage initiation } \\
\text { Energy } \sim+150 \%\end{array}$ & [212] \\
\hline $\begin{array}{l}\text { Polyethylene-co- } \\
\text { acrylic acid film }\end{array}$ & Carbon/epoxy & $\begin{array}{l}\text { Damage area }-69 \% \\
\text { CAI strength }-36 \%\end{array}$ & [213] \\
\hline $\begin{array}{l}\text { PET (Polyethylene } \\
\text { terephtalate) film }\end{array}$ & Carbon/epoxy & $\begin{array}{l}\mathrm{G}_{\mathrm{IC}} \sim-70 \% \\
\mathrm{G}_{\mathrm{IIC}} \sim+120 \%\end{array}$ & [214] \\
\hline $\begin{array}{l}\text { PEK-C w/10 wt. \% } \\
\text { CNT }\end{array}$ & Carbon/BMI & $\begin{array}{l}\text { Damage area }-29 \% \\
\text { CAI strength }+33 \%\end{array}$ & {$[215]$} \\
\hline $\begin{array}{l}\text { Epoxy film w/20 } \\
\text { wt.\% }\end{array}$ & Carbon/epoxy & $\begin{array}{l}\mathrm{G}_{\mathrm{IIC}} \text {-init } \sim+90 \%, \\
\mathrm{G}_{\mathrm{IIC}}-\text { prop } \sim+100 \%\end{array}$ & \\
\hline \multicolumn{4}{|c|}{ Particulate interlayers } \\
\hline $\begin{array}{l}\text { Nylon particles } \\
\text { interlayers }\end{array}$ & Carbon/epoxy & $\begin{array}{l}\text { GIC-init + 300\% } \\
\text { GIC-prop no change }\end{array}$ & [216] \\
\hline
\end{tabular}




\begin{tabular}{|c|c|c|c|}
\hline $\begin{array}{l}\text { Spray epoxy } \\
\text { tackifier with } \\
\text { nylon } 6 \text { particles }\end{array}$ & Carbon/epoxy RTM & $\begin{array}{l}\mathrm{G}_{\mathrm{IC}}-10 \%, \mathrm{G}_{\mathrm{IIC}}+30 \% \\
\text { No change in ILSS and compressive } \\
\text { strength }\end{array}$ & [217] \\
\hline \multicolumn{4}{|c|}{ Non-woven fiber veils } \\
\hline $\begin{array}{l}\text { High density } \\
\text { polyethylene } \\
\text { (high areal weight) } \\
\text { veil }\end{array}$ & Carbon/epoxy & $\begin{array}{l}\text { Damage area }-20 \% \\
\text { Compressive strength }+2 \% \\
\text { CAI strength }+32 \%\end{array}$ & [218] \\
\hline $\begin{array}{l}\text { Interlayers of high } \\
\text { performance } \\
\text { Polyethylene }\end{array}$ & Carbon/epoxy & $\begin{array}{l}\text { Ductility index }(\mathrm{DI}) \\
\text { Baseline }-\mathrm{DI}=0.2 \\
9 \text { interlayers }-\mathrm{DI}=6.6 \\
16 \text { interlayers }- \text { DI }=7.0\end{array}$ & [219] \\
\hline $\begin{array}{l}\text { Hybrid PET/carbon } \\
\text { veil }\end{array}$ & Carbon/epoxy & CAI strength $+150 \%$ & [220] \\
\hline PA adhesive web & Carbon/epoxy & $\begin{array}{l}\text { Peak impact load } \sim+25 \% \\
\text { CAI strength } \sim-50 \%\end{array}$ & [221] \\
\hline PA adhesive web & Carbon/epoxy tape & $\mathrm{G}_{\mathrm{IC}} \sim+300 \%$ & [222] \\
\hline $\begin{array}{l}\text { Polyester veil } \\
\text { Polyamide veil } \\
\text { Hybrid PE/C 70:30 } \\
\text { veil } \\
\text { Hybrid PE/C 80:20 } \\
\text { veil }\end{array}$ & $\begin{array}{l}\text { Plain weave } \\
\text { carbon/epoxy }\end{array}$ & $\begin{array}{l}\text { GICinit }+100 \% \text { GIcprop }+200 \% \\
\text { GICinit }+150 \% \text { G G } \\
\text { GICprop }+300 \% \\
\text { GICinit }+0 \% \text { GI }+0 \% \text { Grop }+25 \% \\
\text { GI prop }+10 \%\end{array}$ & [223] \\
\hline $\begin{array}{l}\text { Polyester veil } \\
\text { Polyamide veil } \\
\text { Hybrid PE/C 70:30 } \\
\text { veil }\end{array}$ & $\begin{array}{l}\text { Plain weave } \\
\text { carbon/epoxy }\end{array}$ & $\begin{array}{l}\mathrm{G}_{\text {IICinit }}+30 \% \mathrm{G}_{\text {IIC }} \text { prop }+\sim 70 \% \\
\mathrm{G}_{\text {IIC }} \text { init }+60 \% \mathrm{G}_{\text {IIC prop }+~ 115 \%} \\
\mathrm{G}_{\text {IIC init }}-15 \% \mathrm{G}_{\text {IIC prop }+\sim 0 \%} \\
\mathrm{G}_{\text {IIC init }}+0 \% \text { GIICprop }+\sim 30 \%\end{array}$ & [224] \\
\hline
\end{tabular}




\begin{tabular}{|c|c|c|c|}
\hline $\begin{array}{l}\text { Hybrid PE/C 80:20 } \\
\text { veil }\end{array}$ & & & \\
\hline $\begin{array}{l}\text { Polyester/carbon } \\
\text { veil }\end{array}$ & $\begin{array}{l}\text { Carbon/epoxy } \\
\text { Infused repairs }\end{array}$ & GICinit $+615 \%$, GICprop $+1100 \%$ & [225] \\
\hline Nylon veil & $\begin{array}{l}\text { Carbon/benzoxazine } \\
9120\end{array}$ & $\begin{array}{l}\text { Interlaminar failure load }+23 \% \text {, } \\
\mathrm{G}_{\mathrm{IC}}+80 \% \text {, Flexural modulus }- \\
15 \%\end{array}$ & [226] \\
\hline
\end{tabular}

